\title{
RACIAL ENVIRONMENT AND POLITICAL PARTICIPATION
}

\author{
A Dissertation \\ by \\ TETSUYA MATSUBAYASHI \\ Submitted to the Office of Graduate Studies of \\ Texas A\&M University \\ in partial fulfillment of the requirements for the degree of \\ DOCTOR OF PHILOSOPHY
}

August 2007

Major Subject: Political Science 


\title{
RACIAL ENVIRONMENT AND POLITICAL PARTICIPATION
}

\author{
A Dissertation \\ by \\ TETSUYA MATSUBAYASHI
}

Submitted to the Office of Graduate Studies of Texas A\&M University in partial fulfillment of the requirements for the degree of

DOCTOR OF PHILOSOPHY

\begin{abstract}
Approved by:
Co-Chairs of Committee, Jan E. Leighley Kim Quaile Hill

Committee Members, Guy D. Whitten Arnold Vedlitz

Head of Department, Patricia A. Hurley
\end{abstract}

August 2007

Major Subject: Political Science 


\author{
ABSTRACT \\ Racial Environment and Political Participation. (August 2007) \\ Tetsuya Matsubayashi, B.S., Doshisha University; \\ M.A., Doshisha University \\ Co-Chairs of Advisory Committee: Dr. Jan E. Leighley \\ Dr. Kim Quaile Hill
}

This research addresses the determinants of mass participation by developing a model of how the racial environment influences mass participation in the United States. Prior literature on this research question presents two competing expectations. The power-threat hypothesis predicts that a larger size of different racial groups in local areas increases citizen participation because of more intensive interracial conflicts, while the relational goods hypothesis predicts that a larger size of different racial groups decreases participation because of less frequent interaction with other in-group members. Both hypotheses, however, are derived from rather weak theoretical expectations, and neither is consistently supported in empirical analyses. This research offers a solution to this puzzle by arguing that economic and political characteristics of local areas determine how the racial composition influences mass participation. Local economic and political competition is expected to structure the nature of interracial and intraracial relations and therefore influence the utility calculation associated with political participation. I hypothesize that the power-threat effect on citizen participation is observed only when the degree of economic or political competition is high, while the relational goods effect is observed only when the degree of economic or political competition is low. Empirical analysis using Verba, Schlozman, and Brady's Citizen Participation Study offers supportive evidence for my hypotheses. This research offers the first theoretically-motivated, rigorous analysis and evidence of the 
impact of immediate racial environment on individuals' participation. 
To my parents 


\section{ACKNOWLEDGMENTS}

First, I would like to thank my committee members - Jan E. Leighley, Kim Quaile Hill, Guy D. Whitten, and Arnold Vedlitz - for their guidance and support throughout the course of this research project. Jan, as one of my dissertation co-chairs, showed me the virtue of contextual models of political behavior and the importance of studying race and politics in the United States. I am also indebted to Jan for her advice regarding a professional life as a scholar. I will never forget the moment in which we talked about various academic and professional issues over a glass of beer or white wine (or diet coke). Kim, my other dissertation co-chair, taught me how to study political phenomena in a scientific way. I learned a lot about becoming a productive scholar by collaborating closely with Kim on several research projects. Guy gave me crucial comments on statistical problems that I would have never recognized. Arnie's advice directed my attention to some fields that study race and politics from a different prospective.

I am also grateful to Justin Vaughn for his helpful advice in the final process of my dissertation project. I would like to thank Yoshitaka Nishizawa for his encouragement and support to pursue my career as a political scientist. Finally, I wish to thank my parents for their support, patience, and love. 


\section{TABLE OF CONTENTS}

CHAPTER Page

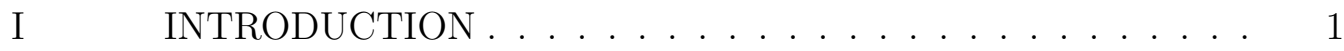

A. Research Context ................. . . 3

B. Theoretical Overview . . . . . . . . . . . . . . . . . . 12

C. Chapter Outline . . . . . . . . . . . . . . . 15

D. Data And Methods . . . . . . . . . . . . . . . 19

E. Contributions . . . . . . . . . . . . . . 20

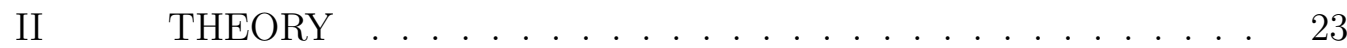

A. The Rational Choice Perspective And Contextual Models Of Political Participation . . . . . . . . . . . 25

B. Political Participation In Multidimensional Environments . 34

1. The Presence of Out-Groups and Power-Threat . . . . 35

2. The Presence of In-Groups and Relational Goods . . . 39

C. Summary . . . . . . . . . . . . . . . . 42

III RACIAL COMPOSITION AND CITIZEN PARTICIPATION: PRELIMINARY ANALYSIS . . . . . . . . . . . . . . . . 44

A. Measuring the Effect of Racial Composition on Citizen Participation ..................... 45

B. Observing Racial Composition . . . . . . . . . . . 54

C. Reexamining The Existing Hypotheses . . . . . . . . 57

D. Summary . . . . . . . . . . . . . . 63

IV RACIAL COMPOSITION, ECONOMIC COMPETITION, AND CITIZEN PARTICIPATION . . . . . . . . . . . . 64

A. Economic Diversity Hypothesis . . . . . . . . . . 65

1. High Income Diversity and Power-Threat . . . . . . . 65

2. Low Income Diversity and Relational Goods . . . . . . 68

3. Summary . . . . . . . . . . . . . . . . 69

B. Economic Affluence Hypothesis . . . . . . . . . . . 70

1. Low Income Status and Power-Threat . . . . . . . . . 71

2. High Income Status and Relational Goods . . . . . . . 72

3. Summary . . . . . . . . . . . . . . 73

C. Measures . . . . . . . . . . . . . . . . . . 74 
D. Findings . . . . . . . . . . . . . . 76

1. Test for Economic Diversity Hypothesis . . . . . . . 76

2. Test for Economic Affluence Hypothesis . . . . . . . . 83

E. Summary . . . . . . . . . . . . . . . . . 88

V RACIAL COMPOSITION, POLITICAL COMPETITION, AND CITIZEN PARTICIPATION . . . . . . . . . . . . 92

A. Political Competition Hypothesis . . . . . . . . . . . . . 92

1. High Political Heterogeneity and Power-Threat . . . . 92

2. Low Political Heterogeneity and Relational Goods . . 95

3. Summary . . . . . . . . . . . . . . . 96

B. Measures . . . . . . . . . . . . . . 97

C. Findings . . . . . . . . . . . . . . . . . . . 99

D. Summary . . . . . . . . . . . . . . . . . . 105

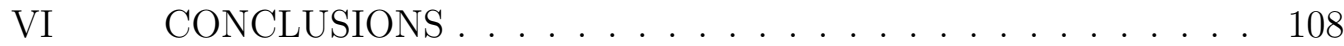

A. Summary . . . . . . . . . . . . . . . 108

B. Theory Construction . . . . . . . . . . . . . . . 111

C. Measures Of Racial Composition . . . . . . . . . . . 113

D. Citizen Participation In Context . . . . . . . . . . . . . . 114

E. Representational Consequences . . . . . . . . . . . 115

REFERENCES . . . . . . . . . . . . . . . . . . 117

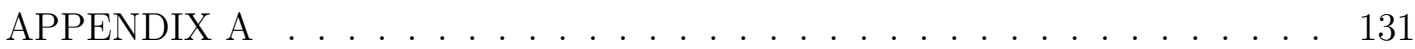

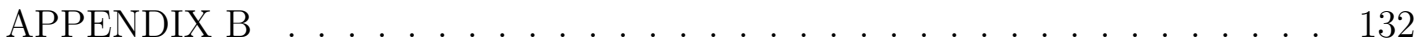

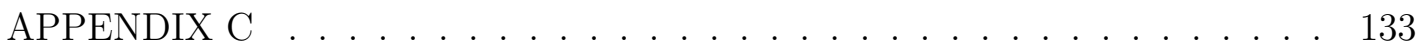

APPENDIX D . . . . . . . . . . . . . . . . . . . . 136

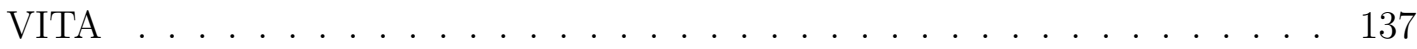




\section{LIST OF TABLES}

TABLE

Page

I Summary of the Underlying Mechanisms . . . . . . . . . . . . . . 13

II Expected Environmental Conditions for Greater Mass Participation . 19

III The Power-Threat Effect on the Probabilities of Voting . . . . . . . . 60

IV The Relational Goods Effect on the Probabilities of Voting . . . . . . 61

V Empirical Test for Hypothesis 1: The Power-Threat Effect and Local Income Diversity . . . . . . . . . . . . . . . . . . . . 77

VI Empirical Test for Hypothesis 2: The Relational Goods Effect and Local Income Diversity . . . . . . . . . . . . . . . . . . . . . . 79

VII Empirical Test for Hypothesis 3: The Power-Threat Effect and Local Income Status . . . . . . . . . . . . . . . . . . . . . . . . 84

VIII Empirical Test for Hypothesis 4: The Relational Goods Effect and Local Income Status . . . . . . . . . . . . . . . . . . . . . . 85

IX Empirical Test for Hypothesis 5: The Power-Threat Effect and Local Political Heterogeneity . . . . . . . . . . . . . . . . . 100

X Empirical Test for Hypothesis 6: The Relational Goods Effect and Local Political Heterogeneity . . . . . . . . . . . . . . . . . . . . 101

XI Summary Statistics . . . . . . . . . . . . . 136 


\section{LIST OF FIGURES}

FIGURE

Page

1 Two Existing Expectations _.................. 9

2 Two Competing Expectations . . . . . . . . . . . . . . . . . . . 10

3 Out-Group Size and Citizen Participation . . . . . . . . . . . . 14

$4 \quad$ In-Group Size and Citizen Participation . . . . . . . . . . 15

5 Racial Composition and Citizen Participation . . . . . . . . 16

$6 \quad$ Policy Preferences by Race and Class . . . . . . . . . . . . . . 35

$7 \quad$ The Relationship between the Out-Group Size and the Size of $P B \quad$. 49

8 Population Size of Counties in the CPS Sample . . . . . . . . . . 53

9 Out-Group Size of Counties . . . . . . . . . . . . 55

10 Out-Group Size of Counties by Race . . . . . . . . . . . . . . 56

11 Average Rates of Voter Turnout in National and Local Elections across Counties of Different Out-Group Sizes . . . . . . . . . 58

12 The Marginal Effects of Racial Composition in Areas of Low, Middle, and High Income Diversity . . . . . . . . . . . . . . 80

13 The Substantive Effects of Racial Composition in Areas of Low and High Income Diversity _. . . . . . . . . . . . . . . . 82

14 The Marginal Effects of Racial Composition in Areas of Low, Middle, and High Income Status . . . . . . . . . . . . . . . . 87

15 The Substantive Effects of Racial Composition in Areas of Low and High Income Status . . . . . . . . . . . . . . . . . . . 89

16 The Marginal Effects of Racial Composition in Areas of Low, Middle, and High Political Heterogeneity . . . . . . . . . . . . . . 104 
FIGURE

Page

17 The Substantive Effects of Racial Composition in Areas of Low and High Political Heterogeneity . . . . . . . . . . . . . . 106 


\section{CHAPTER I}

\section{INTRODUCTION}

Why do citizens participate in politics? The dominant approach to understanding citizen participation in the United States has been individualistic, focusing on individuals' socioeconomic status and psychological involvement as predictors. Much of the previous empirical research demonstrates that individuals' propensity to engage in political activities is a function of their education, income, political knowledge, political interest, and other personal characteristics (e.g., Campbell et al., 1960; Verba and Nie, 1972; Verba, Schlozman and Brady, 1995; Wolfinger and Rosenstone, 1980). Thus, understanding citizens' involvement in politics is equivalent to exploring "who they are." Importantly, most of the studies with the individualistic approach rely on an implicit assumption that those personal characteristics solely account for levels and modes of political participation and that individuals' propensity to participate are independent of their social and political environments (Leighley, 2001).

This assumption, unfortunately, limits our understanding of citizen participation in three ways. First, the individualistic approach has offered no persuasive explanation for temporal variation in participation levels. For example, political scientists have struggled with the "puzzle" that voter turnout has declined since the 1960s despite the improvement of socioeconomic status and the liberalization of registration laws (Brody, 1978). ${ }^{1}$ Second, the individualistic approach is not suitable to illuminate the different participation levels across space; for example, the gap in political participation between the South and the other areas of the United States after controlling

This dissertation follows the style of American Political Science Review.

${ }^{1}$ McDonald and Popkin (2001) demonstrate that their alternative measure of voter turnout shows no significant decline in the turnout rates. 
for major demographic and psychological variables (e.g., Rosenstone and Hansen, 1993). That is, spacial variation in the participation levels is another research issue that the existing individualistic approach fails to address. These weaknesses of the individualistic approach suggest that the personal characteristics are not the single form of explanation for citizen participation in politics.

Third, the assumption of the individualistic approach is theoretically unrealistic. Huckfeldt and Sprague $(1995,8)$ argue that the dominant approach "ignores the reality that every citizen is located within a setting, and the characterization of the citizen apart from the setting lacks meaning. The real electorate is composed of interrelated, interacting, and interdependent citizens." Huckfeldt and Sprague suggest that mass political behavior is a function of both personal and environmental characteristics. Further, the previous literature overlooks a possibility that individuals' immediate environments shape their incentives to engage in political activities. As noted by Oliver (2001, 24), "politics is a lot more exciting in some places than in others." When social and political environments make citizens interested and excited about politics, they are more likely to find a strong reason to participate in the political process. We should therefore examine the roles of social, economic, and political settings in which individual citizens decide whether to participate as alternative predictors (e.g., Berelson, Lazarsfeld and McPhee, 1954; Campbell, 2006; Leighley, 2001; Oliver, 2001; Rosenstone and Hansen, 1993). Citizen participation is individual behavior nested in social and political environments.

This research addresses the determinants of mass participation in politics by specifically focusing on how racial environment influences citizen participation in politics in the United States. I elaborate a theoretical framework of how and why the racial composition of citizens' immediate environments shape their incentives to engage in political activities. Hypotheses drawn from my theoretical argument will 
be tested using Verba, Schlozman, and Brady's Citizen Participation Study. I first briefly review literature related to my research agenda and then present an overview of my theoretical framework.

\section{A. Research Context}

Contextual studies of voter turnout and other forms of participation have typically focused on how neighborhood socioeconomic status affects individuals' decisions to engage in political activities. Huckfeldt and Sprague's (1992) investigation of South Bend, Indiana, demonstrated that individuals residing in high status contexts were more likely to vote than were individuals in low status contexts (see also Leighley, 1990, who provides evidence of contextual effects using national survey data) . They argue that the norms of civic engagement predominant in high status neighborhoods are easily conveyed through informal social interaction and observation and that these norms increase individuals' likelihood of participation. Interestingly, Huckfeldt's (1979) earlier study of Buffalo, New York, also confirmed the existence of contextual effects, though such effects were conditional on the individual's socioeconomic status: high status individuals residing in high status neighborhoods were more likely to participate than high status individuals in low status neighborhoods, while low status individuals residing in high status neighborhoods were less likely to participate than low status individuals in low status neighborhoods. While this suggested that status conflicts might lead individuals to disengage from the political environment, the general conclusion from these studies of socioeconomic context and participation is that contextual effects, if any, will be linear.

In contrast, Oliver (1999) demonstrates that high status environments are unrelated with greater political involvement. He argues that middle income cities are 
most likely to increase mass participation because high income diversity among residents produces high political conflicts for the public good between the haves and the have-nots and as a result stimulates residents to be interested in local political issues such as education, taxes, and land use. By contrast, citizens in higher or lower income cities are less interested in politics and therefore less likely to participate in politics because in those places the level of income diversity is low and residents have similar policy preferences. His analysis reports a curvilinear (convex) linkage between socioeconomic status of local communities and mass participation.

The theoretical motivation of studies linking the racial environment and mass participation is imprecise, too, in part because that theory is borrowed from studies of racial composition and prejudice. The dominant theoretical orientation, referred to as "real group conflict" or "power-threat," was developed most carefully by Blalock (1967), who argued that a greater size of nonwhite groups in local communities led to whites' fear of economic competition and political domination, which in turn increased whites' tendency to hold prejudicial attitudes and engage in discriminatory practices.

Blalock's argument was consistent with Key's (1949) earlier observations of Southern politics. He argued that as the proportion of blacks increased in the county, whites were more likely to support conservative candidates and to cast a vote on election day. Similarly, Matthews and Prothro (1966) found that as the size of the black community in Southern counties increased, white support of blacks' right to vote decreased and that whites were more likely to engage in behaviors that sought to control or minimize the power of blacks.

The power-threat hypothesis has been used more recently in the study of electoral behavior and racial attitudes (e.g., Giles and Evans, 1986; Giles and Hertz, 1994; Taylor, 1998; Tolbert and Hero, 1996). For example, high black population concentrations in Louisiana parishes are associated with greater Republican party identi- 
fication (Giles and Hertz, 1994) and greater support for conservative segregationist David Duke's senatorial candidacy (Giles and Buckner, 1993; but also see Voss, 1996 and Giles and Buckner, 1996). Taylor (1998) demonstrates that black population increases in local areas have a broad negative impact on whites' racial views, while Glaser (1994), too, shows that racial threat shapes policy-related attitudes. Tolbert and Hero (1996) found that citizens' support for the "illegal immigrant" initiatives in California in 1994 was greater where Latino population sizes in local communities were larger. Oliver and Wong's recent research (2003) demonstrates that nonwhite groups also show hostile attitudes toward out-group members in metropolitan areas with higher racial diversity. In sum, the existing empirical evidence endorses the longstanding hypothesis that citizens (especially whites) react negatively to the significant presence of other racial and ethnic groups in their immediate environments.

Yet how the power-threat argument applies to individuals' decisions to participate is not clear. Leighley and Vedlitz (1999) borrowed the language used by Giles and his colleagues to argue that individuals threatened by the presence of other racial and ethnic groups should be more likely to participate to defend their interests. A threat resulting from the presence of out-group members generates a strong incentive for individuals to voice their preferences in the political process. Nevertheless, their empirical evidence, based on a statewide survey of Texans that included over-samples of African-Americans, Latinos and Asian-Americans, suggested just the opposite: Anglos are less likely to participate when threatened by the increased size of minority groups, while individuals of racial/ethnic minority status are unaffected by the racial composition of their communities. Further, using a nationally-representative sample, Leighley (2001) found that the presence of other racial and ethnic groups in local areas has no significant effect on participation levels of whites, blacks, and Latinos.

Leighley (2001) proposes another theoretical linkage between the local racial 
composition and mass participation. Her "relational goods" hypothesis, drawn from Uhlaner's (1989) argument on the linkage between social interaction and political participation, suggests that citizens surrounded by their fellow members are more likely to be politically active. Leighley argues that the larger size of individuals' self-identified racial group promotes social interaction and racial solidarity, which in turn produces "relational goods" relevant to collective actions. Leighley's empirical analysis demonstrates that individuals are more likely to participate as the size of their own racial groups in local areas increases.

Economists (Alesina and Ferrara, 2000; Costa and Kahn, 2003) also predict a linkage between racial composition and civic engagement consistent with Leighley's relational goods hypothesis. Alesina and and La Ferrra (2000) demonstrate that individuals are less likely to have a strong incentive to engage in various types of group activities when surrounded by other group members, while Costa and Kahn's analysis (2003) confirmed that higher racial fragmentation reduces civic engagement. In short, though the nature of the dependent variable is slightly different, the bottom line of the argument in the economics literature matches Leighley's prediction: when individuals reside among members of their own racial or ethnic groups, they are more motivated to participate in public activities.

The theoretical murkiness of how the local racial environment may influence participation levels is reflected in Oliver's discussion of the effects of racial segregation on civic participation, in which he summarizes the implications of the previous literature as three possible competing "models": ethnic community, ethnic conflict, and ethnic correlates (Oliver, 2001, 109-115). The ethnic community model would suggest a positive linkage between the size of fellow group members and individual participation, in that residing in a context that is consistent with one's own race will enhance one's identification with the group and therefore increase incentives to par- 
ticipate, especially among minority groups. The ethnic conflict model, drawn from Blalock and others, suggests that individuals see politics as a zero-sum game, one in which racial groups compete for resources and power. In this model, the more diverse the community, the more likely individuals are to participate to protect their group interests.

Oliver's third approach to understanding the effect of racial environment on participation suggests that the effects of racial environment may be somewhat indirect; that the correlates of racial diversity - the distinct characteristics that are associated with racially-mixed communities - amount to political environments in which the need to compete for political resources provides an incentive for all citizens (in these racially-diverse environments) to participate more.

Oliver's empirical evidence reflects the weak development of the theoretical expectations. He writes $(2001,131)$ :

On the one hand, racial segregation seems to boost certain types of civic activities, particularly those involving more symbolic gestures or social connections between residents. Both whites and blacks are more interested in local politics, are more likely to take part in local organizational activity, and are more likely to vote in local elections when surrounded by people of their own race.... On the other hand, this greater social connection does not translate into more politically active citizens across the board. Residents of predominantly white cities, both white and nonwhite, are much less likely to contact officials, attend community board meetings, or work informally with their neighbors than people in racially mixed places. Although the sources of these differences cannot be precisely determined with existing data, the most likely cause is the social condition 
of racially mixed places... most racially mixed cities not only contain a disproportionate share of minority populations, they also contain a disproportionate share of social problems requiring collective solutions. If racial heterogeneity also gives these conflicts a racial flavor, then the social circumstance of racially mixed places can stimulate other types of political involvement.

The relationships between the racial composition of citizens' immediate environments and their participation levels in the previous literature are summarized in Figure 1. To simplify the argument, I use the terms "out-group size" and "in-group size" hereafter. The out-group size in area $j$ denotes the total size of all racial and ethnic groups other than the individuals' self-identified group, while the in-group size in area $j$ denotes the size of the racial and ethnic group that individuals identify with. The proportion of out-group size plus the proportion of in-group size is equal to the total size of the population in a geographical unit and they are standardized as follows:

$$
\text { Out-Group Size }_{j}+\text { In-Group }_{\text {Size }}=1
$$

Therefore, as the percentage of out-group size in local areas increases, the percentage of in-group size decreases, and vice versa. ${ }^{2}$

The power-threat hypothesis predicts that the probability of involvement in politics increases as the out-group size increases, as shown by the left chart in Figure 1. The relational goods hypothesis predicts that the probability of political engagement increases as the in-group size increases, as shown in the right chart.

Importantly, these existing hypotheses present competing explanations for the re-

\footnotetext{
${ }^{2}$ The larger out-group size or the smaller in-group size corresponds to higher degrees of racial diversity, while the smaller out-group size or the larger in-group size corresponds to lower degrees of racial diversity.
} 
Fig. 1. Two Existing Expectations

(A) Power-Threat Hypothesis

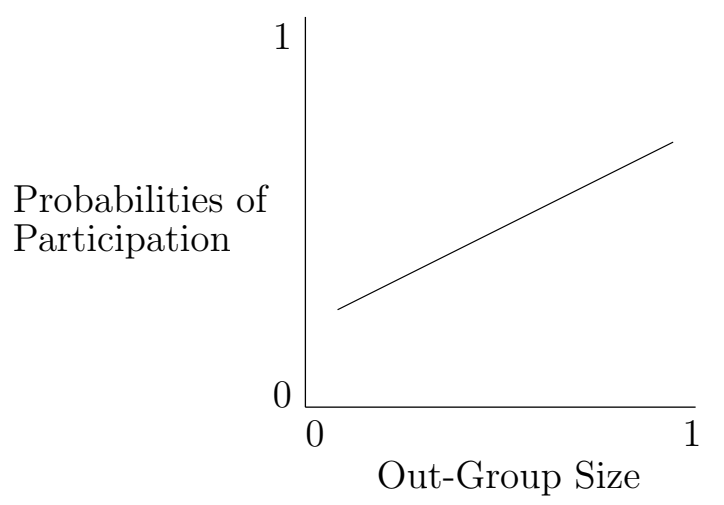

(B) Relational Goods Hypothesis

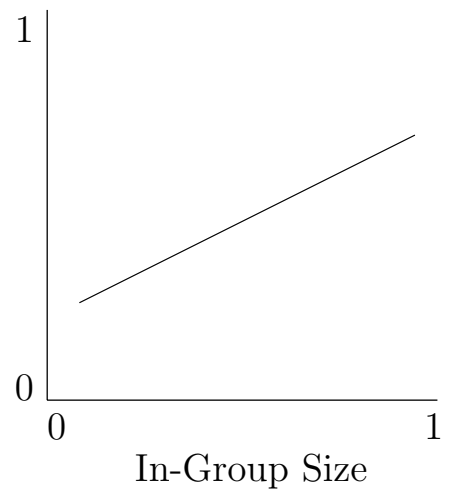

lationship between racial composition and citizen participation. Since Out-Group Size ${ }_{j}+$ In-Group Size $_{j}=1$, we can interpret the relational goods hypothesis in terms of the out-group size without changing the essence of the hypothesis. When the out-group size is used, the relational goods hypothesis suggests a negative relationship; the probability of political engagement decreases as the out-group size increases, as shown in Figure 2. In contrast, the power-threat hypothesis suggests a positive relationship.

Thus, these two hypotheses suggest obviously conflicting expectations regarding the direction of the effects of the racial composition. ${ }^{3}$ Further, the previous literature has presented inconclusive evidence for these two hypotheses. How can we solve this puzzle? How does the racial environment influence citizen participation?

The goal of this research is to resolve this puzzle. I argue that the theoretical

\footnotetext{
${ }^{3}$ Note that Leighley (2001) develops the power-threat hypothesis for Anglo whites and the relational goods hypothesis for African Americans' and Latinos' participation. Thus, these hypotheses are not conflicting in her theoretical framework. Conversely, Oliver (2001) views them as conflicting arguments.
} 
Fig. 2. Two Competing Expectations

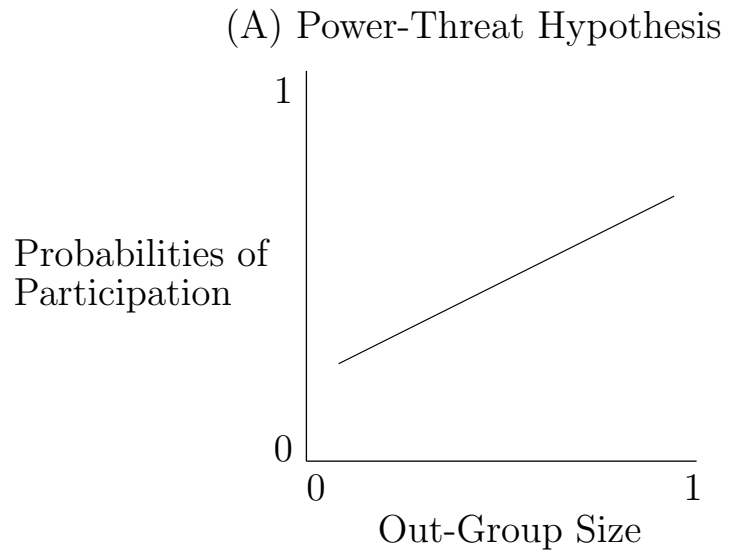

(B) Relational Goods Hypothesis

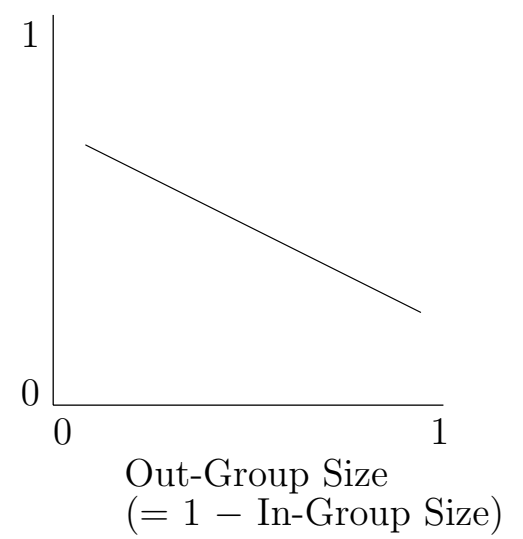

puzzle and mixed evidence in the prior literature derive from lack of careful theoretical development regarding the underlying causal mechanisms and lack of careful operationalization of racial composition. First, the existing hypotheses are limited because of their implicit assumption that racial composition is the only determinant of interracial and intraracial relations in local areas. The power-threat hypothesis assumes that the larger out-group size always produces high interracial conflicts and consequently generates the greater benefits of political participation. In other words, citizens in racially diverse areas always view out-group members as a threat to their economic and political interests and perceive strong incentives to defend those interests. Some cross-national research on ethnic conflicts (e.g., Posner, 2004), however, reports that this assumption is not always valid. While several nations or areas have significant ethnic, religious, or linguistic cleavages in their societies, those cleavages are not always politically salient and conflictual. Stated differently, cohabitation of multiple ethnic groups in a single geographical area is not always associated with the 
intensive group conflicts. Thus, the racial composition per se may not fully determine the degree of racial threat and therefore may not always change the relative importance of the benefits and costs of participating in politics.

Similarly, the relational goods hypothesis rests on an assumption that the substantial presence of in-group members in local areas always activates social interaction among in-group members and produces strong group ties. This group-based interaction is expected to increase the benefits of collective action and decreases the informational costs of participating in politics. This assumption is also questionable because opinion conflicts within intraracial networks have a crucial influence on the formation of relational goods. Prior literature implies that personal interaction with other in-group members who have conflicting political views and dissimilar social status would weaken group ties and consequently reduce the mobilizing effect of personal interaction on political participation (e.g., Huckfeldt, 1979; Mutz, 2006). In addition, research on group interaction (Cohen and Dawson, 1993; Gay, 2004) suggests that economic environments influence how actively citizens interact with other in-group members. Hence, racial composition per se may not fully shape the formation of relational goods and therefore may not always influence the utility calculation related to political participation.

Second, the existing literature addresses little about how the local racial composition is measured for examining the power-threat argument. The existing empirical research utilizes either the simple group size (e.g., Oliver, 2001) or the modified version of the Herfindahl index (e.g., Leighley and Vedlitz, 1999) as an indicator of the power-threat effect. Unfortunately, neither indicator is appropriate for testing the power-threat effect on citizen participation. Those indicators fail to incorporate an implication drawn from the rational choice perspective that citizens are less likely to participate when the probability of being successful is small. 


\section{B. Theoretical Overview}

This research offers a solution to the previously discussed puzzle by proposing that the economic and political characteristics of individuals' immediate environments determine how racial composition influences their engagement in politics. As suggested in the existing literature on race and ethnic relations (Branton and Jones, 2005; Gay 2006; Quillian, 1995), I argue that the effects of racial composition on individuals' political behavior are contingent on other environmental characteristics. More specifically, how strongly individuals perceive out-group members as threats to their interests and how actively they communicate with in-group members on political matters depend on the levels of local economic and political competition.

My argument is guided by the core theoretical principles of the power-threat and the relational goods hypothesis. The bottom line is that the larger out-group size increases citizen participation because of higher power-threat, while the larger in-group size increases participation because of more relational goods. I modify these explanations by arguing that the relationship between racial composition and the degree of power-threat and the amount of relational goods is conditional on local economic and political competitiveness. This argument assumes that competition essentially structures the nature of interracial and intraracial relations and therefore shapes individuals' utility calculations. The larger out-group size produces a high power-threat and increases the benefits of participation only when local economic or political competition is high. The larger in-group size activates social interaction and influences the utility of participation only when local economic or political competition is low. The underlying linkages are summarized in Table I.

My first proposition is that the presence of out-groups in local areas mobilizes citizen participation only when (1) the out-group size is relatively close to the in-group 
Table I. Summary of the Underlying Mechanisms

\begin{tabular}{|lc|c|}
\hline & \multicolumn{2}{c|}{ Economic or Political Competition } \\
& Low & High \\
Larger In-Group Size & More Relational Goods & Less Relational Goods \\
\cline { 2 - 3 } Larger Out-Group Size & Lower Power-Threat & Higher Power-Threat \\
\hline
\end{tabular}

size and (2) local economic or political competition is high, as shown in Figure 3. Unlike previous research, I argue that the effect of out-group size on mass participation should be weighted by the in-group size. The rationale behind this argument is that individuals care about both the benefits of achieving preferable outcomes (represented by the out-group size) and the probability of being successful in their efforts (represented by the in-group size). Thus, I expect that citizens are most likely to participate as out-group size is equal to in-group size in their immediate environments.

Further, I maintain that the presence of out-groups threatens individuals and produces the greater benefits of participating in politics only when high economic or political competition induces individuals to perceive that the out-groups yield an unfavorable impact on their economic or political interests. In contrast, the presence of out-groups yields no mobilizing impact on participation in areas of low competition because low competition deemphasizes the importance of preference polarization on policy issues among racial groups and thus reduces the likelihood that citizens perceive out-groups as threats. In sum, I expect to observe a curvilinear relationship between the out-group size and political participation only in areas of high economic or political competition.

My second proposition is that the presence of in-group members increases citizen participation only when local economic or political competition is low, as shown 
Fig. 3. Out-Group Size and Citizen Participation

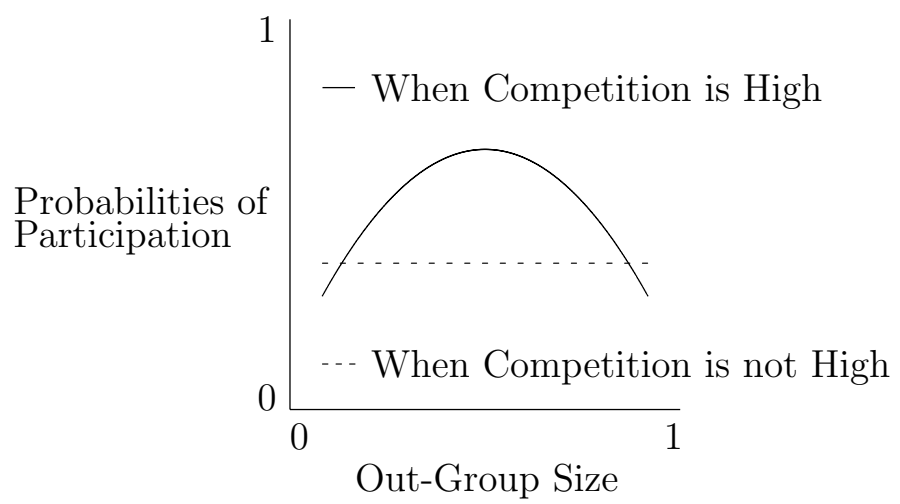

in Figure 4. The presence of in-group members in local areas increases the benefits and decreases the costs of participating in politics only when the low degrees of economic or political competition help individuals establish like-minded or sophisticated intraracial networks that can produce strong group ties and more relational goods. Hence, the larger in-group size mobilizes individuals to engage in political activities only in areas of low competition. Conversely, the presence of in-group members is hypothesized to have no mobilizing impact on participation when economic or political competition is high because it produces cross-cutting or unsophisticated intraracial networks that weaken group ties and the effectiveness of information exchange among individuals. As a result, high competition reduces the impact of group interaction on the utility of participation.

In my theoretical framework, the power-threat effect and the relational goods effect are not competing but complementary with each other, as shown in Figure 5 . Here I reconsider the relational goods impact in terms of the out-group size (i.e., Out-Group Size ${ }_{j}=1$ - In-Group Size ${ }_{j}$ ). When local economic or political compe- 
Fig. 4. In-Group Size and Citizen Participation

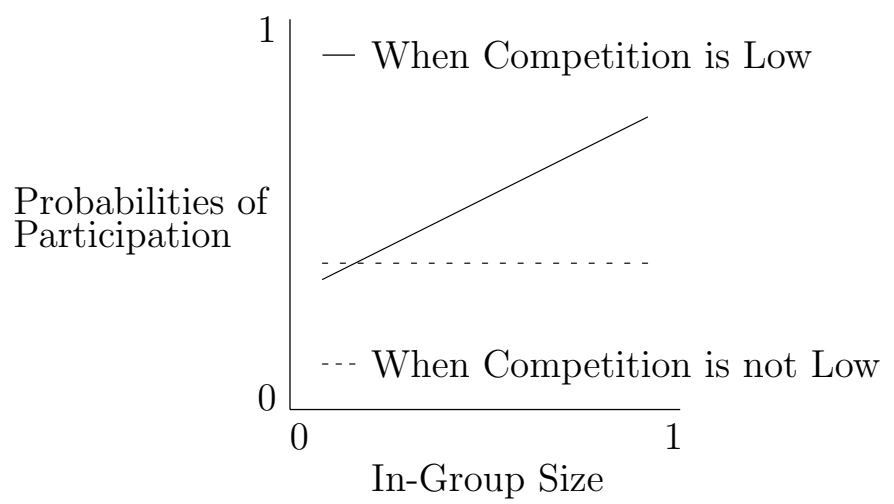

tition is high, it is expected to observe the curvilinear power-threat effect, which is depicted by the reverse u-shaped curve in Figure 5. When local economic or political competition is low, it is expected to observe the linear relational goods effect, which is depicted by the dashed line in the figure. Thus, how the racial composition influences mass participation levels is conditional on the degree of local economic or political competition. My theoretical framework relies heavily on the principles of the existing hypotheses and reconciles their competing expectations into a single consistent argument using the concept of "competition." In sum, citizens' participation levels are sensitive to the racial composition of their immediate environments only when some other conditions are met.

\section{Chapter Outline}

Following Chapter I, in which I present my theoretical argument in more depth, Chapter III first addresses measurement issues concerning racial composition, and then demonstrates results of some preliminary analyses. The first part of the chapter 
Fig. 5. Racial Composition and Citizen Participation

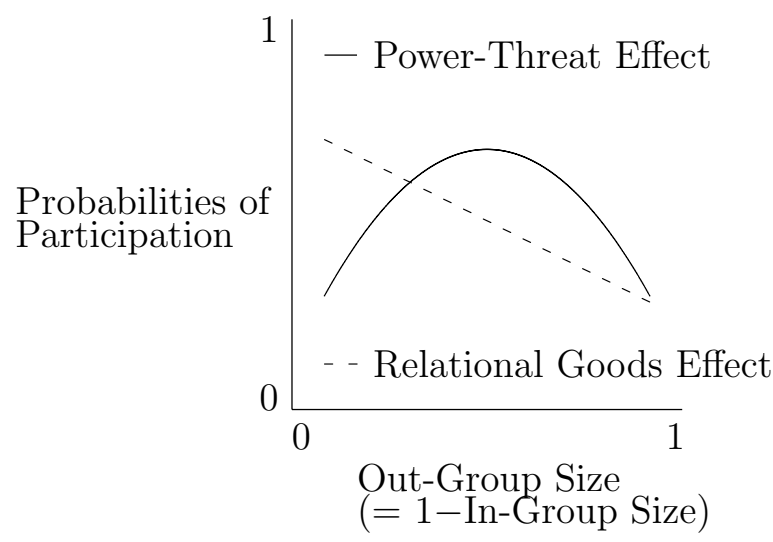

discusses a disadvantage of the simple out-group size and the racial diversity index based on the Herfindahl index as an indicator of racial diversity to test the powerthreat hypothesis. The second part illustrates distribution of survey respondents of three racial/ethnic groups (blacks, Latinos, and whites) across different degrees of racial composition and then reexamines how individuals' participation levels vary as the racial composition changes. My analysis demonstrates that racial composition varies considerably across locations, suggesting that some citizens reside in racially diverse areas, while others reside mostly with their fellow members. Additionally, the reexamination of the existing hypotheses reports that the relational goods hypothesis receives some supportive evidence, yet the power-threat hypothesis is not consistent with my empirical observations.

Chapter IV tests for the conditional linkages between the racial environment and political participation by exploring how local economic competition structures the nature of interracial and intraracial relations. Economic competition is conceptualized in two ways, competition among different income groups (i.e., economic diversity) and 
competition within the same income groups (i.e., economic affluence). The "economic diversity" hypothesis proposes that local income diversity determines the nature of competition for resources among different racial groups and the nature of social interaction among in-group members. High income diversity in racially diverse areas highlights preference polarization on policy issues among racial groups, which in turn induces individuals to be concerned about (re)distribution of the public goods. Thus, I hypothesize that the power-threat effect on mass participation is observed only when local income diversity is high. Moreover, low income diversity in areas with a substantial presence of in-group members helps individuals establish active intraracial networks without any status conflicts, which strengthen group ties and facilitate information exchange on politics. Thus, I expect that the relational goods impact on mass participation is observed only when local income diversity is low.

The "economic affluence" hypothesis proposes that average income status of local areas shapes the nature of competition among racial groups and the nature of social interaction among in-group members. Low income environments in racially mixed areas intensify competition for resources among racial groups because of the limited amount of resources and conflicting policy goals among different racial groups. As a result, this maximum-threat environment (Branton and Jones 2005) induces citizens to be concerned about (re)distribution of the public goods and enhances their incentives to participate. Thus, I hypothesize that the power-threat impact on citizen participation is observed only when local income status is low. Further, high income environments with a significant presence of in-group members help individuals establish resourceful and sophisticated intraracial networks and therefore strengthen group ties, which in turn increase the benefits and decrease the costs of participation. Hence, I hypothesize that the relational goods impact is observed only when local income status is high. 
Chapter $\mathrm{V}$ explores the conditional linkage between racial composition, political competition, and mass participation. Political competition denotes the degree of partisan heterogeneity measured using the average level of electoral competition in counties. The "political competition" hypothesis proposes that high political heterogeneity intensifies the interracial conflicts and therefore enhances the incentives of participation, while low political heterogeneity strengthens the intraracial ties and therefore enhances the effectiveness of information exchange. I hypothesize that the power-threat impact is observed only when local political heterogeneity is high, while the relational goods impact is observed only when local political heterogeneity is low.

Chapter VI summarizes the findings of my empirical investigations, evaluates the robustness of my theoretical arguments, and draws several conclusions and implications. I will return to the fundamental question of the study on political participation, that is, "why citizens participate in politics?" and offer some answers derived from my arguments and empirical evidence. I argue that my propositions and empirical evidence reconcile the conflicting expectations on how the racial environment influences citizen participation in the previous literature (e.g., Oliver 2001) and demonstrate that those expectations are not actually competing but rather complementary with each other. Further, I address the implications of my findings to representational consequences in the United States.

The hypotheses tested in the subsequent chapters are summarized in Table II. This research tests two existing hypotheses and three new conditional hypotheses. The column, "Key Conditions," in the table specifies environmental conditions that are expected to increase citizen participation in politics. The last column, "Chapter," indicates in which chapter these hypotheses are empirically tested. 
Table II. Expected Environmental Conditions for Greater Mass Participation

\begin{tabular}{|c|c|c|}
\hline Hypothesis & Conditions & $\mathrm{Ch}$ \\
\hline Power-Threat & Larger Out-Group Size & III \\
\hline Relational Goods & Larger In-Group Size & III \\
\hline $\begin{array}{l}\text { Economic } \\
\text { Diversity }\end{array}$ & $\begin{array}{l}\text { (A) Power-Threat } \times \text { High Income Diversity } \\
(B) \text { Relational Goods } \times \text { Low Income Diversity }\end{array}$ & IV \\
\hline $\begin{array}{l}\text { Economic } \\
\text { Affluence }\end{array}$ & $\begin{array}{l}\text { (A) Power-Threat } \times \text { Low Income Status } \\
\text { (B) Relational Goods } \times \text { High Income Status }\end{array}$ & IV \\
\hline $\begin{array}{l}\text { Political } \\
\text { Competition }\end{array}$ & $\begin{array}{l}\text { (A) Power-Threat } \times \text { High Political Heterogeneity } \\
\text { (B) Relational Goods } \times \text { Low Political Heterogeneity }\end{array}$ & $\mathrm{V}$ \\
\hline
\end{tabular}

D. Data And Methods

Data used for empirical tests comes from Verba, Schlozman, and Brady's American Citizen Participation Study 1990 (CPS), which is merged with 1990 census data (STF3) and General Election Data for the United States. ${ }^{4}$ The CPS was specifically designed for assessment of participation in political and non-political activity in the United States. Respondents were asked about their involvement in political and non-political activities, psychological engagement in politics, attitudes on national and local political issues, and personal experiences and demographic characteristics. The study includes over-samples of African-American and Latino respondents using a special procedure (for more details, see Verba, Schlozman, and Brady, 1995).

Contextual information is aggregated at the county level. Respondents' zip codes in the CPS data set allowed me to identify racial, economic, and partisan character-

${ }^{4}$ The CPS data and General Election Data are available through the ICPSR data archive. The study numbers are No.6635 and No.13, respectively. The census data are available through the US Census Bureau web site. 
istics of counties. ${ }^{5}$ Therefore, the individual-level variables in the CPS were supplemented with the contextual-level variables drawn from 1990 census data and General Election Data aggregated at the county areas.

A simple logit model is used for estimation since the dependent variables are dichotomous (i.e., vote/not vote). Although the data have a multilevel structure, a hierarchical modeling technique is not employed as a primary estimation procedure in this research because of lack of variation in individual-level data for many counties. However, though not reported in this research, empirical analyses using a multi-level modeling technique confirm that findings based on non-hierarchical estimation are valid. ${ }^{6}$

\section{E. Contributions}

Theory in political science literature often presents conflicting expectations on a causal linkage between the same set of independent and dependent variables. As noted above, the previous studies of socioeconomic contexts and mass participation suggest that, holding other variables constant, high status contexts (Huckfeldt, 1979) and middle income contexts (Oliver, 1999) are associated with the highest probabilities that individuals participate. A body of research on negative campaigns and voter turnout predicts that attack advertisements demobilize citizens (e.g., Ansolabehere et al., 1994; Ansolabehere, Iyenger and Simon, 1999) on the one hand and mobilize them or have no effect (e.g., Brooks, 2006; Finkel and Geer, 1998; Goldstein and

\footnotetext{
${ }^{5}$ See Appendix A for detailed information on county identification. Note that respondents' zip codes are not included in the data file from the ICPSR.

${ }^{6}$ In addition, since the considerable number of cases is lost in the process of estimation due to missing information in the original data and the contextual data, I used multiple imputation (e.g., King et al., 2001, Schafer, 1997, 1999) to replicate my findings. Results are not reported.
} 
Freedman, 2002; Wattenberg and Brians, 1999) on the other hand. Beyond the study of mass participation, prior research on partisanship presents interesting controversies that individuals' partisanship is dynamic and responds to short-term political changes (e.g., Erikson, MacKuen and Stimson, 1998; MacKuen, Erikson and Stimson, 1989) and that partisanship is stable and persistent in nature (e.g., Green, Palmquist and Schickler, 1998, 2002).

In the field related to this research, prior literature on the racial environment and political attitudes offers three competing hypotheses on the effect of the out-group population on citizens' racial attitudes, suggesting that residing among out-group members produces negative attitudes (the power-threat hypothesis), positive attitudes (the contact hypothesis), and has no effect although residing among in-group members or low status citizens produces negative attitudes (the segregation hypothesis). Most scholars have tested these hypotheses to determine which one demonstrates superior empirical leverage, yet they have been reluctant to explore why they are competing and, further, to integrate them into a more consistent theoretical framework (see some exceptions such as Branton and Jones, 2005; Stein, Post, and Rinden, 2001). Unifying conflicting arguments into a consistent model is as an important theoretical contribution as identifying a new causal linkage in the process of theory building.

This research offers the first theoretically-motivated, rigorous analysis and evidence of the impact of immediate racial context on individuals' participation. My research solves the theoretical and empirical puzzle in the prior literature and presents a more rigorous model of how the racial environment influences citizen participation. The conditional hypotheses examined in the subsequent chapters demonstrate that the principles of the power-threat hypothesis and the relational goods hypothesis yield both valid and effective explanations for the linkage between the racial composition and citizen participation. The lack of careful theoretical development and 
operationalization in the existing hypotheses results in the conflicting expectations and mixed empirical evidence. Racial environments play a significant role as a determinant of mass participation, but in ways more complicated than simple models of contextual effects might suggest. 


\section{CHAPTER II}

\section{THEORY}

Citizens' propensity to participate in politics is a function of both personal and environmental characteristics. Most of the prior research on political participation has focused on the role that personal characteristics play in the process of theory building. Scholars elaborate why and how citizens participate in politics by exploring variations in their demographic characteristics and political orientations. Verba, Schlozman, and Brady's (1995) Civic Voluntarism model offers the most comprehensive illustration of the individual-level determinants of citizens' involvement in politics. They organize major existing explanations for citizen participation (e.g., Downs, 1957; Rosenstone and Hansen, 1993; Verba and Nie, 1972; Wolfinger and Rosenstone, 1980) into a single theoretical model in which resources, psychological engagement, and mobilization are specified as the key predictors of levels and modes of political participation. They contend that citizens engage in political activities because they can, they want to, and they are requested. This simple explanation fully illustrates how and why individuals' characteristics are associated with their engagement in political activities.

In contrast, less effort has been made to explore the roles of environmental characteristics. Previous studies of contextual influences (Campbell, 2006; Huckfeldt and Sprague, 1995; Leighley, 2001; Oliver, 2001; Rosenstone and Hansen, 1993) suggest that citizen participation is contingent on social and political environments, yet some of the hypotheses are conflicting and their empirical evidence is mixed. Specifically, we have no agreement on whether and how the racial composition of citizens' immediate environments influences their participation levels (Campbell, 2006; Leighley, 2001; Leighley and Vedlitz, 1999; Oliver, 2001). The power-threat hypothesis predicts that a larger out-group size in local areas increases citizen participation, while the 
relational goods hypothesis predicts that a larger out-group size decreases participation. These hypotheses are not consistently supported in empirical analyses. Further, Campbell's (2006) recent analysis reports that voter turnout is unaffected by racial and ethnic composition. Thus, we are still unclear about whether and how the racial environment influences citizen participation. How can we reconcile these competing theoretical expectations into a consistent argument? Is racial composition a crucial determinant of citizen participation?

This chapter presents a new argument regarding how racial environment shapes mass participation. The limited theoretical development in the previous literature derives principally from a failure to fully explore underlying mechanisms of contextual influences of racial composition. I therefore reconsider the underlying process more carefully and propose that economic and political characteristics of citizens' immediate environments are the key to understand interracial and intraracial relations. My argument is drawn from research on the rational choice model of political participation, on race relations in divided societies, and on social networks and political behavior.

I begin with the rational choice model of citizen participation to argue that social environments exercise a significant influence on mass participation since they shape the utility associated with individuals' calculations of the benefits and costs of participating in politics.

I then specify two mechanisms under which the racial environment structures interracial and intraracial relations. First, I apply the competition theory on race relations (e.g., Barth, 1969; Bates, 1983; Blalock, 1967; Bonacich, 1972; Olzak, 1992) to the study of political participation and contend that the presence of out-groups produces a high racial threat and therefore generates greater incentives for individuals to participate only when the levels of local economic or political competition are high. 
Second, I extend previous literature on communication networks (e.g., Huckfeldt and Sprague, 1995; Mutz, 2006) and suggests that the presence of in-groups activates interaction and therefore changes the relative importance of the costs and benefits of participation when the levels of local economic and political competition are low.

My conditional perspective suggests that the racial composition of local areas is not a single determinant of interracial and intraracial relations. Most of the existing contextual models overlook the fact that residential environments are multidimensional. Yet recent studies focus on the interactive effects of racial diversity with economic environments on mass racial attitudes (Branton and Jones, 2005; Gay, 2006). My approach is consistent with this recent theoretical development; that is, racial composition has a strong influence on the utility of political participation only when some types of economic or political conditions are met.

In the next section, I address the implications of the rational choice perspective for contextual models of political participation. Following this, I elaborate how economic and political competition mediates the relationship between racial composition and citizen participation.

\section{A. The Rational Choice Perspective And Contextual Models Of Political Participa- tion}

The rational choice perspective offers a simple but sophisticated explanation for the underlying causal processes of political participation (especially voter turnout). It reveals how individual-level and contextual-level predictors shape levels of mass participation. The first part of this section briefly summarizes the rational choice model of voter turnout and then illustrates its implication to the study of contextual influences, especially of the racial environment, on mass participation. 
Downs (1957) and Riker and Ordeshook (1968) formalize the expected utility associated with voter turnout in the following equation that

$$
R=P B-C
$$

where $R$ denotes the reward that an individual receives from voting, $P$ denotes the probability that an individual makes a difference in an election's outcome, $B$ denotes the benefit that an individual receives when a preferred candidate wins the election, and $C$ denotes the non-negative cost of voting. This calculus of voting model indicates that citizens as utility-maximizers go to the polls only when the expected utility is greater than zero $(R>0)$.

Despite its theoretical leverage, this decision-theoretic model contradicts with the reality of the contemporary electorate. The probability $p$ that an individual plays a pivotal role in a given election is tiny and almost equal to zero because the size of the electorate in a single district for any type of election is quite large. Competitive elections may enhance the probability, yet "saying that closeness increases the probability of being pivotal... is like then short men to bump their heads on the moon" (Schwartz, 1987, 118). As a result, the size of $P B$ always becomes negligible, while the cost of participation is sizable for citizens. Thus, the model always results in $R<0$ and predicts that no rational actor casts a vote in elections. In reality, however, we observe the significant proportion of citizens voting in every presidential and local election. This inconsistency between theory and reality is called "the paradox of not voting."

Although decision-theoretic and game-theoretic analysts have attempted to solve the paradox within the original setting of the model or with some extensions (e.g., Fedderson and Pesendorfer, 1999; Morton, 1991; Palfrey and Rosenthal, 1985), behavioral scholars have utilized the above model as an analytical tool to specify determinants of 
citizen participation. They conceptualize the individual terms in the original model (i.e., the benefits and the costs of participation) as a underlying factor that accounts for how and why individual-level and institutional-level characteristics affect individuals' decision to participate (e.g., Aldrich, 1993; Rosenstone and Hansen, 1993; Verba, Schlozman and Brady, 1995; Wolfinger and Rosenstone, 1980). The rational choice model principally implies that individual traits or social and political settings that enlarge the benefits and reduce the costs can increase probabilities that individuals participate, holding other variables in the calculus of voting model constant. Behavioral scholars then address how participation levels are determined by individual-level and contextual-level variables through the unobservable costs and benefits. Importantly, the major goal of behavioral scholars is to construct a substantively reasonable model with the assistance of the rational choice perspective. Therefore, most of the studies do not explicitly intend to solve the paradox within the original framework. ${ }^{1}$

A body of contextual models of political participation elaborate how social and political settings determine the costs and benefits of political activities. For example, Rosenstone and Hansen (1993) argue that elite mobilization and social interaction reduce the informational cost of participation. Political leaders and communication partners subsidize campaign information through mobilization activity and daily interaction respectively, which help individuals reduce the informational burden necessay for participation. Verba, Schlozman, and Brady (1995) contend that non-political organizations such as religious organizations and community groups play a role simi-

\footnotetext{
${ }^{1}$ The rational choice perspective also implies that as the probability of being increases, citizens are more likely to participate. However, as noted earlier, it is theoretically implausible to hypothesize that closeness enhances voter turnout. Some scholars then rest on the assumption that actors are the backward-looking adaptive learners instead of the forward-looking utility maximizers and argue that the $P$ term is sizable and citizens are expected to vote in large national elections. See Kanazawa (1998, 2000) and Bendor, Diermeier, and Ting (2003) for further discussions.
} 
lar to elite mobilization and social interaction. Further, some research demonstrates that institutional settings have a considerable effect on the size of the costs. Wolfinger and Rosenstone (1980) report that citizens are less likely to vote when they reside in states with more restrictive registration laws which impose additional costs (see also Powell [1986] for cross-national evidence).

Other contextual research emphasizes the linkage between political environments and the size of $B$ or "the importance of the options available to individuals" (Zipp, 1985, 50). Some political environments offer greater incentives for individuals to participate in politics. A greater size of $B$ or a greater difference in the expected utility provided by two candidates or parties $\left(E\left(U_{1}\right)-E\left(U_{2}\right)\right)$ are associated with higher probabilities of participating in politics, holding other variables constant. Zipp (1985) extends this theory and demonstrates that the size of the benefits represented by a difference between the perceived ideological positions of presidential candidates and those of individuals predicts who voted in the presidential election: the smaller the size of perceived ideological difference between candidates and citizens, the greater the probability of voting (see also Adams, Dow, and Merrill [2006]; Plane and Gershtenson [2004]). Beck and Jennings $(1979,747)$ argue that active participation of the liberal and the young in the 1970s could be attributed to "the nature and attractiveness of the ideological alternatives presented to the mass public" by the elite. State-level analyses by Hill and Leighley $(1993,1996)$ demonstrate that an intraparty ideological difference between the activists and the mass public has a significant effect on voter turnout. Ideological proximity between the activists and the electorates enhances the utility of voting and consequently the probability of doing so. Further, Campbell (2003) demonstrates that a political threat to welfare programs encourages senior citizens to voice their concerns in politics through political activities. Smith (2001) observes positive correlation between the salience of ballot initiatives or referendum 
and voter turnout. He argues that "the initiatives and referenda with the highest public salience should show the strongest relationship with turnout because of their impacts upon the benefits of voting" (Smith, 2001, 700).

Although most of the previous contextual research using the implications of the rational choice perspective focuses on the relationships between the macro-level environmental variables (institutional settings and the national-level or state-level elite behavior) or the micro-level contextual variables (social networks and civic organizations) and the utility associated with the costs and benefits, Leighley (2001) applies the rational choice perspective to her investigation of the link between the intermediate-level environments and mass participation. She suggests that racial composition of citizens' immediate environments shapes the benefits and costs of participating in politics and the likelihood of being successful. That is, the sizes of $B, C$, and $P$ in the calculus of voting vary across geographical locations where individuals experience different levels of racial composition.

Leighley (2001, 7-8) summarizes her argument as follows:

[Racial environments] may indirectly reduce the costs of participating by affecting the likelihood of elite mobilization and the provision of relational goods, but more important, it increases the benefits of participating more directly. For minority individuals, the potential benefits of participating are greater as the racial/ethnic group increases in size because the group consequently enjoys a higher probability of being successful in its political efforts. For Anglos, an increase in minority group size acts as an informational cue of group threat - which again should increase the potential policy benefits of engaging in political activity.

Leighley contends that, for minority citizens, the significant presence of in-group 
members in their immediate environments enhances the probability of being mobilized by the elite and interacting with their fellow group members, which in turn reduces the informational costs of participation. Further, the larger in-group size also enhances a belief by minority citizens that they could be successful in their effort and that their participation yields political benefits for their group members. In short, the larger in-group size produces relational goods relevant to participation (Uhlaner, 1989) and therefore increases citizen participation (i.e., the relational goods hypothesis). On the other hand, for Anglos, the presence of other racial groups leads them to perceive that their political interests are threatened by those out-group members. Consequently, this perceived racial threat increases the benefits of participating in politics and stimulates their participation (i.e., the power-threat hypothesis).

Note that Leighley (2001) develops the power-threat hypothesis for white participation, while she elaborates the relational goods hypothesis for minority (African Americans and Latinos) participation. Nonetheless, some existing research indicates that both the power-threat argument (Gay, 2006; Oliver and Wong, 2003) and the relational goods argument (Alesina and Ferrara, 2000; Uhlaner, 1989) can explain political behavior of the general public, as well as specific racial groups. Thus, in this research, I view the power-threat and relational goods hypothesis as general explanations for the linkage between racial environment and political participation of any racial groups.

The hypothesized relationships between the racial environment and citizen participation levels in the previous literature are summarized in Figure 1 in Chapter I. Further, the two hypotheses suggest conflicting expectations regarding the direction of the effects of racial composition on mass participation (See Figure 2).

I argue that the hypotheses in the literature rest on weak assumptions concerning the underlying mechanisms, which I believe produce the conflicting expectations and 
inconsistent empirical evidence. The key limitation of the assumptions lies in that the racial composition fully determines the nature of interracial and intraracial relations in local areas. Prior research, however, implies that how individuals compete for resources with out-group members and how they interact with their in-group members is often conditional on other environmental elements. Thus, the failure to specify the roles that other environmental characteristics play in the underlying processes explains why the two hypotheses are competing and receive inconsistent empirical evidence. A careful review of the literature on the power-threat and relational goods arguments illuminates this point more clearly.

The power-threat hypothesis derives from the argument originally developed by Blalock (1967), in his study on majority-minority group relations. Blalock argues that whites' fears of intensive competition for economic resources and political power intervene the causal relationship between the size of minority population and their motivation to discriminate minority citizens. Blalock $(1967,73)$ conceptualizes competition as "the idea that two or more individuals are striving for the same scarce objectives, so that the success of one implies a reduced probability that others will also attain their goals." Blalock theorizes that the larger out-group population reinforces fears of majority individuals for economic competition in a zero-sum situation, which in turn enhances their motivation to discriminate against minority citizens (see also Sniderman, Hagendoorn, and Prior, 2004). Blalock also defines power as "the actual overcoming of resistance in a standard period of time" $(1967,110)$. A larger minority group population enhances majority individuals' perception that numerical dominance of the minority citizens produces political power that allows them to dominate the decision-making process. Consequently, the fear of political dominance drives majority individuals to engage in discriminatory behaviors toward minority groups. In sum, Blalock suggests that the presence of out-groups always results in 
greater fears for economic and political competition.

The existing cross-national research, however, observes no one-to-one relationship between the out-group size and the interracial conflict in divided societies. In his recent article on ethnic conflicts in Africa, Posner (2004, 529) asks, "Why do some cultural differences matter for politics and others not?" While several nations or areas have significant ethnic, religious, or linguistic cleavages in their societies, those cleavages are not politically salient and conflictual. Citizens in some divided societies face no violent conflict with other group members. In other words, cohabitation by multiple ethnic groups in a single geographical area is not always associated with intensive group conflicts. Thus, Posner $(2004,543)$ contends that "cultural differences are neither sufficient nor necessary for the emergence of political and social divisions."

In this research I apply Posner's argument to race relations in the United States and contend that high racial diversity is neither sufficient nor necessary for the emergence of interracial conflicts in local areas. Individuals in racially diverse areas require economic or political reasons to perceive out-group members as threats to their interests. With respect to political participation, the presence of out-groups motivates individuals to participate in politics only when some economic or political conditions are met. In sum, the power-threat hypothesis in the existing literature is limited because the racial composition per se is assumed to structure interracial relations and change the relative importance of the costs and benefits of participating in politics.

The relational goods hypothesis in Leighley's research derives from Uhlaner's (1989) relational goods model of political participation. Uhlaner introduces the concept of relational goods, defined as any instrumental and consumption benefits shared and enjoyed by multiple citizens, to the rational choice model of voter turnout. Uhlaner theorizes that the relational goods make participation a rational action for individuals under a wide range of circumstances. Uhlaner's model proposes that social 
interaction allows individuals to perceive political preferences of others and therefore enhances group consciousness. A stronger group tie, in turn, increases their participation. This theoretical argument leads Uhlaner to predict two important turnout patterns $(1989,219)$ : "turnout should be higher among groups the more unanimous their preferences for a candidate," and "turnout should be higher the greater the geographic concentration and interpersonal interaction of members of a group, and the denser the social networks within the group."

Based on these predictions, Leighley hypothesizes that the presence of more in-group members in the immediate environments helps individuals establish active and dense intraracial networks, which results in stronger intraracial ties and greater participation. This hypothesis is consistent with other research demonstrating that heavy concentrations of in-group members reinforce group solidarity and intraracial interaction (e.g., Welch et al., 2001) and that group solidarity increases the benefits and reduces the informational costs of participation (Chong and Rogers, 2005).

Unfortunately, Leighley's hypothesis rests on a weak assumption that the larger in-group size always produces more relational goods and therefore changes the utility calculation. Prior research, however, demonstrates that the larger in-group population is not always linked with active and dense intraracial interaction. For example, Cohen and Dawson (1993) find that poor black neighborhoods in urban areas tend to isolate residents from social networks. That is, a significant presence of in-groups in some types of economic settings fails to produce active intraracial networks. Gay (2004) shows that socioeconomic status of black neighborhoods has a strong impact on group identity. She finds that high status black communities are more likely to develop racial solidarity because of active intraracial interaction among residents. Hence, these works imply that the presence of in-group members in citizens' immediate environments enhances group interaction and solidarity only in limited types of 
economic settings.

Furthermore, though race is a crucial predictor of individuals' political preferences, we also observe significant variations in policy attitudes within the racial groups (Johnson and Gordon, 2005; Nicholson and Segura, 2005; Uhlaner and Garcia, 2005). Interaction with other in-group members does not necessarily mean interaction with other like-minded individuals. Group ties among in-group members can be weaker when intraracial networks are composed of individuals with dissimilar political views. Some findings in prior literature on political discussion (e.g., Campbell et al., 1960; Huckfeldt, 1979; Mutz, 2006) imply that status and opinion conflicts reduce the impact of personal communication on citizens' attitude formation and behavior. Thus, the presence of in-groups can produce stronger group ties only in limited types of political or economic settings.

In short, the existing hypotheses are restricted by their assumptions that racial composition fully structures local interracial and intraracial relations. Conversely, I begin with the assumption that racial composition is neither a sufficient nor a necessary condition for race relations and theorize that those relations relations is conditioned by two forms of competition.

\section{B. Political Participation In Multidimensional Environments}

In this section, I elaborate how local economic and political characteristics structure race relations. A substantial presence of out-groups is expected to produce high perceived racial threat and therefore increases the benefits of participation only when local economic or political competition is high. A substantial presence of in-group members is expected to strengthen group ties and therefore increase the benefits and decrease the costs of participation only when such competition is low. 
Fig. 6. Policy Preferences by Race and Class

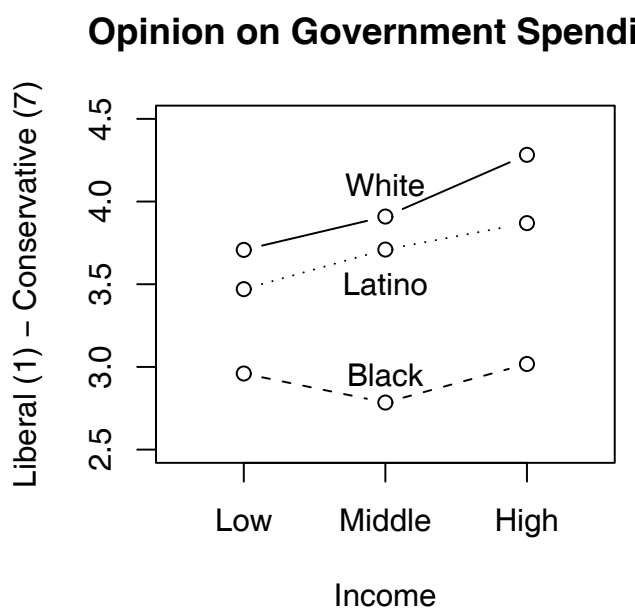

Opinion on Government and Jobs

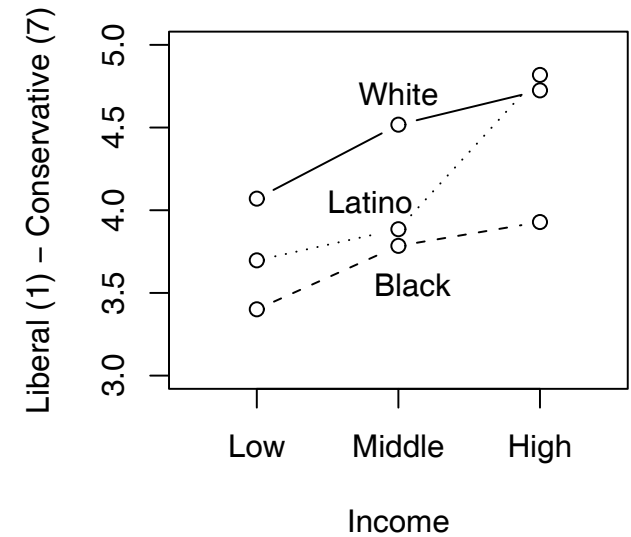

Note: Data comes from the Citizen Participation Study (Verba, Schlozman, and Brady, 1995). The question wording and coding rules are presented in the data appendix. The number of cases analyzed for "Opinion on Government Spending" is 2129. The number of cases analyzed for "Opinion on Government and Jobs" is 2135.

\section{The Presence of Out-Groups and Power-Threat}

When does the presence of out-groups produce high levels of power-threat? In this section I first identify a source of power-threat in racially diverse areas. I then specify what environmental conditions induce individuals in racially diverse areas to perceive out-group members as threats to their interests and enhance their incentives to engage in political activities.

Preference polarization on policy issues among racial groups is the first source of power-threat. Research on public opinion reports that racial groups show different partisan orientation and divergent policy preferences (e.g., Kinder and Sanders, 1996; Kinder and Winter, 2001). Figure 6 demonstrates that policy opinions on government 
spending and government responsibility of providing jobs vary across racial categories after controlling for the effect of income status. Smaller values on the y-axis represent a more liberal response ("Government should increase in spending for welfare" and "Government has responsibility for providing jobs"). The figure shows that race has a greater impact on citizens' attitudes on policy issues than class. The high degrees of preference polarization indicate that individuals of different racial groups pursue different policy goals in a zero-sum game and compete against each other for scarce resources. In short, the presence of out-groups poses a serious threat to individuals because political preferences are significantly different among racial groups.

Limited provision of public goods is the second source of power-threat in racially diverse areas. Alesina, Baqir, and Easterly (1999) argue that the size of public goods provided by local governments decreases as preference polarization increases. Alesina, Baqir, and Easterly $(1999,1251)$ note that "if [the degree of preference polarization] is high, a large fraction of the population have preferences that are very far from the chosen type of public good; therefore, they would prefer to keep taxes low and devote more resources to private consumption rather than public consumption." These scholars argue that areas of high racial diversity where preference polarization is high reduce the amount of public goods provided to residents. Consequently, high racial fragmentation with the limited availability of public resources leads citizens to care more about political decisions over the amount of taxation and the size and type of public goods since scarce public resources are more likely to be consumed for outgroup members who pursue different policy goals unless citizens voice their preferences in the political process. In sum, the presence of out-groups poses a serious threat to individuals because the available public resource is limited.

I argue that the presence of out-groups motivates individuals to engage in political activities only when high levels of economic and political competition induce 
individuals to recognize political consequences of the presence of out-group members. Citizens participate only if high competition highlights preference polarization among racial groups and/or the limited availability of public goods as a crucial political issue for their lives. On the contrary, low economic and political competition shift their attention away from the linkage between out-group members and policy consequences. As a result, racial threat is a less crucial issue for individuals' decisions to participate.

The importance of economic and political competition derives from previous sociological literature proposing that the emergence of interracial conflicts originates from competitive economic and political situations at the national and local levels (Beck and Tolnay, 1990; Bonacich, 1972; Jacobs and Wood, 1999; Olzak, 1992). Specifically, Olzak (1992) argues that, in addition to the presence of out-group members, economic and political competition for economic resources and political power generate ethnic conflicts such as riots and protests. She $(1992,28)$ writes:

So when competitive forces among ethnics are released, ethnic boundaries become highly salient during periods of intense competition over resources. What kinds of social processes activate ethnic boundaries? A central hypothesis derived from the ecological theory of Barth [1969] and others is that ethnic competition intensifies ethnic boundaries when two or more ethnic populations try to acquire the same valued resources, such as jobs, housing, or marriage partners.... In this way we can begin to understand that ethnic boundaries are activated in contrast to other possible boundaries in any given interaction setting.... Competition processes spark ethnic conflicts when ethnic groups attempt to occupy the same resource environment and compete for same limited set of resources (emphasis in original). 
Olzak specifies racial, economic, and political conditions under which the powerthreat effect is activated. First, obviously, the significant presence of the out-group population in geographical areas matters for the emergence of group conflicts. Large immigration from other countries and from other places within the U.S. is hypothesized to raise ethnic competition for resources and power and spark ethnic conflicts. The second set of conditions relates to economic situation. Olzak expects that economic contraction, low levels of job segregation, and increases in minority groups' socioeconomic status intensify economic competition for scarce resources and therefore produce more collective actions by ethnic groups. The third set of conditions focuses on political situation. Olzak hypothesizes that political and social movements such as the growth of new parties and labor organizations intensify political competition over power through mobilization and consequently raises rates of collective actions by ethnic minorities.

Thus, high competition is the key for individuals to perceive out-group members as threats and mobilizes them to participate in politics. Economic or political competition is an information cue signaling to individuals that high preference polarization and limited provisions of the public good in racially diverse areas have an unfavorable impact on their political and economic interests. When individuals connect preference polarization among racial groups with substantive economic and political issues, they are more likely to feel threatened and find larger incentives to participate in order to protect their interests. Hence, competition activates the effect of racial threat on the benefit of participating in politics.

On the contrary, in areas of low political or economic competition with the substantial presence of out-groups, citizens are less likely to perceive out-group members as economic and political threats because the lack of competition obscures the political consequences of the presence of out-groups in local areas. More specific illustrations 
on the roles of economic and political competition will be given in Chapters IV and V.

Note that what distinguishes Olzak's hypotheses from Blalock's argument is the role of economic and political competition in the causal process. While Blalock theorizes perceived economic and political competition as an intervening mechanism between racial composition and citizens' behavior, Olzak conceptualizes the objective degrees of economic and political competition as independent and direct causes of ethnic conflicts.

In sum, the out-group size is expected to have an interactive effect with the local political and economic characteristics on the benefit of participating in politics. The first proposition drawn from the above argument is that the power-threat effect on mass participation is observed only when the degree of local economic or political competition is high.

\section{The Presence of In-Groups and Relational Goods}

When does the presence of in-groups in local areas activate social interaction among in-group members and produce more relational goods? Research on political communication indicates that economic and political characteristics of local environments determine the nature of intraracial relations. I specify an economic and political condition under which intraracial communication network has a powerful impact on citizens' decisions to participate.

Traditional contextual models of political behavior suggest that social interaction is the key underlying mechanism connecting local contexts with citizens' behavior. Eulau and Rothenberg $(1986,131)$ note that "underlying the use of social context as a scientific term is the assumption that context emerges from and is created by a person's interactions with other individuals." This argument is supported by some 
evidence that partisan context exerts an influence on formation of citizens' political attitudes only through social interaction (MacKuen and Brown, 1987; Putnam, 1966; Weatherford, 1982). With respect to political participation, Huckfeldt's model of socioeconomic contexts was the first to rely on the assumption of social interaction as an underlying process: "people can be stimulated to participate both by being around others who participate and by adopting prevalent group norms which encourage participation" (1979, 581; see also Kenny, 1992, Leighley, 1990, and Rosenstone and Hansen, 1993). Social interaction is expected to increase instrumental and expressive benefits and reduce the informational costs of participation.

Previous studies identify two environmental conditions that determines the effectiveness of information exchange in social networks. First, the political expertise of social networks plays a significant role. Huckfeldt (1979) and Kenny (1992) argue that interaction with those who are likely to participate in politics is effective for participation. Thus, Huckfeldt emphasizes the importance of social interaction in high status communities where most of the citizens have the experience of political participation. Further, La Due Lake and Huckfeldt (1998) and McClurg (2006) demonstrate that citizens involved in networks with higher levels of political knowledge are more likely to participate in politics. Thus, higher degree of political expertise within social networks is more influential on the likelihood of participation.

Second, opinion and status conflicts within social networks are not preferable for information exchange. The classic works such as the People's choice and the American Voter argue how composition of social networks affects mass participation. In the People's Choice, Lazarsfeld, Berelson, and Gaudet (1944, 60) note, "Whatever the source of the conflicting pressures, whether from social status or class identification, from voting traditions or the attitudes of associates, the consistent result was to delay the voter's final decision." The authors of the American Voter suggest that, "The 
person who experiences some degree of conflict tends to cast his vote for President with substantively less enthusiasm... and he is somewhat less likely to vote at all than the person whose partisan feelings are entirely consistent" (Campbell et al., 1960, 83).

Systematic evidence is presented on how status and opinion conflicts affect participation levels. Huckfeldt (1979) demonstrates that when citizens reside in an economic environment inconsistent with one's own income status (e.g., high income individuals in low income neighborhoods), they are less likely to participate. Further, Mutz's (2002b) analysis of cross-cutting networks demonstrates that citizens in crosspressured political networks are less likely to participate because of high political ambivalence and social accountability. In sum, opinion and status dissimilarity in social networks weaken the effects of interaction on political participation. Mutz $(2006,100)$ notes, "It is not social networks per se that are implicated in stimulating collective action, but networks among those who are like-minded."

I apply these two insights to the relationship between the in-group size and political participation. Since the composition of communication networks is dependent on economic and political characteristics of local environments because of availability and selectivity of communication partners (e.g., Mutz, 2006), local environments essentially determine whether citizens can establish favorable communication networks for information exchange and political participation. I argue that citizens are more likely to participate when local environments enable citizens to produce intraracial networks that are composed of sophisticated or like-minded in-group members.

First, I expect that local environments that help individuals establish intraracial networks with high political expertise would enhance effective information exchange and produce more relational goods. In contrast, local environments that keep citizens away from sophisticated networks impede information exchange and therefore impedes the formation or relational goods (Cohen and Dawson, 1993). Second, I 
expect that local environments that help individuals establish like-minded intraracial networks enhance effective information exchange and, therefore, more relational goods. In contrast, local environments that involve citizens in cross-pressured networks impede effective information exchange and therefore the formation of relational goods.

In short, I maintain that local economic and political structures determine the nature of intraracial networks. Specifically, local economic or political competition determines whether individuals can form like-minded or sophisticated intraracial networks. In areas of low degrees of economic or political competition with a significant presence of in-group members, citizens are more likely to establish sophisticated and homogeneous intraracial networks with respect to political preferences and class status. The sophisticated and like-minded intraracial networks are then expected to produce more relational goods and enhance effectiveness of information exchange. Conversely, in areas of high degrees of economic or political competition with a substantial presence of in-group members, citizens are more likely to engage in unsophisticated intraracial or cross-cutting networks, which produces less relational goods and reduce the effectiveness of information exchange. Since more relational goods and more effective information exchanges increase the benefits of collective action and decrease the informational costs of participation, the second proposition is that the relational goods effect on mass participation is observed only when the degree of local economic or political competition is low.

\section{Summary}

I have proposed that the racial composition is not a single determinant of interracial and intraracial relations in local communities. Most of the existing contextual models 
of political behavior overlook the fact that local contexts are multidimensional and characterized by a wide range of environmental factors simultaneously. It is therefore reasonable to expect that a relationship between one environmental characteristic and citizen behavior is conditional on another environmental characteristic. Contextual influences on mass behavior are not as simple as the prior research suggests.

This conditional perspective is compatible with recent studies on racial attitudes in sociology and political science. A cross-national analysis on racial prejudice toward immigrants in Europe by Quillian (1995), for example, reports that the effect of racial threat is greater in nations with poor economic situations. Quillian argues that individuals in a dominant group feel more threatened by the increase in the number of immigrants when national economic conditions are precarious. Branton and Jones (2005) argue that whites who live in highly diverse and low socioeconomic contexts have less positive attitudes toward racial policies. Branton and Jones (2005, 360) argue that a poor socioeconomic environment coupled with high racial heterogeneity produces "a maximum threat context" that enhances inter-group competition among racial and ethnic groups. Increased competition among racial groups leads whites to hold negative attitudes toward other group members.

Subsequent chapters examine several hypotheses drawn from the two propositions using interactive terms between racial composition and economic competition (Chapter IV) and between racial composition and political competition (Chapter V). The next chapter will explore how we can precisely measure racial composition of citizens' immediate environments for hypothesis testing and then revisit the original hypotheses in the literature for replication. 


\section{CHAPTER III}

\section{RACIAL COMPOSITION AND CITIZEN PARTICIPATION: PRELIMINARY ANALYSIS}

The main focus of this chapter concerns a measure of racial environment for the study of political participation. Previous research on the racial environment and political behavior addresses little about a contextual measure and unit of racial composition and uses different indicators (see Baybeck, 2001 and 2006; Branton and Jones, 2005). Specifically, Oliver (2001) utilizes the proportion of white population within municipalities (i.e., cities) to examine the relationship between the group size and political participation of whites, blacks, and Latinos. Leighley and Vedlitz (1999) and Leighley (2001) employ the modified version of the Herfindahl index as the measure of the power-threat effect in zip code areas. Additionally, Leighley (2001) uses a simple in-group size measure to assess the relational goods effect on citizen participation. These studies present a weak theoretical justification of why their measures reflect the theoretical expectations, particularly, drawn from the power-threat argument. The lack of valid operational measures of racial composition might play some role in producing mixed empirical findings on the relationships between racial composition and citizen participation.

This chapter proceeds as follows: First, I attempt to develop a new measure of the power-threat effect on citizen participation. I illustrate a few disadvantages of the out-group size and the Herfindahl index as indicators of the power-threat effect. I then suggest that the power-threat effect can be represented by the curvilinear relationship between the out-group size and the probabilities of participating in politics. I further briefly discuss the measure of the relational goods impact and the contextual unit of racial environment. The second part of this chapter presents some descriptive 
statistics regarding the racial composition of counties where the CPS survey respondents reside. In the final part, I reexamine the original hypotheses in the previous studies to replicate their findings using different contextual measures and units of racial composition.

\section{A. Measuring the Effect of Racial Composition on Citizen Participation}

Previous empirical research measures the power-threat effect on mass attitudes and behavior in a few different ways. First, we can distinguish an objective indicator from a subjective one. The subjective indicator derives from a survey question asking respondents about the degree of racial diversity in their neighborhoods or municipalities. The power-threat effect is hypothesized to be stronger when respondents perceive that they reside in a racially diverse area. Note that the subjective indicator may suffer from measurement errors since citizens' response to the survey question is determined not only by the local racial composition but also by individual-level and other contextual-level elements. Further, a question wording may have a strong impact on their responses.

The objective indicator is based on contextual-level information drawn from aggregate data sources, such as the census. Contextual information is often easily available and precisely measures racial composition of various geographical units where survey respondents reside. Note that any empirical research using the objective indicator rests on an assumption that citizens can precisely perceive demographic and political characteristics of their residential areas (Baybeck and McClurg, 2005).

The objective measure of the power-threat effect is further divided into two types: one assesses this effect simply using the total size of out-group population within a geographical unit, while the alternative measure is based on a specific formula (the 
Herfindahl index) that takes account of the number of groups comprising out-groups. ${ }^{1}$ The out-group size is calculated first by separating in-group members (the racial and ethnic group that the respondent identifies with) from others (all racial and ethnic groups other than the respondents' self-identified group) within a geographical unit. Then, the size of the in-group population is divided by the total population size of the unit. Finally, using the formula below, one can identify the out-group size within the unit:

$$
\text { Out-Group Size }_{j}=1 \text { - In-Group Size }{ }_{j}
$$

This indicator assesses the relative size of the in-group population to the total size of the out-group population in an area $j$. It ranges from 0 to 1 , where a higher score denotes a greater size of out-group population and, therefore, a greater power-threat effect.

The Herfindahl index was originally developed for examining industry concentration in economics and business. The modified version of the indicator (hereafter I call this the racial diversity index) is based on the following formula:

$$
\text { Racial Diversity Index }{ }_{j}=\sum_{i=1}^{N}\left(P_{i j}\right)-\sum_{i=1}^{N}\left(P_{i j}\right)^{2}
$$

where $n$ denotes the number of groups in a geographical unit $j$, and $P_{i j}$ denotes the proportion of the racial and ethnic group $i$ in that area. The formal definition of the index is therefore "the probability that two randomly drawn individuals from the population belong to different types" (Alesina and Ferrara, 2000, 858). This index ranges from 0 to 1 , where greater scores refer to more racially diverse areas and a higher power-threat effect. On the contrary, lower scores refer to areas in which one

\footnotetext{
${ }^{1}$ Rae and Taylor (1970) also develop the same indicator of diversity for measuring political cleavages.
} 
of the racial groups dominates other groups in size and, thus, exhibits a lower powerthreat effect. Importantly, the racial diversity index takes into account the relative size and distribution of multiple racial groups in a geographical unit and approaches 1 when a unit consists of a large number of racial groups of relatively equal size. The index increases both as the number of groups in the geographical unit increases and as the disparity in size between those groups decreases.

Much of the literature examines the power-threat effect on racial attitudes in political science and sociology using the out-group size in local areas, except for a few studies that use the subjective indicator (e.g., Kinder and Mendelberg, 1995). ${ }^{2}$ Out-group size is often defined as the population size of African-Americans since the theory was originally designed to assess the psychological and behavioral reaction of Anglo whites to the presence of black population in their immediate environments (Key, 1949; Emerson, Chai and Yancey, 2001; Giles and Evans, 1985, 1986; Glaser, 1994; Oliver and Mendelberg, 2000; Quillian, 1996; Voss, 1996; Welch et al., 2001). Recent rapid increases in the sizes of other minority population such as Latinos and Asians, however, have induced scholars to target non-black minority groups as the out-groups (Oliver and Wong, 2003; Stein, Post and Rinden, 2000; Taylor, 1998; Tolbert and Hero, 1996).

The racial diversity index has been utilized in a wide range of subfields. For example, Alesina et al. (2003) create a new measure of ethnic, religious, and linguistic fractionalization in about 190 nations using the formula of the racial diversity index. Hero (1998) employs the index and examines the linkage between racial diversity of the American states and policy representation. Research on civic engagement (Alesina and Ferrara, 2000; Costa and Kahn, 2003) assesses how local racial frag-

\footnotetext{
${ }^{2}$ Kinder and Mendelberg (1995) used survey questions about sizes of African Americans in neighborhoods, churches, and workplaces.
} 
mentation measured by the racial diversity index affects citizen engagement in civic activities. Branton and Jones's seminal work (2005) is one of the first to use the index to investigate the effect of the racial environment on whites' policy attitudes. Finally, Leighley (2001) and Leighley and Vedlitz (1999) test the power-threat effect on political participation by adding the racial diversity index to their statistical models.

What is the best indicator to test the power-threat effect on citizen participation? I contend that neither out-group size nor the racial diversity index fully accounts for the power-threat effect on individuals' decisions to participate. Suppose that $B$ denotes the size of the benefits of participating in politics and is proportional to the out-group size. In other words, $B$ represents the degree of racial threat. Suppose $P$ denotes the probability of being successful in an election's outcome and is proportional to the in-group size. The original power-threat argument suggests that a power-threat and therefore $B$ is maximized when the out-group size approaches to 1 . Hence, we predict that the probability of participating in politics is also maximized as the outgroup size increases to 1 . This argument overlooks the possibility that citizens also care about the likelihood of being successful. When the out-group size approaches to 1, in-group members are not likely to participate in politics despite the high level of power-threat because the size of the in-group population that shares political preferences becomes too small to make a difference in the outcome. In other words, $P$ is tiny and therefore the benefit multiplied by the probability is approximately equal to zero $(P \times B \approx 0){ }^{3}$ Hence, the maximum size of the out-group population is not necessarily associated with the maximum probabilities of participation.

The relationship between the out-group size and the size of $P B$ is illustrated in

${ }^{3}$ This argument is based on the conventional calculus of voting (Riker and Ordeshook, 1968). 
Fig. 7. The Relationship between the Out-Group Size and the Size of $P B$

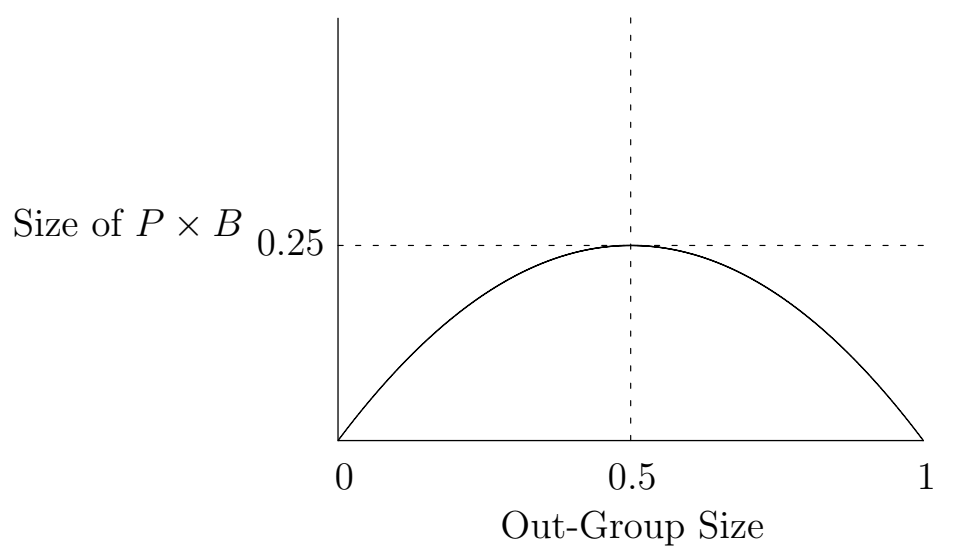

Figure 7. As the out-group size increases from 0 to 0.5 , citizens are more likely to participate because the size of $P B$ increases. As the out-group size further increases from 0.5 to 1 , however, citizens are less likely to participate because the size of $P B$ decreases (i.e., the power-threat, $B$, increases, but the probability of being successful, $P$, decreases). Therefore, the simple out-group size measure fails to take account of two relevant considerations for rational actors.

The racial diversity index also has two limitations as a measure of the powerthreat effect on citizen participation. Suppose an area where the population is $40 \%$ whites, 30\% black, 20\% Latino, and 10\% Asian. The score of the index is 0.7 (= $\left.1-\left[(0.4)^{2}+(0.3)^{2}+(0.2)^{2}+\left(0.1^{2}\right)\right]\right)$ and applies to all of the individuals in this area regardless of their racial identities. Nonetheless, the relative size of the in-group population to the out-group population varies across racial groups; therefore, the size of $P B$ is different among individuals of four racial groups. For example, I expect that whites are more likely to participate than Asians in this area because the size of $P B$ 
is greater for whites $(P B=0.4 * 0.6=0.24)$ than for Asians $(P B=0.1 * 0.9=0.09)$. The racial diversity index overlooks this point and fails to measure the utility for individuals of different racial groups.

In addition, suppose a place with 100 people who belong to 100 different racial groups. The score of the index for this area is very close to 1; therefore, people should be most likely to vote in this area than in any other places of racial composition, holding other factors constant. However, race will not be a significant factor for individuals' decisions to participate in this area because the very high level of racial fragmentation reduces the importance of group differences. Thus, as the number of racial groups increases in a geographical area, the racial diversity index becomes less consistent with the theoretical expectation.

I propose that the measure of the power-threat effect should take account of both the benefits of participating in politics, $B$, and the probabilities of being successful, $P$. The new measure is then the out-group size weighted by the in-group size where the out-group size represents the size of $B$, while the in-group size represents the size of $P$. The new indicator is formulated as:

$$
\begin{aligned}
\text { Power-Threat Effect }_{j} & =\text { Out-Group Size }_{j} \times \text { In-Group Size } \\
& =\text { Out-Group Size }_{j} \times\left(1-\text { Out-Group Size }_{j}\right)
\end{aligned}
$$

The power-threat effect on political participation approaches to 0 when the out-group size is too large and the in-group size is too small or vice versa. In such cases, citizens have no strong incentive to participate in politics and therefore are not likely to participate. By contrast, the power-threat effect is stronger as the out-group size is relatively closer to the in-group size. Specifically, when the out-group size is equal to the in-group size (Out-Group Size $=$ In-Group Size $=0.5)$, the power-threat effect 
on citizen participation is maximized, as shown in Figure 7. Therefore, citizens have both strong incentives to engage in political activities and strong expectations to be successful in their efforts and, as a result, are more likely to participate. To

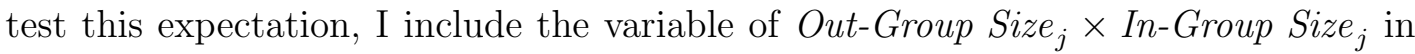
my statistical models. As the value of this variable increases, the probabilities of participating in politics also increase.

Note that the new measure of the power-threat effect ignores the number of racial categories in out-groups because it lumps all of other racial groups into the same category as a single out-group. For example, one area of $25 \%$ white, $40 \%$ black and $35 \%$ latino is treated equal for whites as the other area of $25 \%$ white and $75 \%$ black. This is because I assume that the number of groups that comprise the outgroup has no significant impact on individual's decisions to participate. Given the assumption that citizens seek to establish a winning electoral coalition in local areas, the relative size of in-group population to the size of out-group population is the key factor to be considered for individuals since it determines whether individuals' selfidentified group can be the majority to make a difference. Thus, citizens pay close attention to the balance of the in-group size to the out-group size. Importantly, I also assume that any racial group makes little effort to establish an electoral coalition with other group members because preference polarization between racial groups is large and elite coordination is hardly made especially at the local level. Thus, in the process of decision-making, individuals do not look at the variation in out-group members but rather focus on the balance between the in-group size and the out-group size.

The measure of the relational goods effect on mass participation is simply obtained through the previous research. The relational goods argument indicates that in-group size relative to out-group size determines the density of intraracial inter- 
actions and the strength of group ties. As the in-group size increases, citizens are more likely to interact with other in-group members and enhance interpersonal ties. Therefore, as the in-group size increases, citizens are more likely to engage in political activities. A simple in-group size measure meets the theoretical expectations regarding the underlying mechanism and is thus appropriate for testing the relational goods effect on political participation.

In short, the power-threat effect on citizen participation is examined using an out-group size weighted by an in-group size. The relational goods effect is tested using a simple in-group size or Out-Group Size ${ }_{j}=1-$ In-Group Size $_{j}$. The larger out-group size is expected to have a linear, negative impact on citizen participation. ${ }^{4}$

I select counties as a contextual unit in this research for both theoretical and practical reasons. First, counties are one of the most important political jurisdictions for individuals (Branton and Jones, 2005; Schneider and Park, 1989). Second, most of the counties are neither too small nor too large as a geographical unit that shapes individuals' social interaction, in comparison to neighborhoods, zip codes, and metropolitan areas (Baybeck and Huckfeldt, 2002; Branton and Jones, 2005). Third, one of the contextual-level variable (i.e., political heterogeneity) is available only at the county level.

The range of county population size in the sample is notably large; the population size ranges from 3,190 (Costilla County, CO) to 8,860,000 (Los Angels County, CA), as shown in Figure 8. This wide range of the county population size is problematic because some counties may be too populous and expansive as a contextual unit. I assume that citizens' ability to perceive demographic and political characteristics of their residential environments is limited; thus, counties such as Los Angeles county

\footnotetext{
${ }^{4}$ I use the out-group size to test the relational goods effect in order to use the $\mathrm{x}$-axis consistent with the test for the power-threat effect.
} 
Fig. 8. Population Size of Counties in the CPS Sample

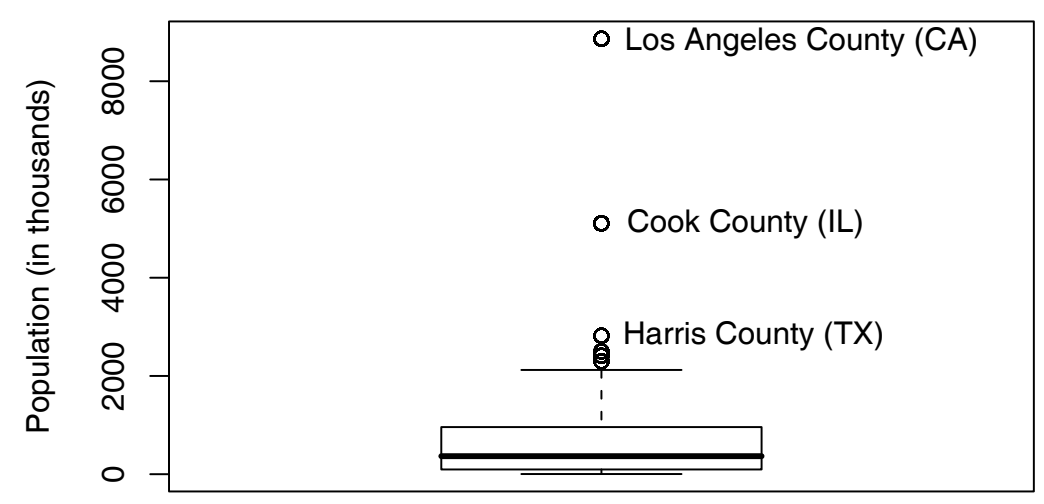

Note: Data comes from the Citizen Participation Study (Verba, Schlozman, and Brady, 1995).

in California, Cook County in Illinois (the population size is 5,105,067), and Harris County in Texas (the size is $2,818,199$ ) in the sample are too populous for citizens to understand their counties' demographic and political characteristics. Imprecise knowledge on the local environments weakens the linkage between contextual characteristics and citizens' political behavior (Baybeck and McClurg, 2005). Hence, I divide the sample into two groups using the average logged size of county population and analyze them separately. ${ }^{5}$ I predict that empirical analysis focusing on respondents in smaller counties show consistent results with my theoretical expectations.

\footnotetext{
${ }^{5}$ Counties are divided by the mean logged population size $(=12.6)$.
} 


\section{B. Observing Racial Composition}

Racial composition is expected to have a significant influence on citizen participation. However, does the racial composition of citizens' immediate environments significantly vary across places? Mutz and Martin (2001) point out that residential contexts might have been playing a less significant role as a contextual determinant of political behavior because of the increasing rate of residential segregation over decades. They (2001, 97) note,

$[\mathrm{T}]$ he recent trend toward residential balkanization based on shared lifestyles heightens concerns about communication across lines of political difference in the United States. To the extent that people live among homogeneous others in self-selected enclaves, their exposure to dissimilar views may be limited.

Mutz and Martin imply that most of the citizens reside near their in-group members. ${ }^{6}$ The lack of variation in racial diversity reduces the importance of racial environment as a determinant of political behavior. Residential segregation therefore may undermine the theoretical relevance of the power-threat and relational goods effects on political participation.

My descriptive analysis demonstrates a significant variation in the level of racial diversity at the county level. Figure 9 illustrates the distribution of CPS survey respondents across counties with different sizes of the out-group population. Bars and smooth lines in the figure represent a histogram and a Kernell density estimate, respectively. I report the distributions of racial composition for the full sample and

\footnotetext{
${ }^{6} \mathrm{~A}$ similar argument on economic segregation is provided by (Dreier, Mollenkopf
} and Swanstrom, 2004). 
Fig. 9. Out-Group Size of Counties

Out-Group Size: Full Counties

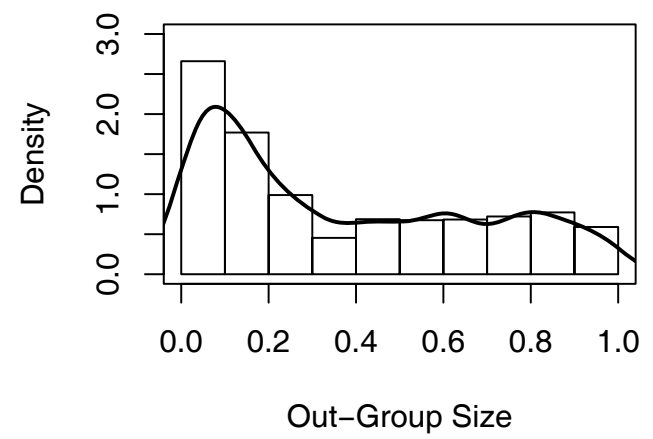

Out-Group Size: Small Counties

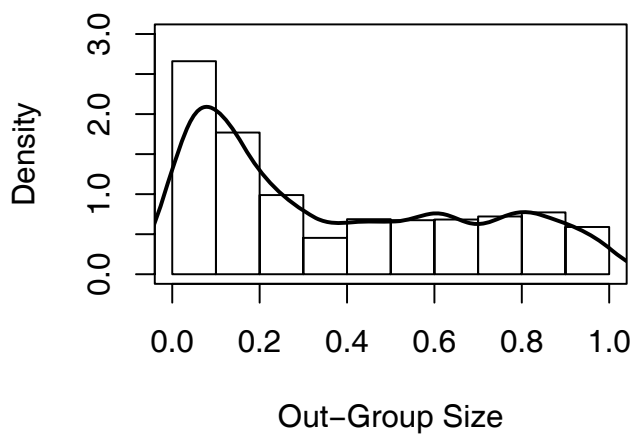

Note: Data comes from the Citizen Participation Study (Verba, Schlozman, and Brady, 1995). The number of counties in the full county sample is 450 . The number of counties in the smaller county sample is 235 .

for the sample below the average size of county population. ${ }^{7}$ The histograms in Figure 9 indicate that the distribution is skewed toward the left side of the scale, where the in-group size is quite large. Half of respondents reside in counties where more than 80 percent of residents is their fellow members. Notably, the other half of the respondents reside near a large amount of out-group members. Thus, the patterns of the distribution suggest that some individuals have more opportunities to interact with their fellow members and produce relational goods, while others are exposed to out-group members in counties and thus perceive those members as a potential threat.

The histograms above might be strongly influenced by the size of white respondents in the original data. To examine this, I break down the sample by racial and

\footnotetext{
${ }^{7}$ The county population size is logged.
} 
Fig. 10. Out-Group Size of Counties by Race

Out-Group Size: Full Counties
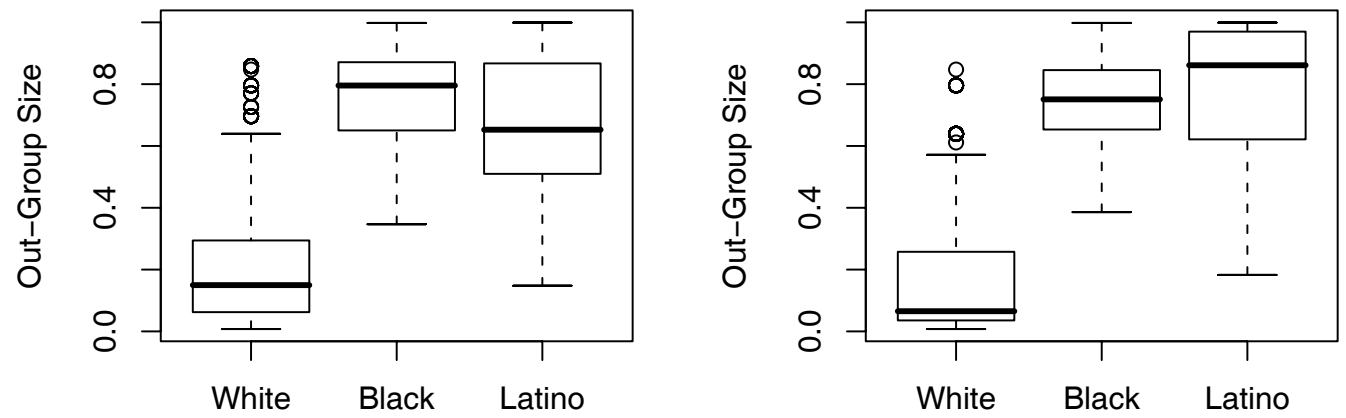

Note: Data comes from the Citizen Participation Study (Verba, Schlozman, and Brady, 1995).

ethnic group categories. Figure 10 reports the out-group size of counties by race. The boxplots show that whites are more likely to reside with their fellow members, although blacks and Latinos are more exposed to high racial fragmentation. This difference is primarily due to the numerical dominance of whites in the society. Importantly, Figure 10 displays the notable variations in the county-level racial composition even after controlling for racial categories. Thus, racial segregation does not necessarily mean that all citizens reside in counties of high racial homogeneity in the contemporary America: some citizens are still exposed to high degrees of racial fragmentation and high preference polarization, yet others are surrounded by their fellow members and potential to interact with them actively. ${ }^{8}$

${ }^{8}$ The latest report by the Census Bureau suggests that the degree of racial segregation has decreased in the last decade (1990 to 2000). See Iceland, Weinberg, and Steinmetz [2002]. 


\section{Reexamining The Existing Hypotheses}

Does the presence of out-group members increase citizen participation, as predicted by the power-threat hypothesis? Does the presence of in-group members increase participation, as predicted by the relational goods hypothesis? The final section of this chapter reexamines the two existing hypotheses using the data of racial composition at the county level.

My two dependent variables are individuals' self-reported turnout in the 1988 presidential election and in a local election held since November 1988. I focus on voter turnout because it is the most conventional form of political participation for the majority of the U.S. citizens. Those who reported voting were coded one while those who reported not voting were coded zero for each election type. For analysis of turnout in local elections, respondents who resided in a municipality that had no local election since 1988 were excluded from my analysis.

Figure 11 presents bivariate relationships between out-group size and voter turnout in the national and local elections using the full sample of counties (left) and the sample of less populous counties (right). The average rates of voter turnout are calculated at three different levels of out-group size at the county level. As shown in Figure 5, the relationship between the out-group size and voter turnout should be curvilinear and convex if the power-threat hypothesis is correct. The relationship should be linear and negative if the relational goods hypothesis is correct. The plots show that voter turnout in the two types of elections decreases as the out-group size increases. The negative effect of out-group size on voter turnout is consistent with the expectation of the relational goods hypothesis. Figure 11, however, demonstrates no supportive evidence for the power-threat hypothesis.

Tables shown below report the logit estimates of the effects of racial composi- 
Fig. 11. Average Rates of Voter Turnout in National and Local Elections across Counties of Different Out-Group Sizes

Full County

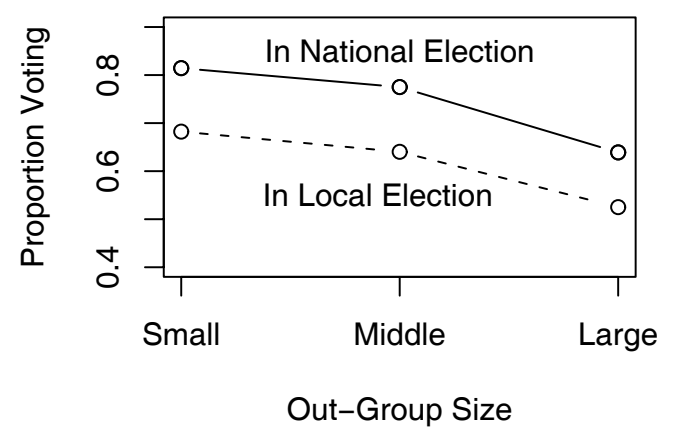

Small County

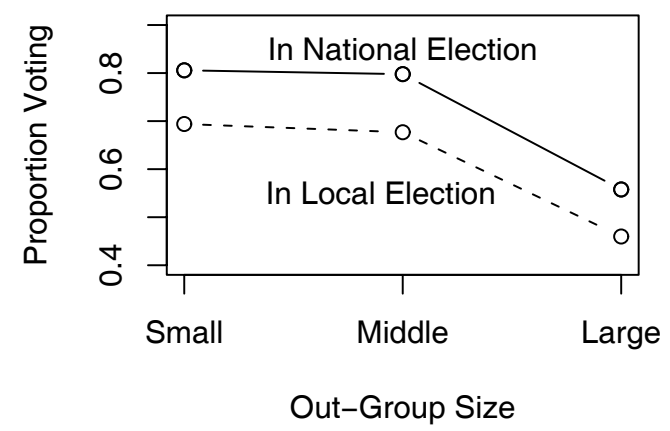

Note: Data comes from the Citizen Participation Study (Verba, Schlozman, and Brady, 1995). The out-group size is divided into low: 0.007-0.338, middle: 0.338-0.669, and high: $0.669-1.000$.

tion on the probabilities of voting in the 1988 presidential and the local elections in 1988 or 1989, controlling for other relevant contextual-level and individual-level variables. The tables report only the estimated results using the sample of smaller counties. $^{9}$ Standard errors are clustered by counties. To control for the effects of other environmental characteristics, income diversity measured by the index of qualitative variation (Oliver 1999), logged median household income, and political heterogeneity measured by the degree of electoral competitiveness are included in the models. ${ }^{10}$ Further, logged county population size is also added to the models. To control for individual-level demographic and psychological traits, the logit models

\footnotetext{
${ }^{9}$ The estimated models with the full sample of counties demonstrate the similar results.

${ }^{10}$ Full details of these contextual measures are described in Chapter IV and V.
} 
include party mobilization, education, income, age, race, gender, marital status, the length of residence, and partisanship as the right-hand side variables (Democrat and Republican; independents are the base category). Party mobilization is measured using respondents' experience of being contacted by political parties, interest groups, and acquaintances who asked for involvement in campaign work or personal contact with local or federal officials in 1988. Full descriptions of the variables in the models, coding rules, and summary statistics are presented in the data appendix.

Table III reports the estimated results regarding the power-threat effect on the probabilities of voting. The hypothesized curvilinear impact is examined by including the variable Out-Group Size $\times$ In-Group Size in the model. The power-threat impact can be observed only when the coefficient of this variable shows a positive and statistically significant impact on voting. The results demonstrate that the estimate is positive in the model of voting in the national election and negative in the model of voting in the local election. Neither estimate is statistically indistinguishable from zero. That is, citizens' decisions to vote are not strongly affected by the relative size of the out-group and in-group populations.

Table IV reports the estimated effects of relational goods on voter turnout. The relational goods effect is tested by including out-group size; thus we should observe a negative and statistically significant effect of the variable on the probabilities of voting. As expected, the out-group size is negatively related with the probabilities of voting in both types of elections. Further, the estimates in both of the models are statistically distinguishable from zero. Thus, the presence of out-group members in local areas is associated with lower probabilities of voting. In other words, the more in-group members in a county, the more likely people are to vote. This result is consistent with the prediction of the relational goods hypothesis. For all of the models in Table III and Table IV, the individual-level control variables demonstrate 
Table III. The Power-Threat Effect on the Probabilities of Voting

\begin{tabular}{|c|c|c|c|c|c|c|}
\hline & \multicolumn{3}{|c|}{ National Election } & \multicolumn{3}{|c|}{ Local Election } \\
\hline & est & se & $\mathrm{p}$ & est & se & $\mathrm{p}$ \\
\hline \multicolumn{7}{|l|}{ Contextual-Level Variables } \\
\hline Out-Group Size $\times$ In-Group Size & 1.604 & 1.699 & 0.345 & -0.484 & 1.448 & 0.738 \\
\hline Income Diversity & -3.511 & 4.983 & 0.481 & -2.550 & 5.670 & 0.653 \\
\hline Log Median Household Income & -0.048 & 0.961 & 0.960 & -0.635 & 0.975 & 0.515 \\
\hline Political Heterogeneity & 0.905 & 1.721 & 0.599 & 0.079 & 1.658 & 0.962 \\
\hline Log Population Size & -0.079 & 0.138 & 0.564 & -0.074 & 0.112 & 0.510 \\
\hline \multicolumn{7}{|l|}{ Individual-Level Variables } \\
\hline Mobilized & 1.438 & 0.541 & 0.008 & 1.210 & 0.399 & 0.002 \\
\hline Republican & 1.147 & 0.309 & 0.000 & 0.448 & 0.259 & 0.083 \\
\hline Democrat & 1.094 & 0.266 & 0.000 & 0.607 & 0.257 & 0.018 \\
\hline Education & 0.264 & 0.041 & 0.000 & 0.207 & 0.051 & 0.000 \\
\hline Income & 0.289 & 0.060 & 0.000 & 0.249 & 0.052 & 0.000 \\
\hline Log Years in Town & 0.131 & 0.077 & 0.087 & 0.241 & 0.099 & 0.015 \\
\hline Age & 0.053 & 0.006 & 0.000 & 0.043 & 0.009 & 0.000 \\
\hline Female & -0.513 & 0.228 & 0.025 & -0.106 & 0.190 & 0.579 \\
\hline Black & -0.513 & 0.328 & 0.118 & -0.212 & 0.272 & 0.437 \\
\hline Latino & -0.388 & 0.466 & 0.405 & -0.238 & 0.478 & 0.618 \\
\hline Constant & -2.274 & 6.518 & 0.727 & 3.593 & 6.204 & 0.562 \\
\hline LR Test $\chi^{2}$ (p-value) & 224 & $34(0.0$ & & 202 & $04(0.0$ & \\
\hline $\mathrm{N}$ & & 780 & & & 704 & \\
\hline
\end{tabular}

Note: Data comes from the Citizen Participation Study (Verba, Schlozman, and Brady, 1995). Standard errors are clustered by counties. The data include 182 counties. The dependent variables are individuals' self-reported turnout in the 1988 presidential election and in a local election held since November 1988. $P$ in the table denotes p-values and is based on two-tail tests. 
Table IV. The Relational Goods Effect on the Probabilities of Voting

\begin{tabular}{l||rrr|rrr}
\multicolumn{1}{c||}{} & \multicolumn{3}{|c|}{ National Election } & \multicolumn{4}{|c}{ Local Election } \\
& est & se & p & est & se & p \\
\hline \hline Contextual-Level Variables & & & & & & \\
Out-Group Size & -1.286 & 0.720 & 0.074 & -1.396 & 0.648 & 0.031 \\
Income Diversity & -4.259 & 5.126 & 0.406 & -3.655 & 5.713 & 0.522 \\
Log Median Household Income & -0.462 & 0.962 & 0.631 & -0.755 & 1.026 & 0.462 \\
Political Heterogeneity & 1.271 & 1.666 & 0.446 & 0.030 & 1.486 & 0.984 \\
Log Population Size & 0.006 & 0.136 & 0.965 & -0.025 & 0.107 & 0.815 \\
Individual-Level Variables & & & & & & \\
Mobilized & & & & & & \\
Republican & 1.549 & 0.545 & 0.004 & 1.262 & 0.392 & 0.001 \\
Democrat & 1.163 & 0.305 & 0.000 & 0.436 & 0.262 & 0.095 \\
Education & 1.093 & 0.265 & 0.000 & 0.619 & 0.257 & 0.016 \\
Income & 0.264 & 0.041 & 0.000 & 0.214 & 0.049 & 0.000 \\
Log Years in Town & 0.287 & 0.058 & 0.000 & 0.250 & 0.053 & 0.000 \\
Age & 0.131 & 0.076 & 0.083 & 0.228 & 0.100 & 0.022 \\
Female & 0.052 & 0.006 & 0.000 & 0.043 & 0.009 & 0.000 \\
Black & -0.524 & 0.228 & 0.022 & -0.116 & 0.189 & 0.538 \\
Latino & 0.298 & 0.473 & 0.529 & 0.556 & 0.403 & 0.168 \\
Constant & 0.437 & 0.623 & 0.483 & 0.582 & 0.609 & 0.340 \\
LR Test $\chi^{2}$ (p-value) & & 780 & & & 704 & \\
N & 1.895 & 6.370 & 0.766 & 5.398 & 6.466 & 0.404 \\
& $227.43(0.000)$ & $207.8(0.000)$ \\
& & & & & &
\end{tabular}

Note: Data comes from the Citizen Participation Study (Verba, Schlozman, and Brady, 1995). Standard errors are clustered by counties. The data include 182 counties. The dependent variables are individuals' self-reported turnout in the 1988 presidential election and in a local election held since November 1988. $P$ in the table denotes p-values and is based on two-tail tests. 
the expected linkages with the probabilities of voting, while none of the county-level control variables are estimated to have a statistically significant impact on voting.

Notably, these results are partly consistent with the prior findings that racial homogeneity stimulates participation. Leighley and Vedlitz (1999) report a negative and significant impact of the racial diversity index on Anglos' participation in politics in their analysis of a stateside survey of Texans. Using the same data set as here, Leighley (2001) found that Latinos' group population is a strong and significant predictor of their participation levels; they are more likely to participate when surrounded by their fellow group members. Further, Leighley demonstrates that, for Anglos, higher degrees of perceived racial diversity in neighborhoods are significantly associated with lower levels of political participation. Finally, these "negative" findings are broadly consistent with Hill and Leighley's (1999) aggregate-level analysis suggesting that higher racial diversity is associated with lower levels of voter turnout at the state-level. Hill and Leighley suggest that the negative association between racial diversity and turnout reflects the adoption of restrictive barriers to voting that were used heavily in states with large black populations yet depressed the turnout of not only blacks but also poor whites.

In contrast, my analysis fails to provide any supportive evidence for the powerthreat hypothesis. Importantly, this result is also consistent with the null finding in Leighley's research (2001) and mixed findings in Oliver's work (2001), though a different contextual measure and unit of racial composition are used here. The estimated results suggest that citizens are not more likely to participate in politics even if they are surrounded by the significant proportion of other racial group members. This inconsistency between the theoretical expectation and the empirical evidence motivates me to explore alternative model specification. 


\section{Summary}

In this chapter, I addressed the measurement issues concerning racial composition and then conducted some preliminary analyses on the linkage between the racial environment and citizen participation. First, I identified the theoretical limitations of the simple out-group size and the racial diversity index as indicators of the power-threat effect on mass participation. These two indicators are disadvantageous primarily because they fail to take account of the benefits of participating in politics and the probabilities of being successful simultaneously. I then suggested that the powerthreat impact is measured by the combination of the out-group size, $B$, and the in-group size, $P$.

Second, my descriptive analysis demonstrated significant variation in racial composition of citizens' immediate environments. Some individuals reside near out-group members in their counties, while others are surrounded by their fellow members. This variation suggests a possibility that different racial environments play a significant role in citizens' political behavior. It is meaningful, therefore, to theorize about the racial environment as a crucial determinant of citizen participation.

Finally, the reexamination of the power-threat and the relational goods hypotheses presented some evidence consistent with the previous analyses in the literature. My findings demonstrate the relational goods impact on voter turnout, while indicating that the power-threat exerts no influence on the probabilities of voting.

The subsequent chapters evaluate my conditional hypotheses to show that the relationship between local racial composition and citizen participation is conditioned by economic and political characteristics of local places. I offer some supportive evidence for the power-threat hypothesis to argue that power-threat also drives citizens to participate in politics in certain types of economic and political settings. 


\section{CHAPTER IV}

\section{RACIAL COMPOSITION, ECONOMIC COMPETITION, AND CITIZEN PARTICIPATION}

The empirical analysis in the previous chapter presents supportive evidence only for the relational goods hypothesis. I found that citizens are more likely to turn out on election day when they are surrounded by the large size of in-group members in their counties, whereas their decisions to vote are unaffected by the substantial presence of out-group population. Do these findings suggest that, in contrast to the theoretical expectation in the literature, racial threats have no mobilizing impact on citizen participation in politics?

In this chapter, I demonstrate that individuals' participation levels are sensitive to the presence of both out-group and in-group populations. I reconcile the powerthreat and relational goods hypotheses into a single argument by integrating the concept of economic competition. I contend that local economic competition determines how the racial environment influences citizen participation because economic competition essentially determines the nature of interracial conflicts and intraracial interaction and therefore shapes the utility calculation. I hypothesize that the powerthreat effect on voter turnout is observed only when the degree of local economic competition is high, while the relational goods effect is observed only when the degree of local economic competition is low.

I conceptualize local economic competition as contention for resources between different income groups and within low income groups. The former type of competition is based on the concept of income diversity and conflicts between the haves and the haves-not (Oliver, 1999), while the latter is based on the concept of socioeconomic environments and economic distress of low income citizens (Branton and Jones, 
2005; Gay, 2004). Two forms of economic competition produce different predictions concerning how the racial environment influences citizen participation.

\section{A. Economic Diversity Hypothesis}

\section{High Income Diversity and Power-Threat}

Income diversity refers to the extent to which local population is composed of individuals of various income groups. In areas of high income diversity, individuals in poverty may reside with middle class and wealthy individuals. In contrast, areas of low income diversity are comprised of either mostly poor, mostly middle class, or mostly affluent individuals.

Oliver (1999) was the first scholar to emphasize the importance of income diversity as a contextual determinant of political participation. Oliver illustrates the linkage between income diversity and participation as follows $(1999,191)$ :

A city's economic composition is a major determinant of political competition because individual income often dictates local preferences: the poor want more redistributive policies, the middle-class are concerned with allocative efficiency, and the affluent want lower taxes (Peterson, 1981). Local politics should be more contentious (and participation highest) in economically diverse cities as these places have more groups pursing contradictory policy goals. Conversely, a greater consensus over local policy in economically homogeneous cities should limit competition, citizen interest, and participation. If these assertions are correct, then... participation should be highest in economically diverse, middle-income cities and lowest at the ends of city income spectrum where populations are more homogeneous. 
Oliver implies that income diversity is an alternative source of preference polarization that shapes citizens' incentives to participate in politics. When local areas are composed of individuals of different income groups, the degree of preference polarization on taxation and (re)distributive policies is high. High preference polarization among residents results in intensive political conflicts for resources. By contrast, when local communities consist of individuals from similar income groups, the degree of preference polarization is low. Low preference polarization results in less intensive conflicts. Thus, Oliver predicts that higher income diversity is associated with greater involvement in political activities.

I extend Oliver's conceptualization of income diversity and argue that high income diversity enhances the effect of power-threat, which in turn mobilizes individuals to participate in politics. This is because areas of high income diversity with the substantial presence of out-group members - areas in which individuals belong to different racial and income groups - highlight the differences in policy preference among racial groups and limit the amount of public goods provisions to individuals.

Preference polarization among racial groups is a more crucial issue for individuals in areas of high income diversity than in areas of low income diversity. Economic disparity is often associated with racial cleavages in local communities. As Bonacich (1972, 553) notes, "the class antagonism takes the form of ethnic antagonism." For example, when wealthy white individuals reside with blacks and Latinos in poverty, the degree of preference polarization among these racial groups is extremely high and more explicit. Class disparity in policy preferences highlights racial disparity. Economic inequality between these racial groups is therefore expected to provide a substantive incentive for members of each group to participate in politics because affluent whites and less affluent minority members pursue contradictory policy goals. Affluent whites feel pressured to participate in politics to defend their political in- 
terests from blacks and Latinos, while less affluent blacks and Latinos are also likely to participate to maximize their policy benefits by reducing resource allocation to whites. Gay's (2006) recent work supports this argument. Gay (2006, 983) demonstrates "[i]n environments where Latinos are economically advantaged relative to their black neighbors, African Americans are not only more likely to harbor negative stereotypes about Latinos, but they are also more reluctant to extend to Latinos the same policy benefits they themselves enjoy and less likely to see black and Latinos political and economic interests as consonant." Hence, high income disparity between racial groups in the immediate environment induces citizens to perceive that out-group members are political rivals who pursue different policy goals in a zero-sum game. Income diversity plays a role as an informational cue that notifies individuals about the degree of preference polarization among racial groups.

Additionally, the high degree of preference polarization among racial groups results in smaller provisions of public goods, as demonstrated by Alesina, Baqir and Easterly (1999). In areas of high preference polarization, individuals prefer private consumption of their resources to public consumption, which weakens the ability of local governments to provide public goods. Therefore, local governments in areas of high income diversity with the high level of racial fragmentation offer the very limited amount of public resources to residents. This limited public provision intensifies competition for resources and therefore induces individuals to be more sensitive about electoral outcomes.

High income diversity in racially diverse areas, therefore, enhances individuals' perceptions that electoral politics rewards participants and ignores non-participants through (re)distributive policies. Citizens would believe that active participation by in-group members produces more favorable policy outcomes to them. Thus, economic conflicts (real or perceived) associated with greater racial heterogeneity are more likely 
to be taken into the electoral realm. I therefore expect that, the presence of out-groups increases the benefits of participation when local income diversity is high.

Conversely, areas of low income diversity - areas in which most of residents belong to the same income groups - depress the effects of preference polarization among racial groups on mass participation since the homogeneous nature of the community's economic environment reduces the likelihood that citizens perceive preference polarization among racial groups as significant threats to their political interests. Thus, for the poor, there are no collective resources to compete over or, and for the relatively and highly affluent, individuals opt out of collective solutions and rely on their individual resources. In either scenario, there is less intergroup competition for resources and (re)distributive policies. Thus, while the significant presence of outgroups, ceteris paribus, may increase conflicts or the perception of interracial conflicts a la power-threat theory, it will not be translated into political involvement due to the homogeneous nature of the community's economic environment. As a result, the presence of out-groups does not significantly increase the benefits of participating in politics when local economic diversity is low.

\section{Low Income Diversity and Relational Goods}

I also argue that the degree of income diversity determines how the presence of ingroup members affects the formation of relational goods. As noted in Chapter II, the literature on communication networks (Mutz, 2006) implies that social interaction only with like-minded in-group members can effectively influences the utility calculation for a decision to participate in politics. Importantly, the level of local income diversity has a significant impact on what types of in-group members are available for social interaction. Areas of high income diversity with the large in-group population raise the likelihood that citizens interact with in-group members whose economic 
status is different from theirs. Status conflicts between individuals are often linked with opinion conflicts, which weakens the effect of social interaction on attitude formation (Campbell et. al. 1960; Lazarsfeld, Berelson, and Gaudet, 1954). Thus, cross-cutting intraracial networks are expected to impede the formation of relational goods. Thus, the presence of in-group members in local areas with high income diversity may increase the frequency of intragroup interaction, yet information exchange among in-group members is not effective.

In contrast, areas of low income diversity with the large in-group population increase the likelihood that most of the in-group members belong to similar income groups. Thus, citizens are more likely to establish intraracial networks that are comprised of homogeneous members with respect to economic status and race. Group interaction with like-minded members would successfully decrease the informational costs and increase the perceived benefits of participating in politics, resulting in more involvement in politics (Huckfeldt, 1979; McClurg, 2003). Thus, when income diversity is low, the presence of in-groups will be associated with greater involvement in politics.

\section{Summary}

The logic of my argument regarding the interactive relationship between racial composition, income diversity, and citizen participation is summarized as follows:

A: The size of out-group population in local areas influences the level of powerthreat, while the size of in-group population influences the amount of relational goods. These linkages are conditional on the degree of local income diversity.

$A_{1}$ : When the degree of local income diversity is high, the presence of out-group members results in the high level of power-threat. When the 
degree of local income diversity is low, the presence of out-group members results in the low level of power-threat.

$A_{2}$ : When the degree of local income diversity is low, the presence of ingroup members promotes the formation of relational goods. When the degree of income diversity is high, the presence of in-group members does not promote the formation of relational goods.

B: The level of power-threat and the amount of relational goods influence individuals' utility of participating in politics.

$B_{1}$ : The higher level of power-threat increases individuals' benefits of participating in politics.

$B_{2}$ : The larger amount of relational goods increases individuals' benefits and decreases the costs of participating in politics.

C: Therefore, the presence of out-group members increases the benefits of participation only when local income diversity is high. The presence of in-group members increases the benefits and decreases the costs of participation only when local income diversity is low.

I test two hypotheses derived from the above arguments. First, the power-threat effect on political participation is observed only when local income diversity is high (Hypothesis 1). Second, the relational goods effect on political participation is observed only when local income diversity is low (Hypothesis 2).

B. Economic Affluence Hypothesis

Local economic affluence is also hypothesized to determine how the racial environment influences citizen participation. Economic affluence refers to the average so- 
cioeconomic status of geographical units. Places that are composed of individuals of high socioeconomic status are defined as more affluent environments, while places that are composed of individuals of low socioeconomic status on average are defined as less affluent environments. I assume that areas of low income status are more contentious for resources than areas of high income status because the amount of public resources available to individuals in low income status environments is limited (Branton and Jones, 2005; Olzak, 1992). Areas of high income status are less competitive for resources and richer in social capital and political expertise (Huckfeldt, 1979).

\section{Low Income Status and Power-Threat}

Branton and Jones (2005) demonstrate a conditional linkage of racial composition and local economic affluence with white attitudes on racial issues. They argue that the degree of racial threat in racially diverse locations is conditioned by local socioeconomic status. Low status (i.e., less affluent) environments enhance the effect of racial threat on white's negative attitude toward minority groups because of real or perceived economic competition with minority group members. They $(2005,360)$ argue that high racial diversity in low socioeconomic environments represents "a maximum-threat contexts" where we are most likely to observe "increased competition and perceived threat between or among groups." On the contrary, high status (i.e., more affluent) environments weaken the effect of racial threat because of active social interaction across racial and ethnic boundaries, which mitigates negative attitudes on race-related policies.

Using Branton and Jones' argument, I contend that the presence of out-group members is more likely to generate significant threats for distribution of public resources when local income status is low. Intensive competition for scarce resources in areas of low income status highlights preference polarization among racial groups 
and leads individuals to perceive out-group members as threats, which in turn enhances their interest in politics. Hence, the presence of out-groups stimulates citizen participation only when local income status is low. By contrast, in areas of high income status, the presence of out-group members has no mobilizing effect on citizen participation because abundant resources weaken the degree of competition for resources and active interracial interaction reduces negative attitudes toward other racial groups. Hence, the presence of out-groups in areas of high income status produces no significant benefits for individuals to participate in politics.

\section{High Income Status and Relational Goods}

The relationship between racial composition and the formation of relational goods also depends on income status of local areas. Some studies demonstrate that neighborhood socioeconomic status has a significant influence on intraracial interaction and racial identity. For example, Cohen and Dawson (1993) find that poor black neighborhoods in urban areas are associated with less active social interaction among in-group members. Gay (2004) shows that affluent black neighborhoods enhance group identity through active social interaction. These works imply that the effect of in-group size on intraracial interaction is conditioned by local income status. Heavy concentration of in-group population in areas of high income status facilitates formation of active and resourceful social networks for political participation. Affluent environments provide citizens more opportunities to interact with others who have greater levels of political expertise (Huckfeldt 1979). McClurg (2006) demonstrates that the higher levels of political expertise in social networks enhance individuals' participation levels. In contrast, in-group population in less affluent areas would not strengthen the intraracial ties because of infrequent intraracial interaction and ineffective information exchange. 
Hence, I argue that the degree of local income status influences the formation of relational goods among fellow group members. In areas of high income status, the presence of in-group members encourages residents to interact with other fellow members with political expertise. Thus, those areas facilitate the formation of relational goods and thus mobilize citizens to participate in politics. On the contrary, the larger size of in-group population in areas of low income status develops less active intraracial networks and therefore impedes the formation of relational goods. Thus, the presence of in-group members has no mobilizing impact on citizen participation when local income status is low.

\section{Summary}

The logic of my argument regarding the interactive relationship between racial composition, local income status, and citizen participation is summarized as follows:

A: The size of out-group population in local areas influences the level of powerthreat, while the size of in-group population influences the amount of relational goods. These linkages are conditional on the degree of local income status.

$A_{1}$ : When the degree of local income status is low, the presence of outgroup members results in the high level of power-threat. When the degree of local income status is high, the presence of out-group members results in the low level of power-threat.

$A_{2}$ : When the degree of local income status is high, the presence of ingroup members promotes the formation of relational goods. When the degree of income status is low, the presence of in-group members does not promote the formation of relational goods. 
B: The level of power-threat and the amount of relational goods influence individuals' utility of participating in politics.

$B_{1}$ : The higher level of power-threat increases individuals' benefits of participating in politics.

$B_{2}$ : The larger amount of relational goods increases individuals' benefits and decreases the costs of participating in politics.

C: Therefore, the presence of out-group members increases the benefits of participation only when local income status is low. The presence of in-group members increases the benefits and decreases the costs of participation only when local income status is high.

I test two hypotheses derived from the above arguments. First, the power-threat effect on political participation is observed only when local income status is low (Hypothesis 3). Second, the relational goods effect on political participation is observed only when local income status is high (Hypothesis 4).

\section{Measures}

My dependent variables are respondents' self-report on voting in the 1988 national election and a local election held in 1988 or 1989. Respondents who experienced no local election in 1988 and 1989 were excluded from analysis of local election.

Racial composition is measured using the out-group size at the county level. Specifically, the power-threat effect is operationalized as the out-group size in county $j$ weighted by the in-group size in $j$, where survey respondents resided. The relational goods effect is measured by the simple out-group size in $j$.

A measure of local income diversity is constructed using the index of qualitative 
variation (IQV) employed in Oliver's analysis (1999). This index is based on the following formula:

$$
\text { Income Diversity }_{j}=\frac{k\left[N_{j}^{2}-\sum_{i=1}^{N}\left(f_{i j}\right)^{2}\right]}{N_{j}^{2}(k-1)}
$$

where $k$ denotes the number of income categories, $N$ denotes the total number of cases in a county $j$, and $f_{i j}$ denotes a frequency in each income category $i$ in that area (Healey, 2002). The census data provide the number of residents in each county within twenty five categories of annual household income. I aggregate them into five categories and then calculate the score. ${ }^{1}$ This index ranges from zero to one; a higher score refers to higher income diversity.

Local income status is measured using logged median household income in counties. Most of the prior contextual research measures economic affluence using the level of educational attainment of residents (i.e., percentages of college graduates) (e.g., Branton and Jones, 2005), yet this is not a particularly suitable indicator of the concept of economic competition in this research. Higher values of the logged median household income refer to higher income status environments.

Models also include other relevant contextual-level and individual-level variables for control. The additional contextual-level variable in the models is logged population size and political heterogeneity. ${ }^{2}$ Individual-level control variables are party mobilization, party identification (Democrats and Republicans; independents are a base category), education, income, age, logged years in town, gender, and racial and ethnic category (blacks and Latinos; whites are a base category). White, black, and Latino samples are used for data analysis. Full descriptions of individual-level vari-

${ }^{1}$ Five income categories are: less than $\$ 14,999, \$ 15,000-\$ 34,999, \$ 35,000-\$ 54,999$, $\$ 55,000-\$ 74,999$, and $\$ 75,000$ and more.

${ }^{2}$ Full details of this indicator is discussed in Chapter V. 
ables, coding rules, and summary statistics are presented in the data appendix.

D. Findings

\section{Test for Economic Diversity Hypothesis}

Tables presented in this chapter report the estimated results for the same models as in Chapter III with the addition of an interactive term consisting of the racial composition measure multiplied by one of the measures of economic competition. The models in Table $\mathrm{V}$ examine Hypothesis 1 that the power-threat effect on voter turnout is observed only when local income diversity is high. The models in Table VI examine Hypothesis 2 that the relational goods effect is observed only when local income diversity is low. Note that in this chapter I focus on the sample of respondents in counties whose logged population size is below the sample mean.

Table $\mathrm{V}$ demonstrates the interactive relationship of the power-threat effect and income diversity on the probabilities of voting in the presidential and local elections. Hypothesis 1 indicates that the interaction term between the power-threat effect (measured using the out-group size weighted by the in-group size) and income diversity should be positive. In contrast to my expectation, the table shows that the direct power-threat effects are estimated to be positive, while the interactive terms of the out-group size and income diversity are estimated to be negative. These two key estimates in the model of voting in the presidential election are statistically discernable from zero, although the estimates in the models of voting in the local election are not significant at the conventional level.

The models in Table VI estimate the relational goods effect conditional on the level of income diversity. The key estimates are statistically indistinguishable from zero. Other control variables, especially at the individual-level, show predicted effects 
Table V. Empirical Test for Hypothesis 1: The Power-Threat Effect and Local Income Diversity

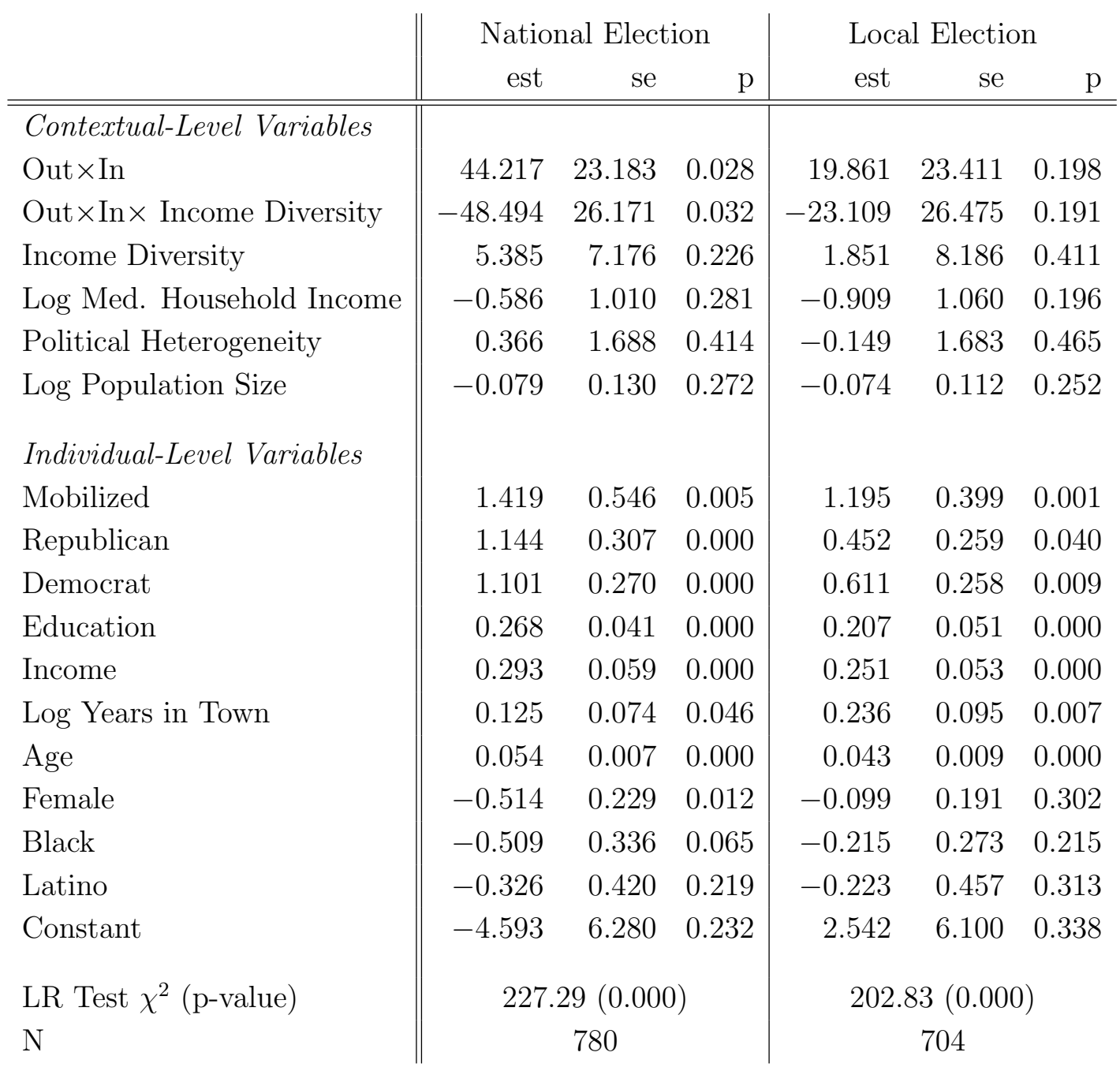

Note: Data comes from the Citizen Participation Study (Verba, Schlozman, and Brady, 1995). "Out" denotes the out-group size and "In" denotes the in-group size. Standard errors are clustered by counties. The data include 182 counties. The dependent variables are individuals' self-reported turnout in the 1988 presidential election and in a local election in 1988 or 1989. $P$ in the table denotes p-values and is based on a one-tail test. 
on the probabilities of voting.

The estimated results in the tables are not helpful for evaluating the nature of the conditional hypotheses because the marginal effects of the key variable (racial composition) and their statistical significance are hypothesized to vary as the degree of the modifying variable (income diversity) changes (Brambor, Clark and Golder, 2006; Friedrich, 1982). To evaluate the varying relationship between racial composition and voter turnout, I simulate the marginal effects of racial composition when local income diversity is set at three different levels by 1000 times. The marginal effects are calculated by taking the first difference in the predicted probability of voting as follows (Brambor, Clark and Golder, 2006):

$$
\text { First Difference }=\operatorname{Prob}\left(Y=1 \mid x_{2}, z_{i}\right)-\operatorname{Prob}\left(Y=1 \mid x_{1}, z_{i}\right)
$$

where $Y=1$ denotes that the individual voted and $x_{1}$ and $x_{2}$ denote the values of racial composition. More specifically, $x_{1}$ denotes the mean value of racial composition and $x_{2}$ denotes a one unit change from $x_{1} \cdot z_{i}$ denotes the degree of income diversity and is set at the values of the 5 percentile (low income diversity), the median (middle income diversity), and the 95 percentile (high income diversity). ${ }^{3}$

The simulated marginal effects of racial composition are presented in Figure 12. The boxplots represent the distributions of the simulated marginal effects when local income diversity is low, middle, and high. The vertical gray bold lines indicate the 95 percent confidence intervals of the distributions. The horizontal black dotted lines indicate the effect of zero.

Hypothesis 1 leads me to expect that the marginal effect of power-threat is positive and statistically significant when the level of income diversity is high, while

\footnotetext{
${ }^{3}$ The details on the simulation procedure are presented in the appendix.
} 
Table VI. Empirical Test for Hypothesis 2: The Relational Goods Effect and Local Income Diversity

\begin{tabular}{l||rrr|rrr}
\multicolumn{1}{l||}{} & \multicolumn{3}{c|}{ National Election } & \multicolumn{3}{|c}{ Local Election } \\
& est & se & $\mathrm{p}$ & est & se & $\mathrm{p}$ \\
\hline \hline Contextual-Level Variables & & & & & & \\
Out & -5.590 & 6.781 & 0.205 & -4.056 & 6.805 & 0.276 \\
Out $\times$ Income Diversity & 7.809 & 7.576 & 0.151 & 6.197 & 7.566 & 0.206 \\
Income Diversity & -6.653 & 6.333 & 0.147 & -5.658 & 6.960 & 0.208 \\
Log Med. Household Income & -0.830 & 0.935 & 0.187 & -1.065 & 0.982 & 0.139 \\
Political Heterogeneity & 1.132 & 1.614 & 0.242 & -0.112 & 1.488 & 0.470 \\
Log Population Size & -0.013 & 0.133 & 0.461 & -0.039 & 0.106 & 0.356 \\
& & & & & & \\
Individual-Level Variables & & & & & & \\
Mobilized & 1.576 & 0.539 & 0.002 & 1.281 & 0.386 & 0.000 \\
Republican & 1.153 & 0.307 & 0.000 & 0.435 & 0.262 & 0.048 \\
Democrat & 1.098 & 0.266 & 0.000 & 0.621 & 0.256 & 0.008 \\
Education & 0.264 & 0.041 & 0.000 & 0.214 & 0.049 & 0.000 \\
Income & 0.294 & 0.061 & 0.000 & 0.254 & 0.054 & 0.000 \\
Log Years in Town & 0.139 & 0.076 & 0.033 & 0.237 & 0.101 & 0.010 \\
Age & 0.053 & 0.006 & 0.000 & 0.043 & 0.009 & 0.000 \\
Female & -0.522 & 0.227 & 0.011 & -0.115 & 0.189 & 0.271 \\
Black & 0.360 & 0.475 & 0.225 & 0.605 & 0.405 & 0.068 \\
Latino & & 780 & & & 704 & \\
Constant & 0.456 & 0.636 & 0.236 & 0.591 & 0.606 & 0.164 \\
LR Test $\chi^{2}$ (p-value) & 6.582 & 7.833 & 0.200 & 9.018 & 8.040 & 0.131 \\
N & & & & & & \\
& $228.82(0.000)$ & 208.75 & $0.000)$ \\
& & & & &
\end{tabular}

Note: Data comes from the Citizen Participation Study (Verba, Schlozman, and Brady, 1995). "Out" denotes the out-group size. Standard errors are clustered by counties. The data include 182 counties. The dependent variables are individuals' self-reported turnout in the 1988 presidential election and in a local election in 1988 or 1989. $P$ in the table denotes p-values and is based on a one-tail test. 
Fig. 12. The Marginal Effects of Racial Composition in Areas of Low, Middle, and High Income Diversity

\section{A. Power-Threat Effect and Voting in National Election}

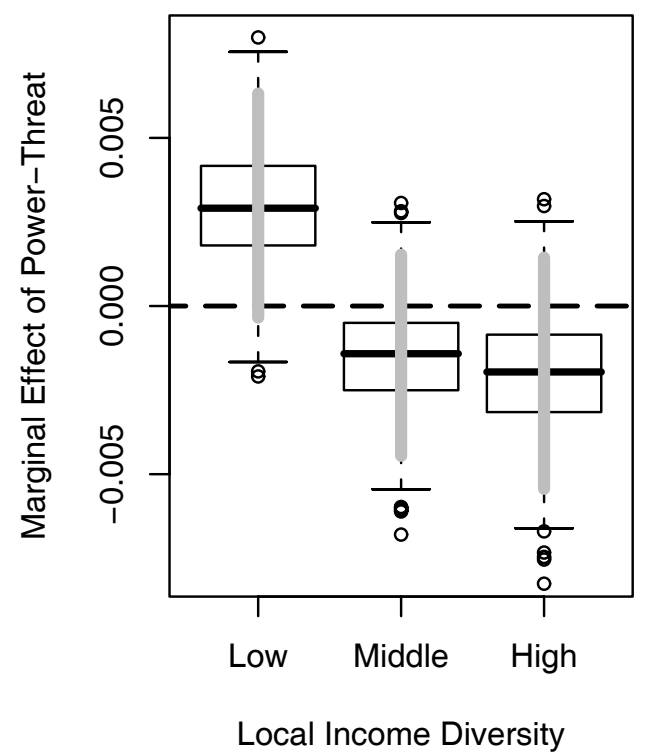

C. Relational Goods Effect and Voting in National Election

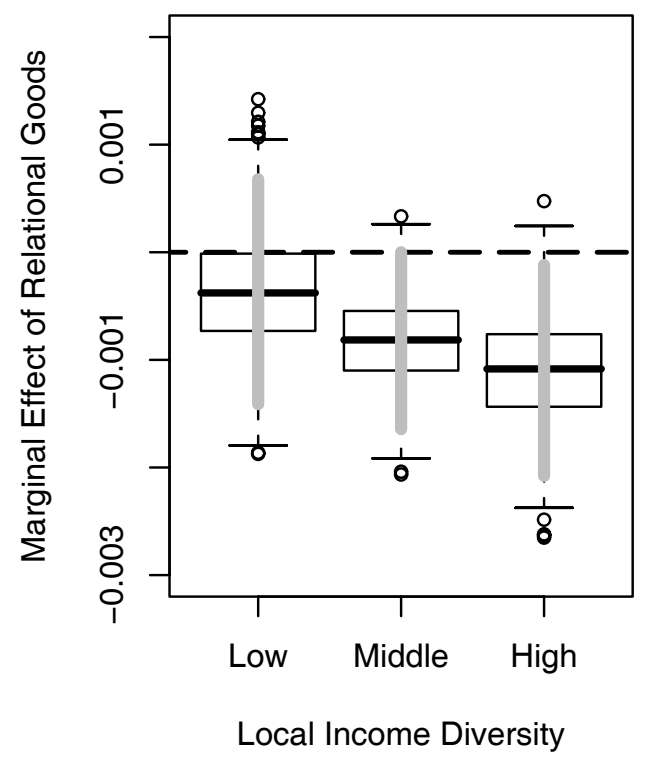

\section{B. Power-Threat Effect and Voting in Local Election}

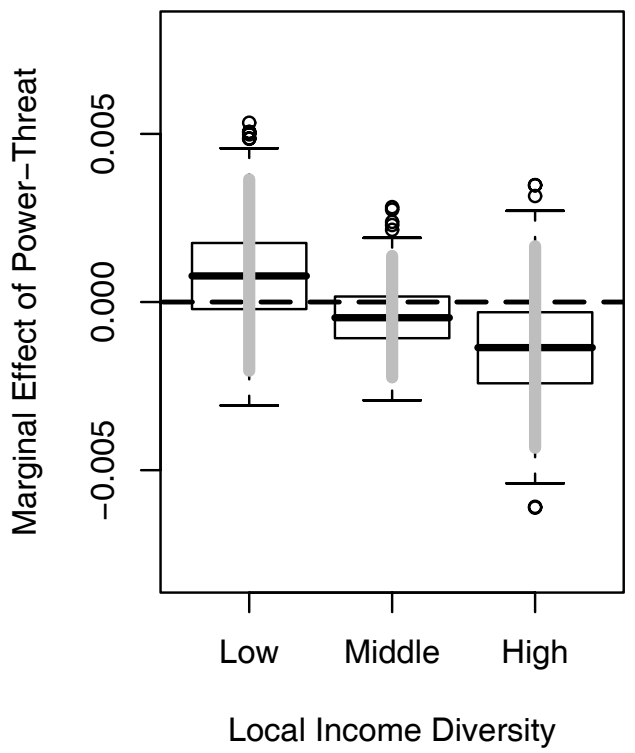

D. Relational Goods Effect and Voting in Local Election

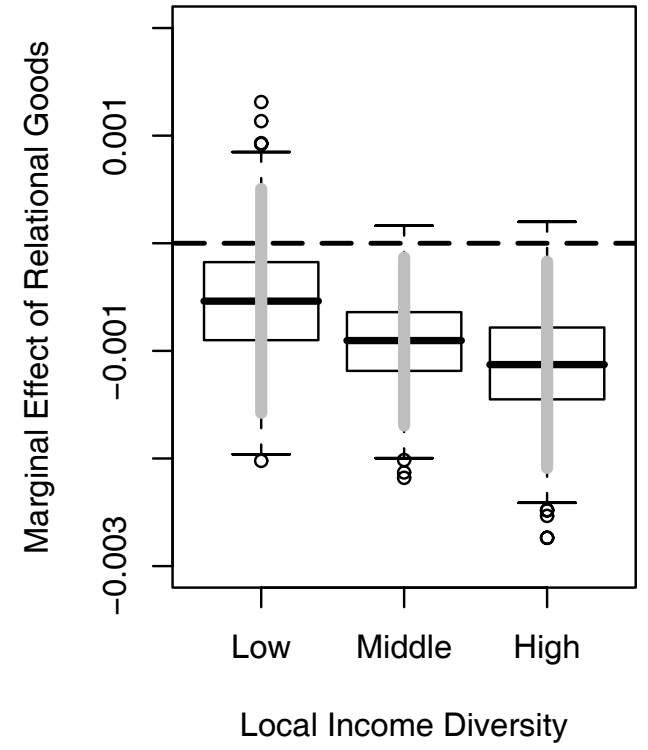


the marginal effect is small or not statistically significant when income diversity is not high. Graphs A and B in Figure 12 report the opposite result with my expectation. The power-threat has no positive effect on voter turnout when income diversity is high. Rather, Graph A demonstrates that the power-threat effect on voting in the presidential election is positive and statistically significant when local income diversity is low. Graph B also demonstrates that the power-threat effect on voting in the local election is statistically insignificant when income diversity is high. Thus, Hypothesis 1 received no support from this analysis.

Next, Hypothesis 2 leads me to expect that the marginal effect of relational goods is negative and statistically significant when the degree of income diversity is low, while the marginal effect is small or statistically insignificant when income diversity is middle to high. Graphs $\mathrm{C}$ and D in Figure 12 demonstrate that the outgroup size has a negative and statistically significant impact on the probabilities of voting only when local income diversity is high. This finding is also inconsistent with Hypothesis 2. This result offers no supportive evidence to Hypothesis 2.

To confirm the unexpected results, I calculated the predicted probabilities of voting in two types of elections when income diversity is low and high and plotted them against the out-group size in Figure 13. The out-group size varies from the minimum to the maximum values. I hold income diversity at the values of 5 percentile (representing areas of low income diversity) and 95 percentile (representing areas of high income diversity) and the other independent variables constant. ${ }^{4}$ Graphs A and B demonstrate that the out-group size has a curvilinear and convex relationship with voter turnout when local income diversity is low. Graphs C and D in Figure 12 demonstrate that the out-group size has a negative and strong impact on voting

\footnotetext{
${ }^{4}$ Numerical variables are set to their mean, ordered variables are set to their median, and dichotomous variables are set to their modes.
} 
Fig. 13. The Substantive Effects of Racial Composition in Areas of Low and High Income Diversity
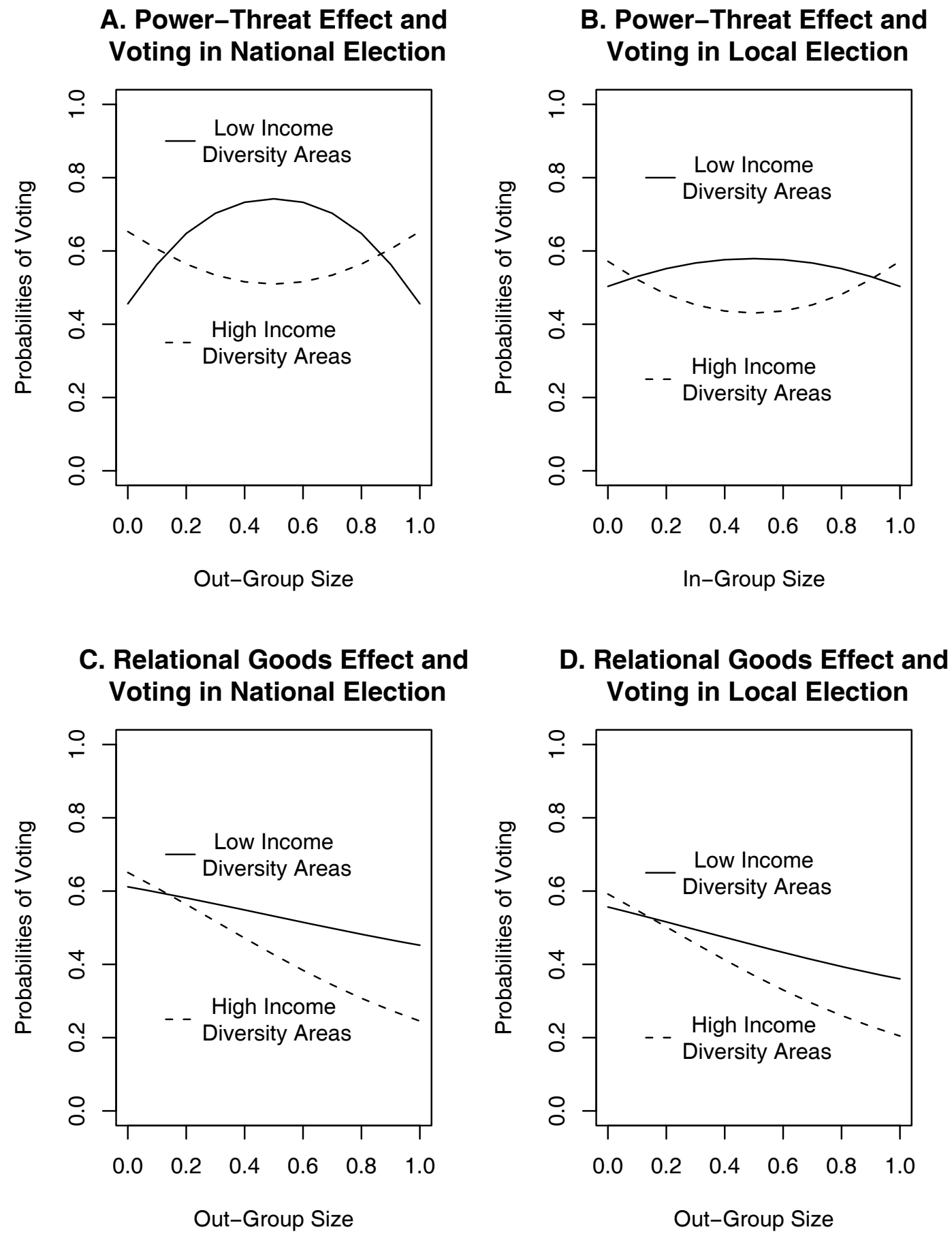
when local income diversity is high. All of these results are inconsistent with the expectations drawn from Hypotheses 1 and 2.

\section{Test for Economic Affluence Hypothesis}

Table VII examines Hypothesis 3 that the power-threat effect is observed only when the degree of local income status is low. Table VIII examines Hypothesis 4 that the relational goods effect is observed only when the degree of local income status is high.

Table VII reports the interactive effects of the power-threat effect, measured by the combination of out-group size and in-group size, and local income status on the probabilities of voting in the national and local elections. The key evidence here is that the interaction terms are estimated to be negative, while the independent effects of the power-threat are now estimated to be positive. Moreover, these estimates are statistically significant and similar for both voting in the local election and voting in the national elections. The models in Table VIII estimate the interactive effects of out-group size and local income status on the probabilities of voting. The interactive effects of relational goods, measured by the out-group size, and income status are estimated to be negative, while the direct effects of out-group size are estimated to be positive. Importantly, the individual-level control variables show expected and statistically significant effects on the probabilities of voting.

As noted above, the estimates and their statistical significance are not helpful for interpreting the nature of the conditional effects. Thus, using the same approach in the previous section, I simulate the marginal effects of racial composition when local income status is set at the 5 percentile (low income status), the median (middle income status), and the 95 percentile (high income status). The simulated marginal effects of the racial composition are presented in Figure 14. Hypothesis 3 leads me to expect that the marginal effect of power-threat is positive and statistically significant 
Table VII. Empirical Test for Hypothesis 3: The Power-Threat Effect and Local Income Status

\begin{tabular}{|c|c|c|c|c|c|c|}
\hline \multirow{2}{*}{ Contextual-Level Variables } & \multicolumn{3}{|c|}{ National Election } & \multicolumn{3}{|c|}{ Local Election } \\
\hline & & & & & & \\
\hline Out $\times \operatorname{In}$ & 100.755 & 54.298 & 0.032 & 73.936 & 51.528 & 0.076 \\
\hline Out $\times$ In $\times$ Median Income & -9.870 & 5.377 & 0.033 & -7.405 & 5.114 & 0.074 \\
\hline Log Med. Household Income & 0.680 & 0.987 & 0.245 & -0.175 & 0.964 & 0.428 \\
\hline Income Diversity & -1.182 & 4.789 & 0.403 & -0.326 & 5.636 & 0.477 \\
\hline Political Heterogeneity & 0.531 & 1.664 & 0.375 & -0.177 & 1.634 & 0.457 \\
\hline Log Population Size & -0.077 & 0.127 & 0.272 & -0.073 & 0.110 & 0.253 \\
\hline Individual-Level Variables & & & & & & \\
\hline Mobilized & 1.409 & 0.545 & 0.005 & 1.190 & 0.399 & 0.001 \\
\hline Republican & 1.152 & 0.306 & 0.000 & 0.461 & 0.258 & 0.037 \\
\hline Democrat & 1.102 & 0.268 & 0.000 & 0.614 & 0.258 & 0.009 \\
\hline Education & 0.266 & 0.041 & 0.000 & 0.206 & 0.051 & 0.000 \\
\hline Income & 0.296 & 0.059 & 0.000 & 0.254 & 0.054 & 0.000 \\
\hline Log Years in Town & 0.129 & 0.075 & 0.042 & 0.236 & 0.096 & 0.007 \\
\hline Age & 0.053 & 0.006 & 0.000 & 0.043 & 0.009 & 0.000 \\
\hline Female & -0.516 & 0.228 & 0.012 & -0.102 & 0.189 & 0.295 \\
\hline Black & -0.505 & 0.333 & 0.065 & -0.217 & 0.272 & 0.212 \\
\hline Latino & -0.351 & 0.437 & 0.211 & -0.230 & 0.457 & 0.307 \\
\hline Constant & -11.627 & 7.878 & 0.070 & -2.939 & 7.275 & 0.343 \\
\hline LR Test $\chi^{2}$ (p-value) & 227 & $9(0.00$ & & & $94(0.00$ & \\
\hline $\mathrm{N}$ & & 780 & & & 704 & \\
\hline
\end{tabular}

Note: Data comes from the Citizen Participation Study (Verba, Schlozman, and Brady, 1995). "Out" denotes the out-group size and "In" denotes the in-group size. Standard errors are clustered by counties. The data include 182 counties. The dependent variables are individuals' self-reported turnout in the 1988 presidential election and in a local election in 1988 or $1989 . P$ in the table denotes p-values and is based on a one-tail test. 
Table VIII. Empirical Test for Hypothesis 4: The Relational Goods Effect and Local Income Status

\begin{tabular}{|c|c|c|c|c|c|c|}
\hline \multirow{2}{*}{ Contextual-Level Variables } & \multicolumn{3}{|c|}{ National Election } & \multicolumn{3}{|c|}{ Local Election } \\
\hline & & & & & & \\
\hline Out & 18.658 & 14.673 & 0.102 & 21.009 & 14.392 & 0.072 \\
\hline Out $\times$ Median Income & -1.979 & 1.446 & 0.085 & -2.226 & 1.416 & 0.058 \\
\hline Log Med. Household Income & -0.190 & 1.024 & 0.427 & -0.636 & 1.014 & 0.265 \\
\hline Income Diversity & -1.611 & 4.737 & 0.367 & -0.160 & 5.307 & 0.488 \\
\hline Political Heterogeneity & 1.200 & 1.595 & 0.226 & -0.185 & 1.494 & 0.451 \\
\hline Log Population Size & -0.010 & 0.132 & 0.470 & -0.041 & 0.106 & 0.351 \\
\hline Individual-Level Variables & & & & & & \\
\hline Mobilized & 1.585 & 0.542 & 0.002 & 1.298 & 0.389 & 0.000 \\
\hline Republican & 1.153 & 0.306 & 0.000 & 0.439 & 0.261 & 0.046 \\
\hline Democrat & 1.105 & 0.267 & 0.000 & 0.636 & 0.257 & 0.007 \\
\hline Education & 0.265 & 0.041 & 0.000 & 0.214 & 0.049 & 0.000 \\
\hline Income & 0.296 & 0.061 & 0.000 & 0.258 & 0.055 & 0.000 \\
\hline Log Years in Town & 0.137 & 0.076 & 0.035 & 0.237 & 0.103 & 0.011 \\
\hline Age & 0.052 & 0.006 & 0.000 & 0.042 & 0.009 & 0.000 \\
\hline Female & -0.526 & 0.228 & 0.010 & -0.121 & 0.191 & 0.262 \\
\hline Black & 0.355 & 0.473 & 0.226 & 0.624 & 0.396 & 0.057 \\
\hline Latino & 0.473 & 0.631 & 0.227 & 0.614 & 0.590 & 0.149 \\
\hline Constant & -3.092 & 7.858 & 0.347 & 1.257 & 7.202 & 0.431 \\
\hline LR Test $\chi^{2}$ (p-value) & \multirow{2}{*}{\multicolumn{3}{|c|}{$\begin{array}{c}229.44(0.000) \\
780\end{array}$}} & \multirow{2}{*}{\multicolumn{3}{|c|}{$\begin{array}{c}210.52(0.000) \\
704\end{array}$}} \\
\hline $\mathrm{N}$ & & & & & & \\
\hline
\end{tabular}

Note: Data comes from the Citizen Participation Study (Verba, Schlozman, and Brady, 1995). "Out" denotes the out-group size and "In" denotes the in-group size. Standard errors are clustered by counties. The data include 182 counties. The dependent variables are individuals' self-reported turnout in the 1988 presidential election and in a local election in 1988 or 1989. $P$ in the table denotes p-values and is based on a one-tail test. 
when the degree of income status is low, while the marginal effect is small or not statistically significant when income status is middle to high. Graphs A and B in Figure 14 show some supportive evidence for my expectations. The marginal effect of power-threat on voter turnout in the national election in Graph A is positive and statistically significant when local income status is low. In contrast, the marginal effect of power-threat decreases and turns out to be statistically insignificant as the level of income status increases. Graph B shows that the marginal effect of the power-threat on voting in the local election is positive but statistically insignificant when local income status is low. Thus, the results offer some supportive evidence to Hypothesis 3 that the power-threat effect is observed only when local income status is low.

Hypothesis 4 leads me to expect that the marginal effect of out-group size is negative and statistically significant when the degree of income status is high, while the marginal effect is small or not statistically significant when income status is low to middle. Graphs C and D in Figure 14 show the expected results. The marginal effects of out-group size on voter turnout are negative and statistically significant when the level of local economic affluence increases. This negative effect in areas of high income status means that people are more likely to vote when the out-group size decreases or when the in-group size increases. In contrast, the marginal effects decrease and become statistically insignificant as local income status decreases. Moreover, these results are similar for both voting in the local election and voting in the national elections. The results here, therefore, offer strong support for the Hypothesis 4 that the relational goods effect is observed especially when local economic affluence is high. ${ }^{5}$

\footnotetext{
${ }^{5}$ Note that, however, the difference between the significant results and nonsignificant results may not be statistically significant. See Gelman and Stern (2006).
} 
Fig. 14. The Marginal Effects of Racial Composition in Areas of Low, Middle, and High Income Status

\section{A. Power-Threat Effect and Voting in National Election}

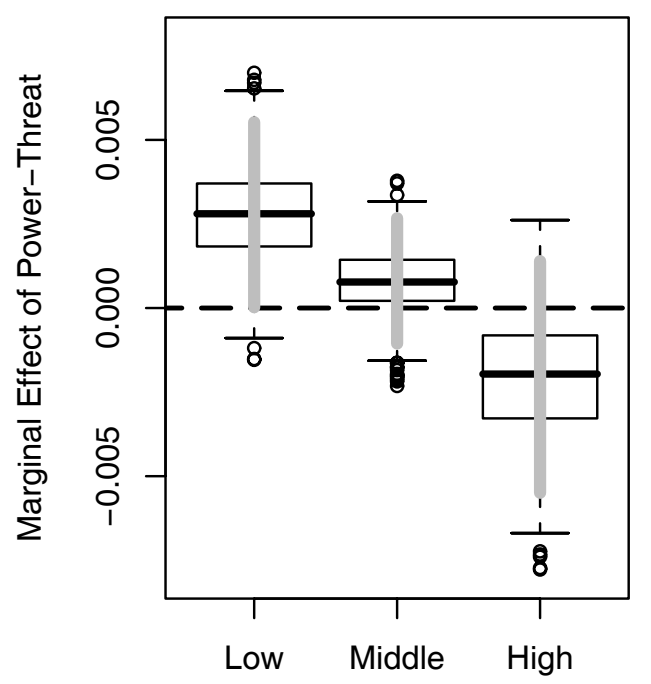

Local Income Status

C. Relational Goods Effect and Voting in National Election

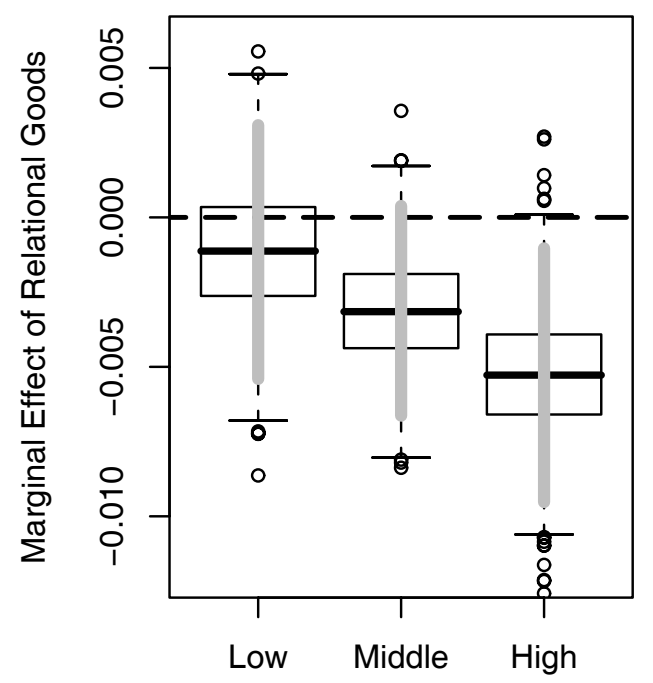

Local Income Status
B. Power-Threat Effect and Voting in Local Election

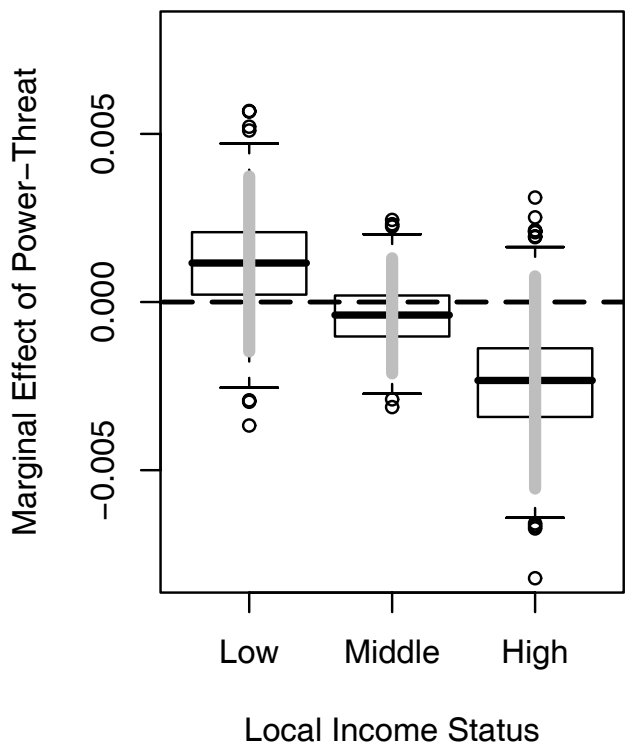

D. Relational Goods Effect and Voting in Local Election

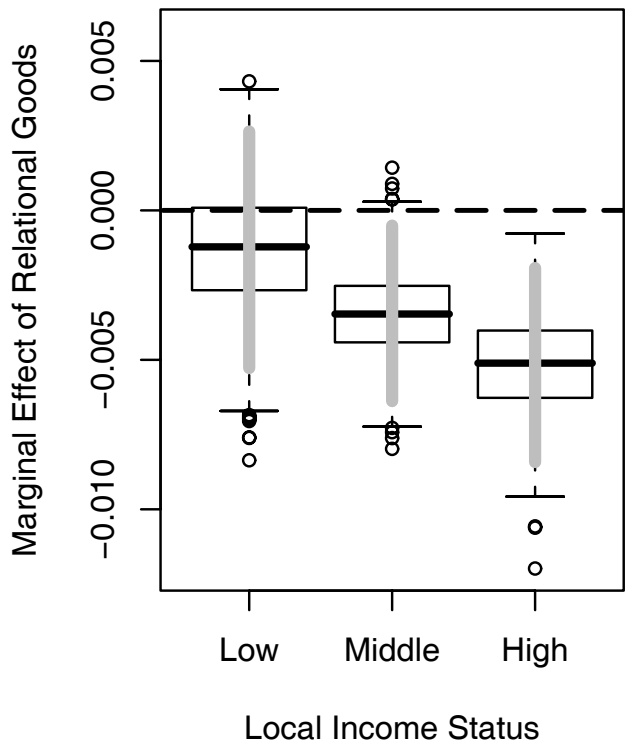


Finally, Figure 15 reports the predicted probabilities of voting in the presidential and local elections when the out-group size varies from zero to one. I hold income status at the values of 5 percentile (representing areas of low income status) and 95 percentile (representing areas of high income status) and the other independent variables constant. ${ }^{6}$ As expected, Graphs A demonstrates a curvilinear, convex relationship between the out-group size and the probabilities in voting in the national election only when local income status is low. Further, Graphs C and D demonstrate that the out-group size has a strong, negative relationship with the probabilities of voting in two types of elections especially when local income status is high.

\section{E. Summary}

The previous research on the racial environment and political participation has been limited by the lack of careful theoretical development. While the principles of the existing hypotheses suggested that the racial environment shapes the utility of political participation and therefore has a significant effect on individuals' decisions to participate, much of the empirical evidence contradicted these expectations. I began this chapter facing mixed empirical evidence, hoping to gain a better theoretical understanding of how the racial environments influence citizen participation in politics.

The theoretical extension I offer builds on the work of recent advances in the sociology and political science literature of race relations, where scholars have emphasized that individuals live in multi-faceted worlds, ones where not just race but also class structure citizens' responses to the political and social spheres. I also build heavily on Oliver's conceptualization of the association between local income diversity and economic competition and Branton and Jones' conceptualization of the associa-

\footnotetext{
${ }^{6}$ Numerical variables are set to their mean, ordered variables are set to their median, and dichotomous variables are set to their modes.
} 
Fig. 15. The Substantive Effects of Racial Composition in Areas of Low and High Income Status
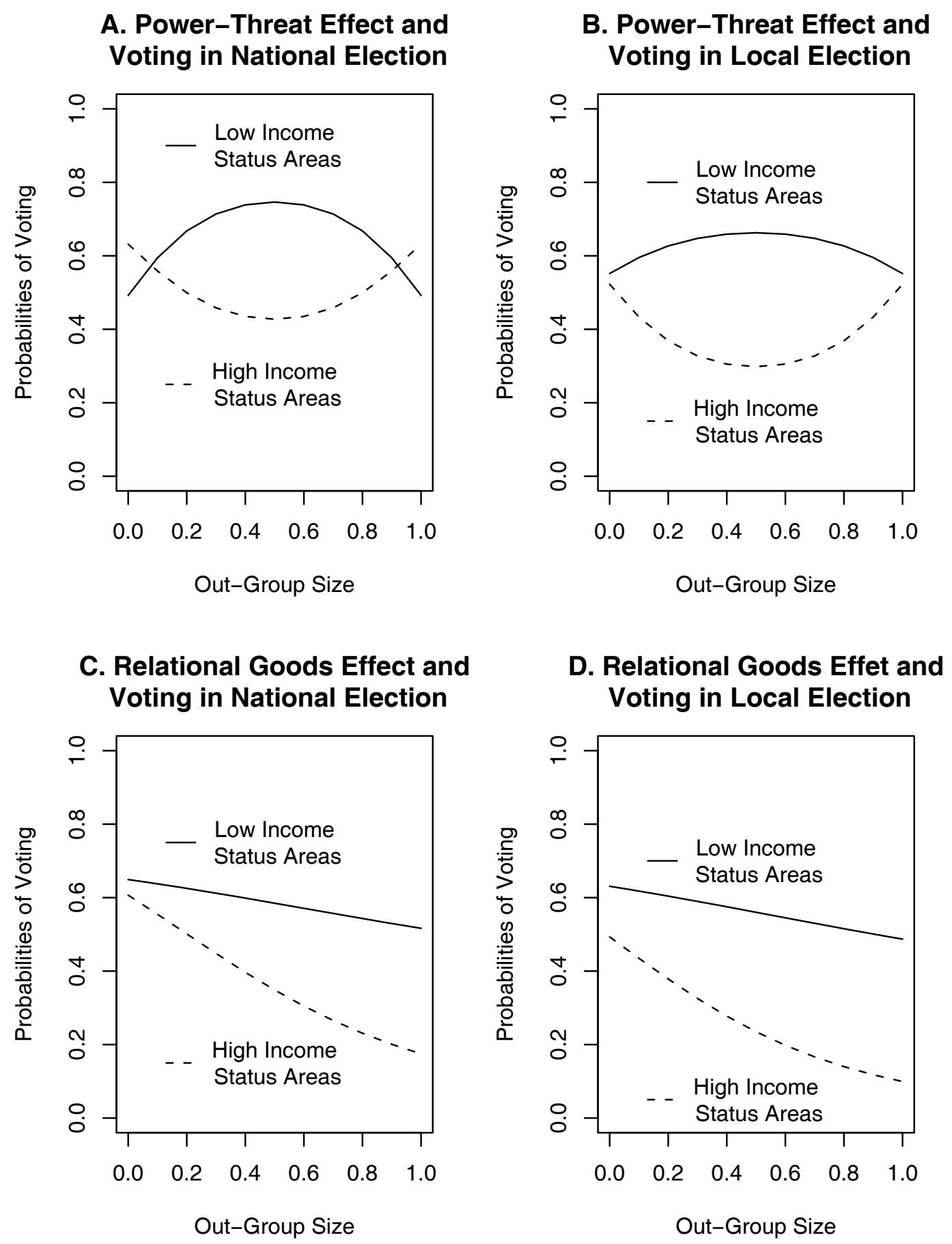
tion between local income status and competition, focusing on how economic conflict is likely an incentive for mass participation. I argue that the theoretical extension that takes into account the role of economic competition as a conditioning variable reinforces the key discussions in the power-threat hypothesis and the relational goods hypothesis.

The first set of my theoretical expectation focused on the role of income diversity of citizens' immediate environments. I hypothesized that the presence of out-group members increases citizen participation only when the degree of income diversity is high (Hypothesis 1), while the presence of in-group members increases participation only when the degree of income diversity is low (Hypothesis 2). My empirical analysis, however, demonstrated that citizens are more likely to vote when the presence of outgroups is associated with low economic diversity and when the presence of in-groups is associated with high income diversity. I offer no reasonable explanation for these contradictory findings. One of the potential problems in the hypothesis test is that the indicator of income diversity employed in the regression analyses might not reflect the concept of income diversity among racial groups.

The second set of my theoretical expectation emphasized the role of income status of local areas. I hypothesized that the presence of out-groups increases citizen participation only when the degree of local income status is low (Hypothesis 3), while the presence of in-groups increases participation only when the degree of income status is high (Hypothesis 4). As expected, the empirical findings demonstrated that individuals are more likely to go to the polls when they reside near other racial group members in areas of low income status. Further, I also found that individuals are more likely to vote when residing with their fellow members in areas of high income status. Note that the evidence for the Hypothesis 3 was limited. I found that the power-threat encourages citizens to engage in political activities, yet the substantive 
impact is not notable.

In the next chapter, I address how local political competition conditions the linkage between the racial environment and citizen participation. 


\section{CHAPTER V}

\section{RACIAL COMPOSITION, POLITICAL COMPETITION, AND CITIZEN PARTICIPATION}

This chapter explores the other conditional linkage between the racial environment and citizen participation. I use the concept of local political competition and elaborate how it structures interracial and intraracial relations. I argue that the presence of out-group members in local areas produces a high racial threat and therefore increases the benefits of participation only when local political competition is high, while the presence of in-group members produces relational goods and therefore influences the utility calculation only when local political competition is low.

I conceptualize local political competition as partisan heterogeneity of individuals in a geographical unit. When the size of supporters for two major parties is balanced, local areas are considered as more heterogeneous and competitive. When either the Republicans or the Democrats numerically dominate the other party supporters, areas are considered as less heterogeneous and competitive.

\section{A. Political Competition Hypothesis}

\section{High Political Heterogeneity and Power-Threat}

Cross-national research on ethnic conflicts suggests that a political setting is an important environmental determinant of ethnic relations in divided societies (e.g., Chandra, 2004; Posner, 2004, 2005; Wilkinson, 2004). More specifically, the level of local political heterogeneity is expected to have a significant impact on the degree of ethnic conflict in a diverse society. When local areas are composed of various partisan supporters and electoral races are competitive, politicians are more likely to use an ethnic 
appeal that emphasizes group interest agendas to mobilize supporters because "an ethnic appeal is an attractive and efficacious weapon in the competition for office" (Bates, 1983, 161) for politicians. ${ }^{1}$ In areas of high political heterogeneity, therefore, citizens are more likely to have strong ethnic identities (Miguel and Posner, 2005) and to view out-group members as a threat to their political interests. By contrast, when local areas are dominated by a single group of partisan supporters and electoral races are less competitive, politicians have a weak incentive to emphasize group interest agendas to appeal their group members for support because the homogeneous nature of the political environments reduces the importance of mobilization activities and of preference polarization among groups. Thus, in areas of low political heterogeneity, citizens are less likely to have strong ethnic identities and to perceive out-group members as political threats.

Elite mobilization activity in electoral races also shapes the degree of powerthreat in racially diverse places in the United States. High political heterogeneity increases the importance of effective mobilizing strategies for campaign activities (Cox and Munger, 1989). Since racial threat is an "easy" issue for citizens to understand (Carmines and Stimson, 1980), using racial appeals would be an efficient mobilizing strategy for candidates and campaign organizations who try to maximize the number of votes with limited resources. In fact, Metz and Tate (1995) demonstrate that more competitive elections encourage white candidates to rely on racial appeals for their campaigns in racially diverse metropolitan areas. Kaufmann (2004), further, demonstrates that candidates' racial appeals, especially by minority candidates, enhance individuals' racial identities and therefore increase the importance of racial threat in

\footnotetext{
${ }^{1}$ An ethnic appeal is attractive for citizens, too, since "voters also seek to gain entry into coalitions that will permit one of their own to win political power" (Posner, 2004, $539)$.
} 
their attitude formation, which results in race-based voting behavior. ${ }^{2}$ In contrast, when local areas are not politically heterogeneous, politicians have a weak incentive to use racial appeals because mobilization activities and group interest agendas make little difference in outcomes. Therefore, individuals are less likely to perceive the presence of out-groups as a political rival for their interests.

Since a high power-threat increases the benefit of participating in politics (e.g., Leighley and Vedlitz, 1999), I expect that the presence of out-group population stimulates citizen participation only when local political heterogeneity is high. Active racial appeals by candidates and political organizations give individuals an information cue that members of other racial groups have an unfavorable impact on their economic and political interests in local areas and as a result enhances their incentives of participation in politics. Consequently, individuals are more likely to engage in political activities. Conversely, I expect that the presence of out-groups has no mobilizing effect on citizen participation in areas of low political heterogeneity. The lack of information cue decreases the likelihood that individuals perceive out-groups as a serious threat for their interests. Therefore, individuals are not more likely to engage in political activities in such areas despite the substantial presence of out-group members.

\footnotetext{
${ }^{2}$ Note that racial appeals by candidates are not necessarily explicit (Kaufmann, 2004). Metz and Tate (1995) argue that explicit racial appeals would reduce the probability that candidates win local elections because apparent emphasis on racial issues alienates people of other races and therefore mobilizes their participation. Importantly, Mendelberg (2001) demonstrates that implicit racial appeals are more effective strategies for electoral campaigns than explicit ones for the purpose of mobilizing citizens to vote based on racial issues (see also Valentino, Hutchings, and White 2002; Huber and Lapinski, 2006). Mendelberg argues that overt emphasis on racial cues violates a shared norm of racial equality in the society and therefore generates strong resentment from the mass public. On the other hand, subtle uses of race prime citizens' racial resentment and encourage them to engage in race-based behavior. Thus, even if racial appeals are not explicit, they could highlight differences in political preference among racial groups and generate conflicts among them.
} 


\section{Low Political Heterogeneity and Relational Goods}

Prior research on political communication implies that there is no one-to-one relationship between in-group size and the formation of relational goods. This is because the magnitude of opinion dissimilarity within intraracial networks plays an important role in the process of information exchange between communication partners. In general, involvement in cross-cutting networks where communication partners have conflicting political views reduces the effectiveness of information exchange. Huckfeldt and Sprague (1995) demonstrates that opinion disagreement between communication partners reduces the effect of political discussion on individuals' attitude formation. Mutz's (2002b) systematic analysis of cross-cutting networks demonstrates that citizens in cross-pressured networks are more ambivalent about political issues and feel greater accountability for their political preferences and choices to their communication partners. More directly, Huckfeldt, Johnson and Sprague (2004) indicate that information exchange is less effective in cross-cutting networks than single-minded networks. Therefore, involvement in cross-cutting networks is expected to have a weaker effect on the formation of relational goods than the one in like-minded networks.

The degree of opinion dissimilarity within communication networks is often dependent on citizens' immediate political environments because of availability and selectivity of communication partners (e.g., Mutz, 2006). When local political heterogeneity is low and therefore the degree of opinion dissimilarity among individuals is low, people can easily find like-minded communication partners who share political preferences (Campbell, 2006; Huckfeldt and Sprague, 1995; Mutz, 2006; Weatherford, 1982). Thus, the substantial presence of like-minded in-group members helps individuals establish active and homogeneous intraracial networks. On the contrary, in 
areas of high political heterogeneity, citizens find it more difficult to interact with like-minded partners. Hence, the substantial presence of in-group members in such areas increases a likelihood to involve in a cross-cutting communication network.

I then argue that the substantial presence of in-group members helps citizens develop relational goods and increases an incentive for them to participate in political activities only when individuals reside in areas of low political heterogeneity. Since more relational goods increase the benefits and decrease the cost of participating in politics (Chong and Rogers, 2005; Leighley, 2001; Uhlaner, 1989), I hypothesize that the presence of more in-group members increases citizen participation only when local political heterogeneity is low. On the other hand, I expect that the presence of in-group members has no mobilizing effect on citizen participation when political heterogeneity is high because the cross-cutting intraracial network does not necessarily produce relational goods relevant to political participation.

\section{Summary}

The logic of my argument regarding the interactive relationship between racial composition, political competition, and political participation is summarized as follows:

A: The size of out-group population in local areas influences the level of powerthreat, while the size of in-group population influences the amount of relational goods. These linkages are conditional on the degree of local political heterogeneity.

$A_{1}$ : When the degree of local political heterogeneity is high, the presence of out-group members results in the high level of power-threat. When the degree of local political heterogeneity is low, the presence of out-group members results in the low level of power-threat. 
$A_{2}$ : When the degree of local political heterogeneity is low, the presence of in-group members promotes the formation of relational goods. When the degree of political heterogeneity is high, the presence of in-group members does not promote the formation of relational goods.

B: The level of power-threat and the amount of relational goods influence individuals' utility of participating in politics.

$B_{1}$ : The higher level of power-threat increases individuals' benefits of participating in politics.

$B_{2}$ : The larger amount of relational goods increases individuals' benefits and decreases the costs of participating in politics.

C: Therefore, the presence of out-group population increases the benefits of participation only when local political heterogeneity is high. The presence of ingroup population increases the benefits and decreases the costs of participation only when local political heterogeneity is low.

I test two hypotheses derived from the above arguments. First, the power-threat effect on political participation is observed only when the degree of local political heterogeneity is high (Hypothesis 5). Second, the relational goods effect is observed only when the degree of local political heterogeneity is low (Hypothesis 6).

\section{B. Measures}

As in the previous chapters, my dependent variables are respondents' decisions to vote or not in the 1988 national election and a local election in 1988 or 1989. Respondents who experienced no local election in 1988 and 1989 were excluded from analysis of voting in local election. 
Racial composition is measured using the out-group size in county $j$. Specifically, the power-threat effect is operationalized as the out-group size weighted by the ingroup size (i.e., 1 - Out-Group Size). The relational goods effect is measured by the simple out-group size.

Local political heterogeneity is measured using the average rate of electoral competition of the 1980, 1984, 1988 presidential elections at the county level. When the vote share by the Democratic candidate is close to the one by the Republican candidate, the county is regarded as more competitive and heterogeneous. When the vote share is dominated by one of the two major parties, the county is less competitive and heterogeneous. The measure is constructed using the following formula:

$$
\text { Political Heterogeneity } y_{j}=\frac{\sum_{y=1}^{n}\left(1-k_{j y}\right)}{n}
$$

where $k$ denotes the share of the vote won by the prevailing party in each county $i$ in year $y, n$ denotes the total number of years (Campbell, 2006). This index ranges from zero to one: a greater score refers to higher political heterogeneity. Note that counties are the smallest geographical unit that provides me with the recodes of presidential votes in the three presidential elections.

Models also include other contextual-level and individual-level variables for statistical control. Additional contextual-level variables in the models are income diversity, logged median household income, and logged population size. These contextuallevel variables measured at the county level using the same formula in the prior chapter. Individual-level control variables are party mobilization, party identification (Democrats and Republicans; independents are a base category), education, income, age, logged years in town, gender, and racial and ethnic category (blacks and Latinos; whites are a base category). White, black, and Latino samples are used for data analysis. Full descriptions of individual-level variables, coding rules, and summary 
statistics are presented in the data appendix. Note that in this chapter I focus on the sample of respondents in the counties whose population size is below the sample mean.

\section{Findings}

Tables presented in this chapter report the estimated results for the same models as in Chapter III with the addition of an interactive term consisting of the racial composition measure multiplied by the measure of political heterogeneity. Table IX shows logit estimates on the interactive effects of the power-threat, measured using the out-group size weighted by the in-group size, and political heterogeneity on the probabilities of voting in the presidential and local elections. The models Table IX are estimated to examine the hypothesis that the power-threat effect on voter turnout is observed only when local political heterogeneity is high. Two models demonstrate the result consistent with my expectations that the interaction terms are estimated to be positive, while the independent effects of power-threat are estimated to be negative.

Two models in Table $\mathrm{X}$ estimate the interactive effects of relational goods and political heterogeneity on the probabilities of voting. The models are estimated to assess the hypothesis that the relational goods effect on voter turnout is observed only when local political heterogeneity is low. As expected, the interactive terms are estimated to be positive, while the direct effects of the out-group size are estimated to be negative.

Other control variables show mixed results in Table IX and Table X. Most of the contextual-level variables show no statistically significant impact on the probabilities of voting. In contrast, the individual-level variables are estimated to have statistically significant effects on individuals' decisions to vote. The findings on the individual- 
Table IX. Empirical Test for Hypothesis 5: The Power-Threat Effect and Local Political Heterogeneity

\begin{tabular}{l||rrr|rrr}
\multicolumn{1}{l||}{} & \multicolumn{3}{c|}{ National Election } & \multicolumn{3}{|c}{ Local Election } \\
& est & se & $\mathrm{p}$ & est & se & $\mathrm{p}$ \\
\hline \hline Contextual-Level Variables & & & & & & \\
Out $\times$ In & -9.736 & 9.282 & 0.147 & -22.000 & 6.604 & 0.000 \\
Out $\times$ In $\times$ Pol. Heterogeneity & 28.957 & 23.500 & 0.109 & 55.261 & 17.343 & 0.001 \\
Political Heterogeneity & -1.072 & 2.407 & 0.328 & -3.792 & 1.637 & 0.010 \\
Income Diversity & -4.166 & 4.844 & 0.195 & -4.134 & 5.425 & 0.223 \\
Log Med. Household Income & 0.179 & 0.983 & 0.428 & -0.189 & 0.981 & 0.424 \\
Log Population Size & -0.077 & 0.131 & 0.278 & -0.078 & 0.103 & 0.224 \\
& & & & & & \\
Individual-Level Variables & & & & & & \\
Mobilized & 1.450 & 0.547 & 0.004 & 1.250 & 0.397 & 0.001 \\
Republican & 1.121 & 0.312 & 0.000 & 0.402 & 0.260 & 0.061 \\
Democrat & 1.099 & 0.265 & 0.000 & 0.633 & 0.257 & 0.007 \\
Education & 0.259 & 0.043 & 0.000 & 0.198 & 0.053 & 0.000 \\
Income & 0.292 & 0.059 & 0.000 & 0.260 & 0.053 & 0.000 \\
Log Years in Town & 0.134 & 0.076 & 0.039 & 0.253 & 0.098 & 0.005 \\
Age & 0.053 & 0.006 & 0.000 & 0.042 & 0.009 & 0.000 \\
Female & -0.534 & 0.235 & 0.012 & -0.188 & 0.185 & 0.155 \\
Black & -0.543 & 0.330 & 0.050 & -0.276 & 0.269 & 0.152 \\
Latino & -0.332 & 0.479 & 0.244 & -0.119 & 0.507 & 0.407 \\
Constant & -3.187 & 6.542 & 0.313 & 2.108 & 6.221 & 0.367 \\
LR Test $\chi^{2}$ (p-value) & & & & & & \\
N & $225.78(0.000)$ & 208.27 & $(0.000)$ \\
& & 780 & & & 704 &
\end{tabular}

Note: Data comes from the Citizen Participation Study (Verba, Schlozman, and Brady, 1995). "Out" denotes the out-group size and "In" denotes the in-group size. Standard errors are clustered by counties. The data include 182 counties. The dependent variables are individuals' self-reported turnout in the 1988 presidential election and in a local election in 1988 or 1989. $P$ in the table denotes p-values and is based on a one-tail test. 
Table X. Empirical Test for Hypothesis 6: The Relational Goods Effect and Local Political Heterogeneity

\begin{tabular}{l||rrr|rrr}
\multicolumn{1}{l||}{} & \multicolumn{4}{c|}{ National Election } & \multicolumn{3}{|c}{ Local Election } \\
& est & se & p & est & se & p \\
\hline \hline Contextual-Level Variables & & & & & & \\
Out & -4.338 & 2.576 & 0.046 & -5.184 & 2.295 & 0.012 \\
Out $\times$ Pol. Heterogeneity & 8.349 & 6.545 & 0.101 & 10.257 & 5.769 & 0.038 \\
Political Heterogeneity & -0.718 & 2.640 & 0.393 & -2.121 & 1.959 & 0.139 \\
Income Diversity & -4.450 & 5.177 & 0.195 & -4.407 & 5.885 & 0.227 \\
Log Med. Household Income & -0.384 & 0.970 & 0.346 & -0.584 & 1.020 & 0.284 \\
Log Population Size & -0.001 & 0.136 & 0.498 & -0.026 & 0.106 & 0.402 \\
& & & & & & \\
Individual-Level Variables & & & & & & \\
Mobilized & 1.594 & 0.532 & 0.001 & 1.321 & 0.409 & 0.001 \\
Republican & 1.124 & 0.303 & 0.000 & 0.399 & 0.262 & 0.063 \\
Democrat & 1.126 & 0.269 & 0.000 & 0.658 & 0.257 & 0.005 \\
Education & 0.266 & 0.042 & 0.000 & 0.217 & 0.050 & 0.000 \\
Income & 0.286 & 0.059 & 0.000 & 0.250 & 0.053 & 0.000 \\
Log Years in Town & 0.139 & 0.074 & 0.030 & 0.238 & 0.099 & 0.008 \\
Age & 0.053 & 0.007 & 0.000 & 0.043 & 0.009 & 0.000 \\
Female & -0.564 & 0.241 & 0.010 & -0.178 & 0.180 & 0.162 \\
Black & 0.172 & 0.495 & 0.364 & 0.420 & 0.414 & 0.155 \\
Latino & & 780 & & & 704 & \\
Constant & 0.412 & 0.633 & 0.258 & 0.632 & 0.613 & 0.151 \\
LR Test $\chi^{2}$ (p-value) & 2.030 & 6.416 & 0.376 & 5.094 & 6.258 & 0.208 \\
N & & & & & & \\
& $230.27(0.000)$ & 212.11 & $0.000)$ \\
& & & & &
\end{tabular}

Note: Data comes from the Citizen Participation Study (Verba, Schlozman, and Brady, 1995). "Out" denotes the out-group size. Standard errors are clustered by counties. The data include 182 counties. The dependent variables are individuals' self-reported turnout in the 1988 presidential election and in a local election in 1988 or 1989. $P$ in the table denotes p-values and is based on a one-tail test. 
level variables are consistent with the ones in the existing literature.

To evaluate the nature of interactive impacts of racial composition and local political heterogeneity, I compute the marginal effects of racial composition when local political heterogeneity is set at three different values by 1000 simulations. They are calculated by taking the first difference in the simulated predicted probabilities of voting as follows:

First Difference $=\operatorname{Prob}\left(Y=1 \mid x_{2}, z_{i}\right)-\operatorname{Prob}\left(Y=1 \mid x_{1}, z_{i}\right)$

where $Y=1$ denotes that the individual voted and $x_{1}$ and $x_{2}$ denote the values of racial composition. More specifically, $x_{1}$ denotes the mean value of racial composition and $x_{2}$ denotes a one unit change from $x_{1} \cdot z_{i}$ denotes the degree of political heterogeneity and is set at the values of the 5 percentile (low political heterogeneity), the median (middle political heterogeneity), and the 95 percentile (high political heterogeneity).

The simulated marginal effects are displayed in Figure 16. The boxplots in the figure demonstrate the distributions of the simulated marginal effects when local political heterogeneity is low, middle, and high. The vertical gray bold lines indicate the 95 percent confidence intervals of the distributions. The horizontal black dotted lines indicate the effect of zero.

Hypothesis 5 leads me to expect that the marginal effect of the power-threat indicator is positive and statistically significant when the degree of political heterogeneity is high, while the marginal effect is small or not statistically significant when the degree is low to middle. Graphs A and B in Figure 16 report that, as expected, the power-threat indicator has a positive and statistically significant effect on the probabilities of voting in two types elections only when local political heterogeneity is high. The presence of out-groups significantly mobilizes citizens to go to the poll in areas of 
high political heterogeneity. Graphs also report that the power-threat indicator has a negative or insignificant impact on voter turnout when local political heterogeneity is not high. These results suggest that the power-threat has no impact unless political heterogeneity is high. In sum, as predicted in Hypothesis 5, the power-threat effect on voter turnout is observed only when local political heterogeneity is high.

Graphs C and D in Figure 16 help us to evaluate Hypothesis 6. This hypothesis leads me to expect that the marginal effect of out-group size is negative and statistically significant when the degree of local political heterogeneity is low, while it is small or not significant when the degree is high. Graphs $\mathrm{C}$ and D demonstrate that when political heterogeneity is low, the out-group size has a negative and statistically significant effect on the probabilities of voting in the national and local elections. This negative impact of out-group size indicates that the smaller out-group size (i.e., the larger in-group size) encourages people to vote only when local political heterogeneity is low. Conversely, the marginal effect of out-group size becomes smaller and statistically insignificant as the degree of political heterogeneity increases. Thus, the relational goods effect is observed only when local political heterogeneity is low. ${ }^{3}$

Finally, I evaluate the substantive effects of racial composition in low and high levels of political heterogeneity using the predicted probabilities of voting. Figure 17 demonstrates the predicted probabilities of voting in the local and national elections when the out-group size varies from zero to one. I hold political heterogeneity at the values of 5 percentile (representing areas of low political heterogeneity) and 95 percentile (representing areas of high political heterogeneity) and the other independent variables constant. ${ }^{4}$

\footnotetext{
${ }^{3}$ Note that, however, the difference between the significant results and nonsignificant results may not be statistically significant. See Gelman and Stern (2006).

${ }^{4}$ Numerical variables are set to their mean, ordered variables are set to their me-
} 
Fig. 16. The Marginal Effects of Racial Composition in Areas of Low, Middle, and High Political Heterogeneity

\section{A. Power-Threat Effect and Voting in National Election}

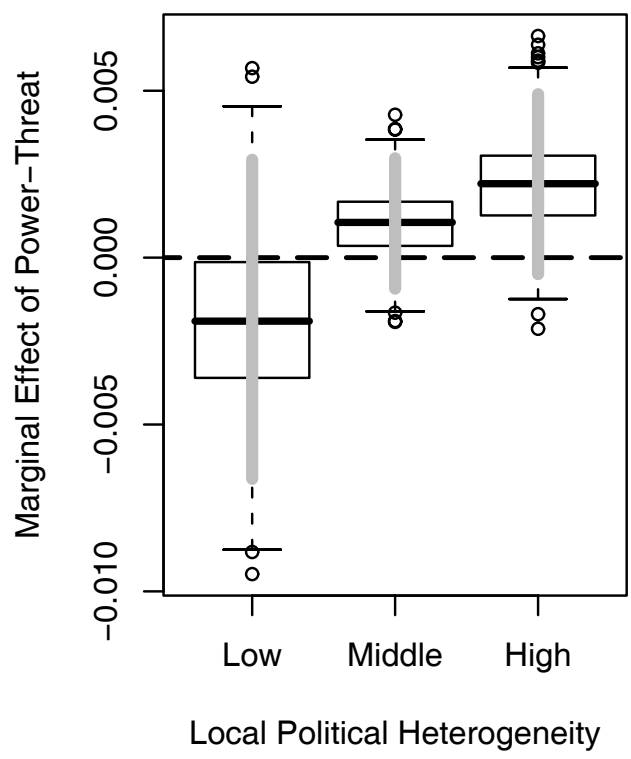

\section{Relational Goods Effect and Voting in National Election}

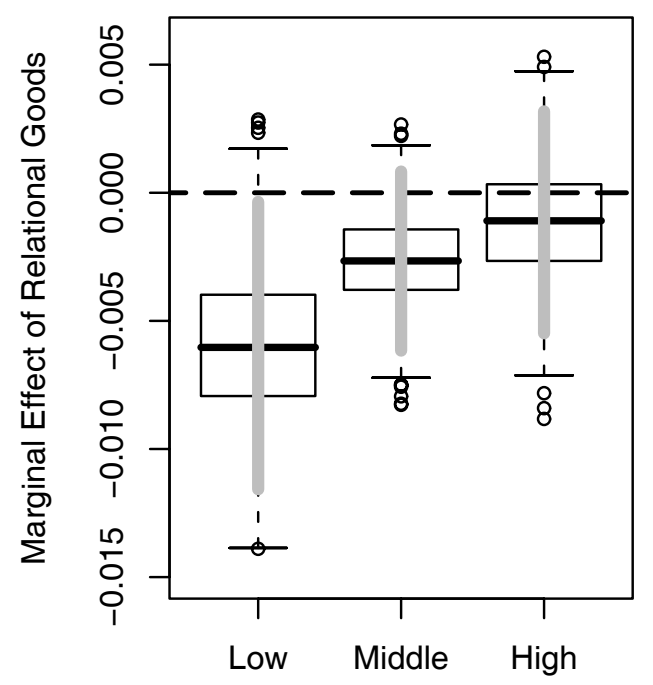

Local Political Heterogeneity

\section{B. Power-Threat Effect and Voting in Local Election}

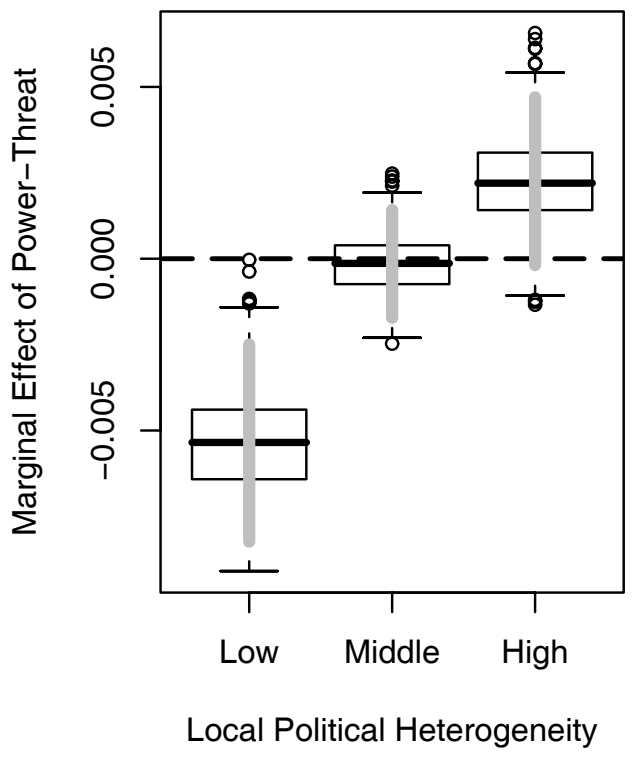

\section{Relational Goods Effect and Voting in Local Election}

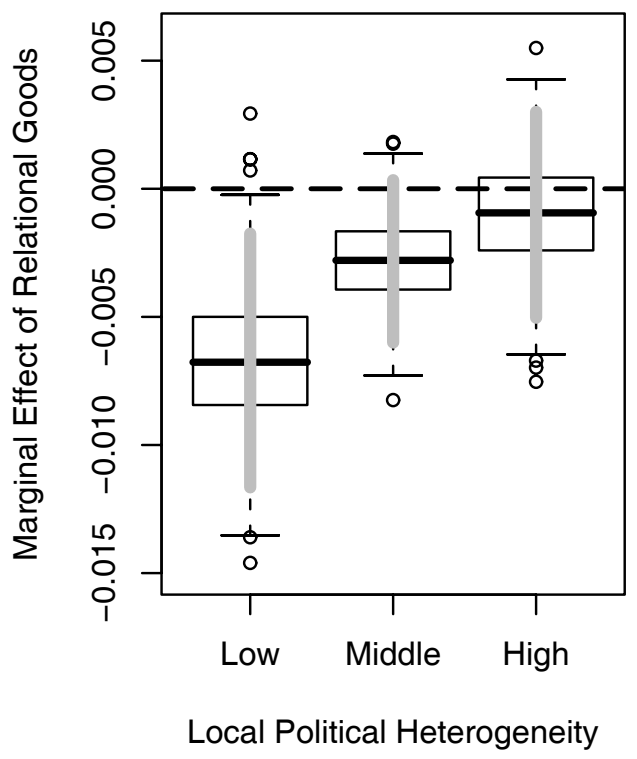


Graphs A and B in Figure 17 demonstrate that the out-group size has a curvilinear impact on the probabilities of voting only in areas of high political heterogeneity. The predicted probabilities increase by $10 \%$ to $20 \%$ points on average as the out-group size is close to 0.5 . Graphs $\mathrm{C}$ and $\mathrm{D}$ in Figure 17 demonstrate a negative impact of the out-group size on the predicted probabilities of voting. As expected, this negative impact is stronger in areas of low political heterogeneity than in areas of high political heterogeneity. As the out-group size increases in areas of low political heterogeneity, the predicted probabilities decreases by $30 \%$ on average. There results suggests that people in areas of low political heterogeneity are more likely to vote as the in-group population increases.

\section{Summary}

This chapter examined the hypothesis that the effect of racial composition on citizen participation is conditioned by the degree of local political competition. The empirical analysis demonstrated that the presence of out-group members encourages citizens to vote in elections only when local political heterogeneity is high, while the presence of in-group members increases their probabilities of voting only when local political heterogeneity is low. Note that these findings were confirmed only in less populous counties.

The findings in this chapter supported the principles of the existing hypotheses in the literature. Citizens are more likely to participate when they reside near other racial group members and with fellow group members of their race. The direction of the effects of racial composition is determined by the degree of local political competition. As hypothesized, the nature of political environments determines how

dian, and dichotomous variables are set to their modes. 
Fig. 17. The Substantive Effects of Racial Composition in Areas of Low and High Political Heterogeneity
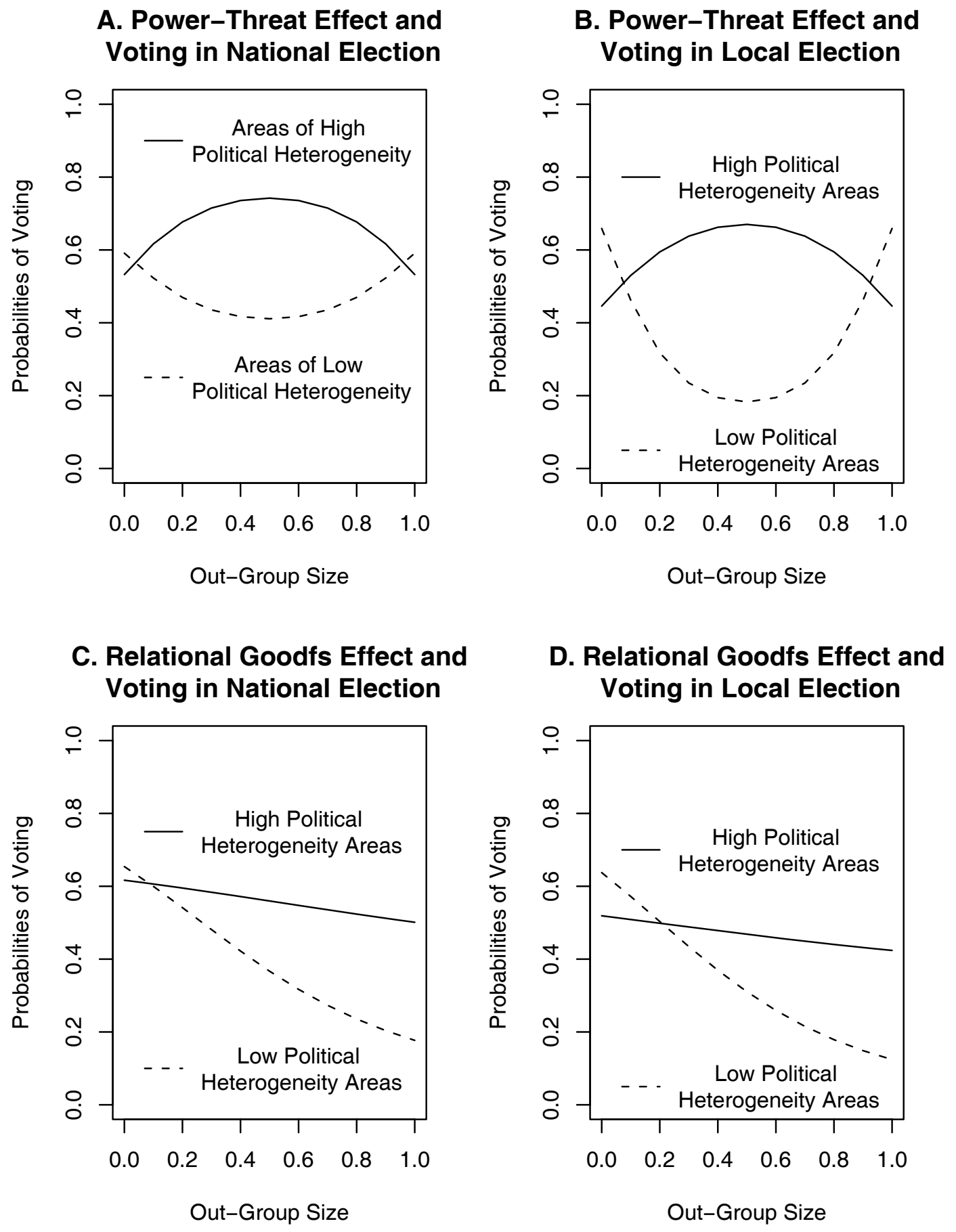
racial compositions influences citizens' utility of participating in politics. 


\section{CHAPTER VI}

\section{CONCLUSIONS}

\section{A. Summary}

This study was motivated by a weak theoretical development and mixed empirical evidence regarding how the racial composition of citizens' immediate environments influences their participation in politics. The previous literature presents two competing expectations, yet neither of them is strongly supported by empirical evidence. Does the presence of out-group population increase citizen participation because of high racial threats? Does the presence of in-group population increase citizen participation because of more relational goods? Is the racial environment a significant predictor of citizen participation? The goal of this research is to answer these questions and show how and when the racial environment influences citizens' decisions to participate in political activities.

I argued that two types of competition in local areas determine how the racial composition of local areas influences the probabilities of participating. Research on ethnic conflicts in divided societies and on race relations in the United States suggests that racial composition is neither a necessary nor sufficient condition for the emergence of racial conflicts and the formation of group ties. Interracial and intraracial relations are often conditional on other environmental characteristics of geographical units where individuals reside. This perspective was extended to argue that the relationship between the racial environment and the utility of participating in politics is conditioned by local economic and political competition.

More specifically, high economic or political competition signals to individuals as an information cue that the substantial presence of out-groups poses a serious 
threat to their interests, while low competition gives no such signal. Low economic or political competition in local areas increases a likelihood that individuals can establish a favorable intraracial network for political participation, while high competition decreases such likelihood. These arguments led me to propose that the power-threat effect on citizens participation in politics is observed only when the degree of local economic or political competition is high and that the relational goods effect on political participation is observed only when the degree of local economic or political competition is low.

I tested six conditional hypotheses derived from the propositions above using the nationally-representative data of the American citizens. My empirical analysis supported four of those hypotheses. In chapter IV, I found some supportive evidence for the "economic affluence hypothesis" that local economic affluence conditions the relationship between the racial environment and voter turnout. The power-threat has a significant impact on the probabilities of voting in the presidential election when local income status is low, while the relational goods have a significant impact on the probabilities of voting only when local income status is low. My analysis, however, offered no supportive evidence for the "economic diversity hypothesis" that local income diversity conditions how the racial composition influences citizen participation. Rather, I found the opposite results with my theoretical expectations: the presence of out-groups increases voter turnout when local income diversity is low, while the presence of in-groups increases voter turnout when income diversity is high. Finally, the "political competition hypothesis" in Chapter V received strong support from my analysis. I observed the strong mobilizing effect of power-threat on the probabilities of voting in two types of elections only when local political heterogeneity is high and also found the strong mobilizing effect of relational goods only when local political heterogeneity is low. 
In sum, my empirical analysis generally supported my propositions that economic and political competition determines how the racial environment influences citizen participation. Citizens' participation levels are sensitive to the racial composition of their immediate environments only when a few other environmental conditions are met. Interestingly, my analysis indicated that the substantive effects of relational goods on political participation seem to be much larger than the effects of powerthreat. Thus, heavy concentration of in-group members in citizens' immediate environments may play a more significant role in the formation of their political attitudes and behavior than the presence of out-group members. This result is partly consistent with Oliver and Wang's (2003) recent research on racial attitudes in multi-ethnic settings, suggesting that the size of in-group population is a stronger determinant of attitudes toward other group members than the one of out-group population.

One remaining question is highlighted by the inconsistency between my theoretical expectation and the empirical finding on the economic diversity hypothesis. One likely problem lies in the operationalization of economic diversity. I did not directly measure income disparity among racial groups and rather focused on the income diversity in the entire population of counties. A direct indicator of income disparity between major racial groups may have an interactive impact with racial composition in a consistent way with my expectation (see Gay, 2006, for her direct measure of income disparity between blacks and Latinos).

The other remaining task is related to a modeling strategy. In this research I have tested the power-threat and the relational goods effects on citizen participation in a separate statistical model. Nevertheless, these effects can work simultaneously. For example, in areas where Out-Group Size $=0.4$ and In-Group Size $=0.6$, citizens participate in politics because of both high racial threat and strong group ties. Thus, a more precise test for my hypotheses is to include the power-threat and relational 
goods effect in a single statistical model simultaneously. The equation below leads me to estimate the effect of (Out-Group Size +1$) *$ In-Group Size to understand the combined influence of racial composition on citizen participation.

$$
\begin{aligned}
& \text { Racial Threat Effect }+ \text { Group Ties Effect } \\
& =\text { Out-Group Size } * \text { In-Group Size }+ \text { In-Group Size } \\
& =(\text { Out-Group Size }+1) * \text { In-Group Size }
\end{aligned}
$$

This specification allows me to identify how the power-threat effect and the relational goods effect simultaneously shape citizens' decisions to participate in politics.

\section{B. Theory Construction}

In the process of theory building, political scientists tend to be enthusiastic about exploring a new hypothesis between variables of interest to present a new causal linkage. Additionally, they are also interested in comparing empirical leverage of competing hypothesis in order to demonstrate that one hypothesis is theoretically and empirically superior to the others. Yet they tend to be reluctant to explore why some existing hypotheses present competing expectations and further to integrate them into a single theoretical framework in which the "spirits" of the competing expectations are taken into consideration simultaneously. That is, when facing conflicting theoretical expectations and mixed empirical evidence on a causal linkage between the same set of independent and dependent variables, researchers often abandon the theoretical expectations that are not strongly supported by their empirical analysis.

In this study, I took a different approach to understanding mass political behavior from the ones in the conventional behavioral literature. I tried to reconcile two conflicting explanations into a single argument without undermining the principles 
of these two hypotheses. My conditional hypotheses suggested that how $X$ affects $Y$ is conditional on the other factor $Z$. I suggest that theoretical and empirical inconsistency derive from misspecification of one relevant variable in the causal linkage between $X$ and $Y$.

Such effort to reconcile two conflicting expectations in the process of theory building has become more popular in the discipline. One prominent recent example is Campbell's (2006) work that explores how community political heterogeneity affects citizen engagement in public activities . Campbell draws two competing expectations from the related literature; one hypothesis suggests that homogeneous communities increase citizen engagement because of prevalent social norms on civic duty and participation among residents, while the other hypothesis suggests that heterogeneous communities increase citizen engagement because of competition for resources. His "dual-motivations model" proposes that both heterogeneity and homogeneity increase individuals' involvement in public activities; he demonstrates that the relationship between heterogeneity and citizen participation is u-shape. That is, citizens are more likely to participate when political heterogeneity of communities is high or low, while they are less likely to participate when the level of heterogeneity is middle. His model further demonstrates that heterogeneity increases political participation, while homogeneity increases civic engagement. The most important contribution of Campbell's theoretical approach is that he combines two critical theories of citizen participation into a single, consistent model without undermining the existing arguments.

One important similarity between my research and Campbell's work is highlighted by our theoretical approach that tries to reconcile two competing explanations for citizen participation. Campbell resolves the theoretical inconsistency by changing the functional form, while I resolve the inconsistency by adding a new variable that conditions the linkage between variables. I believe that this approach is beneficial to 
the discipline because the competing theories are often based on strong theoretical reasonings and they help us understand complicate political phenomena. Thus, picking up one of the theories over the others could lead us to ignore useful information on political phenomena under investigation. The important lesson of my research is that causal relationships are often conditional on other factors.

\section{Measures Of Racial Composition}

The previous studies on the racial environment and citizen participation have addressed little about a measurement issue of racial composition. Much of the empirical research examined the power-threat and relational goods effects on citizens' decisions to participate by using the existing measures of racial composition in the literature on racial attitudes. Importantly, however, citizens' decisions to participate are a conceptually different dependent variable from their attitudes on racial policy issues and prejudice; thus, the existing indicators developed for assessing the effects of racial composition on attitudes might not be appropriate for the study of political participation, even if the theoretical principles are shared.

In this research, I develop a new measure of the power-threat effect on citizen participation. A simple out-group size and the racial diversity index used for empirical analysis in the literature are disadvantageous because they fail to take account of both the benefits of achieving preferable outcomes and the probability of achieving them in the political process simultaneously. The new indicator of power-threat is based on the out-group size weighted by the in-group size and represents the benefits multiplied by the probability of being successful in election's outcomes. When both the benefits and the probabilities of participating in politics are large, citizens are likely to participate in politics. When one of the terms is small, citizens are less likely 
to participate.

A unit of racial contexts is another important measurement issue for the study of the racial environment. It is still unclear as to which racial context matters for citizen participation in politics. In this research, I assume that racial composition at the county level plays an important role independently of other racial environments, yet the recent study by Baybeck (2006) demonstrates that multiple racial contexts have an interactive effect on whites' racial attitudes. For example, whites in a predominantly white neighborhood in a racially diverse county might show different racial attitudes from whites in a racially diverse neighborhood in a diverse county. Focusing exclusively on counties as the contextual unit is a reasonable choice for studying political participation since they are an important political jurisdiction for individuals and have relevant policy implications to their lives. Nevertheless, it is also interesting and beneficial to examine how racial composition of multiple residential spaces simultaneously affects citizens' decisions to participate in politics.

\section{Citizen Participation In Context}

This study began with the fundamental research question on political participation, that is, "why do citizens participate in politics?" Much of the existing research has explored the roles of individual-level predictors such as demographic characteristics and psychological orientations. The Civic Voluntarism model by Verba, Schlozman, and Brady (1995) suggests that citizens engage in political activities because they can, they want, and they are requested. A question arising from this model is when people feel that they "want to" participate in politics, holding other individual-level variables constant.

One answer to this question is given by the contextual models of political be- 
havior that stress the importance of social and political environments where citizens reside, work, and interact with other members of the society. Environmental characteristics play an important role as a determinant of political participation because they shape individuals' utilities of participating in politics. When social and political environments make politics more exciting and interesting, citizens are more likely to find a strong incentive to participate in politics. When social and political environments reduce the informational burdens of participation as a short cut, the costs of participation decrease. As a result, they want to participate in politics.

Thus, the individualistic approach and the contextual approach are not competing but rather complementary. My argument can be easily incorporated into the Civic Voluntarism model. Racial composition and economic/political competition are expected to shape the degree of citizens' psychological engagement in politics. ${ }^{1}$ High power-threat and more relational goods enhance citizens' interest in politics, knowledge about political figures and policy issues, and external efficacy. Thus, in this sense, contextual characteristics are the anteceding variables of individuals' psychological engagement in the Civic Voluntarism model for political participation.

\section{E. Representational Consequences}

What is an implication of my findings to representational consequences in the United States? Previous research on democratic representation demonstrates that active citizen participation is associated with higher elite responsiveness to mass policy preference (e.g., Hill and Matsubayashi, 2005; Verba and Nie, 1972). This positive relationship between mass participation and democratic representation leads us to draw two important expectations from the findings in this research. First, higher

\footnotetext{
${ }^{1}$ Oliver $(1999,2000)$ offers the similar argument.
} 
racial diversity (i.e., the larger out-group size) increases citizen participation and consequently enhances elite responsiveness to the mass only when local economic or political competition is high. Second, lower racial diversity (i.e., the larger in-group size) increases citizen participation and consequently enhances elite responsiveness to the mass only when local competition is low.

The latter expectation is partly supported by empirical evidence in the previous literature. For example, Hill and Matsubayashi (2007) report that higher racial diversity reduces the degree of policy agenda agreement between the elite and the mass in American local communities. By contrast, no previous research demonstrates that higher racial diversity can enhance elite responsiveness. Active participation by individuals who have diverse political preferences makes it difficult for the elite to be responsive to their demands in areas of high racial diversity. This is an interesting counterargument to the conventional wisdom on the relationship between political participation and democratic representation and worth examining in the future research. 


\section{REFERENCES}

Adams, James, Jay Dow and Samuel Merrill III. 2006. "The Political Consequences of Alienation-Based and Indifference-Based Voter Abstention: Applications to Presidential Elections." Political Behavior 28(1):65-86.

Aldrich, John H. 1993. "Rational Choice and Turnout." American Journal of Political Science 37(1):246-78.

Alesina, Alberto, Easterly Devleeschauwer, Kurlat Sergio William and Romain Wacziarg. 2003. "Fractionalization." Journal of Economic Growth 8(2):155-94.

Alesina, Alberto and Eliana La Ferrara. 2000. "Participation in Heterogeneous Communities." Quarterly Journal of Economics 115(3):847-904.

Alesina, Alberto, Reza Baqir and William Easterly. 1999. "Public Goods and Ethnic Divisions." Quarterly Journal of Economics 114(4):1243-1284.

Ansolabehere, Stephen, Shanto Iyenger and Adam Simon. 1999. "Replicating Experiments Using Aggregate and Survey Data: The Case of Negative Advertising and Turnout." American Political Science Review 93(4):901-09.

Ansolabehere, Stephen, Shanto Iyenger, Adam Simon and Nicholas Valentino. 1994. "Does Attack Advertising Demobilize the Electorate?" American Political Science Review 88(4):829-38.

Barth, Frederik. 1969. Ethnic Groups and Boundaries. Boston, MA: Little Brown.

Bates, Robert. 1983. Modernization, Ethnic Competition, and the Rationality of Politics in Contemporary Africa. In States versus Ethnic Claims: African Policy 
Dilemmas, ed. Donald Rothchild and Victor A. Olunsorola. Boulder, CO: Westview Press pp. 152-71.

Baybeck, Brady. 2006. "Sorting Out the Competing Effects of Racial Context." Journal of Politics 68(2):386-96.

Baybeck, Brady and Robert Huckfeldt. 2002. "Spatially Dispersed Ties Among Interdependent Citizens: Connecting Individuals and Aggregates." Political Analysis 10(3):261-75.

Baybeck, Brady and Scott D. McClurg. 2005. "What Do They Know and How Do They Know It? An Examination of Citizen Awareness of Context." American Politics Quarterly 33(4):492-520.

Beck, E. M. and Steward E. Tolnay. 1990. "The Killing Field of the Deep South: The Market for Cotton and the Lynching of Blacks, 1832-1930." American Sociological Review 55(4):526-39.

Beck, Paul Allen and M. Kent Jennings. 1979. "Political Periods and Political Participation." American Political Science Review 73(3):737-50.

Bendor, Jonathan, Daniel Diermeier and Michael Ting. 2003. "A Behavioral Model of Turnout." American Political Science Review 97(2):261-80.

Berelson, Bernard R., Paul E. Lazarsfeld and William N. McPhee. 1954. Voting: A Study of Opinion Formation in a Presidential Campaign. Chicago: University of Chicago Press.

Blalock, Hubert M. 1967. Toward a Theory of Minority-Group Relations. New York: John Wiley and Sons. 
Bonacich, Edna. 1972. "A Theory of Ethnic Antagonism: The Split Labor Market." American Sociological Review 37(5):547-59.

Brambor, Thomas, William Roberts Clark and Matt Golder. 2006. "Understanding Interaction Models: Improving Empirical Analyses." Political Analysis 14(1):63-82.

Branton, Regina P. and Bradford S. Jones. 2005. "Reexamining Racial Attitudes: The Conditional Relationship Between Diversity and Socioeconomic Environment." American Journal of Political Science 49(2):359-372.

Brody, Richard A. 1978. The Puzzle of Political Participation in America. In The New American Political System, ed. Anthony King. Washington DC: AEI pp. 287-324.

Brooks, Deborah Jordan. 2006. "The Resilent Voter: Moving Toward Closure in the Debate over Negative Campaigning and Turnout." Journal of Politics 68(3):684-96.

Campbell, Andrea Louise. 2003. How Policies Make Citizens: Senior Political Activism and the American Welfare System. Princeton, NJ: Princeton University Press.

Campbell, Angus, Philip E. Converse, Warren E. Miller and Donald E. Stokes. 1960. American Voter. New York: John Wiley and Sons.

Campbell, David E. 2006. Why We Vote: How Schools and Communities Shape our Civic life. Princeton, NJ: Princeton University Press.

Carmines, Edward G. and James Stimson. 1980. "The Two Faces of Voting." American Political Science Review 74(1):78-91.

Chandra, Kanchan. 2004. Why Ethnic Parties Succeed: Patronage and Ethnic Head Counts in India. New York: Cambridge University Press. 
Chong, Dennis and Reuel Rogers. 2005. "Racial Solidarity and Political Participation." Political Behavior 27(4):347-74.

Cohen, Cathy J. and Michael C. Dawson. 1993. "Neighborhood Poverty and African American Politics." American Political Science Review 87(2):286-302.

Costa, Dora L. and Matthew E. Kahn. 2003. "Civic Engagement and Community Heterogeneity: An Economist's Perspective." Perspectives on Politics 1(1):103-111.

Cox, Gary W. and Michael C. Munger. 1989. "Closeness, Expenditures, and Turnout in the 1982 U.S. House Elections." American Political Science Review 83(1):217-31.

Downs, Anthony. 1957. An Economic Theory of Democracy. New York: Harper and Row.

Dreier, Peter, John Mollenkopf and Todd Swanstrom. 2004. Place Matters: Metropolitics for the Twenty-First Century. Lawrence: KS: University Press of Kansas.

Emerson, Michael O., Karen J. Chai and George Yancey. 2001. "Does Race Matter in Residential Segregation? Exploring the Preferences of White Americans." American Sociological Review 66(6):922-35.

Erikson, Robert S., Michael B. MacKuen and James A. Stimson. 1998. "What Moves Macropartisanship? A Response to Green, Palmquist, and Schickler." American Political Science Review 92(4):901-12.

Eulau, Heinz and Lawrence Rothenberg. 1986. "Life Space and Social Networks as Political Contexts." Political Behavior 8(2):130-57.

Fedderson, Timothy J. and Wolfgang Pesendorfer. 1999. "Abstention in Elections with Asymmetric Information and Diverse Preferences." American Political Science Review 93(2):381-98. 
Finkel, Steven E. and John G. Geer. 1998. "A Spot Check: Casting Doubt on the Demobilizing Effect of Attack Advertising." American Journal of Political Science $42(2): 573-95$.

Friedrich, Robert J. 1982. "In Defense of Multiplicative Terms in Multiple Regression Equations." American Journal of Political Science 26(4):797-833.

Gay, Claudine. 2004. "Putting Race in Context: Identifying the Environmental Determinants of Black Racial Attitudes." American Political Science Review 98(4):54762.

Gay, Claudine. 2006. "Seeing Difference: The Effect of Economic Disparity on Black Attitudes toward Latinos." American Journal of Political Science 50(4):982-997.

Gelman, Andrew and Hal Stern. 2006. "The Difference Between "Significant" and "Not Significant" is not Itself Statistically Significant." American Statistician 60(4):328-31.

Giles, Micheal W. and Melanie Buckner. 1994. "David Duke and Black Threat: An Old Hypothesis Revisited." Journal of Politics 55(3):702-13.

Giles, Micheal W. and Melanie Buckner. 1996. "Comments." Journal of Politics $58(4): 1171-80$.

Giles, Micheal W. and Arthur Evans. 1985. "External Threat, Perceived Threat, and Group Identity." Social Science Quarterly 66(1):50-66.

Giles, Micheal W. and Arthur Evans. 1986. "The Power Approach to Intergroup Hostility." Journal of Conflict Resolution 30(3):469-86.

Giles, Michael W. and Kaenan Hertz. 1994. "Racial Threat and Partisan Identification." American Political Science Review 88(2):317-26. 
Glaser, James M. 1994. "Back to the Black Belt: Racial Environment and White Racial Attitudes in the South." Journal of Politics 56(1):21-41.

Goldstein, Ken and Paul Freedman. 2002. "Campaign Advertising and Voter Turnout: New Evidence for a Stimulation Effect." Journal of Politics 64(3):721-40.

Green, Donald, Bradley Palmquist and Eric Schickler. 1998. "Macropartisanship: A Replication and Critique." American Political Science Review 92(4):883-99.

Green, Donald, Bradley Palmquist and Eric Schickler. 2002. Partisan Hearts and Minds: Political Parties and the Social Identities of Voters. New Haven: CT: Yale University Press.

Healey, Joseph F. 2002. Statistics: A Tool for Social Research. Belmont, CA: Wadsworth/Thomson Learning.

Hero, Rodney E. 1998. Faces of Inequality: Social Diversity in American Politics. New York: Oxford University Press.

Hill, Kim Quaile and Jane E. Leighley. 1993. "Party Ideology, Organization, and Competitiveness as Mobilizing Forces in Gubernatorial Elections." American Journal of Political Science 37(4):1158-78.

Hill, Kim Quaile and Jane E. Leighley. 1996. "Political Parties and Class Mobilization in Contemporary United States Elections." American Journal of Political Science $40(3): 787-804$.

Hill, Kim Quaile and Jane E. Leighley. 1999. "Racial Diversity, Voter Turnout, and Mobilizing Institutions in the United States." American Politics Quarterly $27(2): 275-95$. 
Hill, Kim Quaile and Tetsuya Matsubayashi. 2005. "Civic Engagement and Mass-Elite Policy Agenda Agreement in American Communities." American Political Science Review 99(2):215-24.

Hill, Kim Quaile and Tetsuya Matsubayashi. 2007. "Racial/Ethnic Diversity and Representation Linkages in American Local Communities." Working paper.

Huber, Gregory A. and John Lapinski. 2006. "The "Race Card" Revisited: Assessing Racial Priming in Policy Contests." American Journal of Political Science 50(2).

Huckfeldt, R. Robert. 1979. "Political Participation and the Neighborhood Social Context." American Journal of Political Science 25(3):579-92.

Huckfeldt, Robert and John Sprague. 1992. "Political Parties and Electoral Mobilization: Political Structure, Social Structure, and the Party Canvass." American Political Science Review 86(1):70-86.

Huckfeldt, Robert and John Sprague. 1995. Citizens, Politics, and Social Communication: Information and Influence in an Election Campaign. New York: Cambridge University Press.

Huckfeldt, Robert, Paul E. Johnson and John Sprague. 2004. Political Disagreement: The Survival of Diverse Opinions within Communication Networks. New York: Cambridge University Press.

Iceland, John, Daniel H. Weinberg and Erika Steinmetz. 2002. Racial and Ethnic Residential Segregation in the United States, 1980-2000: Census 2000 Special Reports. Washington D.C.: U.S. Census Bureau.

Jacobs, David and Katherine Wood. 1999. "Interracial Conflict and Interracial Homi- 
cide: Do Political and Economic Rivalries Explain White Killings of Blacks or Black Killings of Whites?" American Journal of Sociology 105(1):157-90.

Johnson, Martin and Stacy B. Gordon. 2005. The Racial Composition of Social Networks and African American Commitment to the Democratic Party. In Diversity in Democracy: Minority Representation in the United States, ed. Gary M. Segura and Shaun Bowler. Charlottesville, VA: University Of Virginia Press. pp. 102-119.

Kanazawa, Satoshi. 1998. "A Possible Solution to the Paradox of Voter Turnout." Journal of Politics 60(4):974-95.

Kanazawa, Satoshi. 2000. "A New Solution to the Collective Action Problem: The Paradox of Voter Turnout." American Sociological Review 65(3):433-42.

Kaufmann, Karen M. 2004. The Urban Voter: Group Conflict and Mayoral Voting Behavior in American Cities. Ann Arbor, MI: University of Michigan Press.

Key, V.O. 1949. Southern Politics in State and Nation. Knoxville, TN: University of Tennessee Press.

Kinder, Donald R. and Tali Mendelberg. 1995. "Cracks in American Apartheid: The Political Impact of Prejudice among Desegregated Whites." Journal of Politics $57(2): 402-24$.

Kinder, Donald R. and Lynn Sanders. 1996. Divided by Color: Racial Politics and Democratic Ideals. Chicago: University of Chicago Press.

Kinder, Donald R. and Nicholas Winter. 2001. "Exploring the Racial Divide: Blacks, Whites, and Opinion on National Policy." American Journal of Political Science 45(2):439-456. 
King, Gary, James Honakerm, Anne Joseph and Kenneth Scheve. 2001. "Analyzing Incomplete Political Science Data: An Alternative Algorithm for Multiple Imputation." American Political Science Review 95(1):49-69.

Lazarsfeld, Paul, Bernard Berelson and Hazel Gaudet. 1944. People's Choice: How the Voter Makes Up His Mind in a Presidential Campaign. New York: Columbia University Press.

Leighley, Jan E. 1990. "Social Interaction and Contextual Influences on Political Participation." American Politics Quarterly 18(4):459-75.

Leighley, Jan E. 2001. Strength in Numbers? The Political Mobilization of Racial and Ethnic Minorities. Princeton, NJ: Princeton University Press.

Leighley, Jan E. and Arnold Vedlitz. 1999. "Race, Ethnicity, and Political Participation: Competing Models and Contrasting Explanations." Journal of Politics 61(4):1092-1114.

MacKuen, Michael and Courtney Brown. 1987. "Political Context and Attitude Change." American Political Science Review 81(2):471-90.

MacKuen, Michael B., Robert S. Erikson and James A. Stimson. 1989. "Macropartisanship." American Political Science Review 83(4):1125-42.

Matthews, Donald R. and James W. Prothro. 1966. Negroes and the New Southern Politics. New York: Harcourt Brace.

McClurg, Scott D. 2006. "The Electoral Relevance of Political Talk: Examining Disagreement and Expertise Effects in Social Networks on Political Participation." American Journal of Political Science 50(3):737-54. 
McDonald, Michael P. and Samuel L. Popkin. 2001. "The Myth of the Vanishing Voter." American Political Science Review 95(4):963-74.

Mendelberg, Tali. 2001. The Race Card: Campaign Strategy, Implicit Messages, and the Norm of Equality. Princeton, MJ: Princeton University Press.

Metz, David Haywood and Katherine Tate. 1995. The Color of Urban Campaigns. In Classifying by Race, ed. Paul E. Peterson. Princeton, NJ: Princeton University Press pp. 262-277.

Miguel, Edward and Daniel P. Posner. 2005. "Sources of Ethnic Identification in Africa.". Working paper.

Morton, Rebecca. 1991. "Groups in Rational Turnout Models." American Journal of Political Science 35(3):758-76.

Mutz, Diana C. 2006. Hearing the Other Side: Deliberative versus Participatory Democracy. New York: Cambridge University Press.

Nicholson, Stephen P. and Gary M. Segura. 2005. Issue Agendas and the Politics of Latino Partisan Identification. In Diversity in Democracy: Minority Representation in the United States, ed. Gary M. Segura and Shaun Bowler. Charlottesville, VA: University Of Virginia Press. pp. 102-119.

Oliver, J. Eric. 1999. "The Effects of Metropolitan Economic Segregation on Local Civic Participation." American Journal of Political Science 43(1):186-212.

Oliver, J. Eric. 2000. "City Size and Civic Involvement in Metropolitan America." American Political Science Review 94(2):361-73.

Oliver, J. Eric. 2001. Democracy in Suburbia. Princeton, NJ: Princeton University Press. 
Oliver, J. Eric and Tali Mendelberg. 2000. "Reconsidering the Environmental Determinants of Racial Attitudes." American Journal of Political Science 44(3):574-89.

Oliver, J. Eric and Janelle Wong. 2003. "Intergroup Prejudice in Multiethnic Settings." American Journal of Political Science 47(4):567-82.

Olzak, Susan. 1992. The Dynamics of Ethnic Competition and Conflict. Stanford, CA: Stanford University Press.

Palfrey, Thomas R. and Howard Rosenthal. 1985. "Voter Participation and Strategis Uncertainty." American Political Science Review 79(1):62-78.

Peterson, Paul. 1981. City Limits. Chicago: University of Chicago Press.

Plane, Dennis L. and Joseph Gershtenson. 2004. "Candidates' Ideological Locations, Abstention, and Turnout in U.S. Midterm Senate Elections." Political Behavior 26(1):69-93.

Posner, Daniel N. 2004. "The Political Salience of Cultural Difference: Why Chewas and Tumbukas Are Allies in Zambia and Adversaries in Malawi." American Political Science Review 98(4):529-546.

Posner, Daniel N. 2005. Institutions and Ethnic Politics in Africa. New York: Cambridge University Press.

Powell, Bingham. 1986. "American Voter Turnout in Comparative Perspective." American Political Science Review 80(1):17-43.

Putnam, Robert D. 1966. "Political Attitudes and the Local Community." American Political Science Review 60(3):640-54. 
Quillian, Lincoln. 1995. "Prejudice as a Response to Perceived Group Threat: Population Composition and Anti-Immigrant and Racial Prejudice in Europe." American Sociological Review 60(4):586-611.

Quillian, Lincoln. 1996. "Group Threat and Regional Change in Attitudes toward African-Americans." American Journal of Sociology 102(3):816-60.

Rae, Douglas W. and Michael Taylor. 1970. The Analysis of Political Cleavages. New Haven, CT: Yale University Press.

Riker, William H. and Peter C. Ordeshook. 1968. "A Theory of the Calculus of Voting." American Political Science Review 62(1):25-42.

Rosenstone, Steven J. and John Mark Hansen. 1993. Mobilization, Participation, and Democracy in America. New York: Macmillan Publishing Company.

Schafer, Joseph L. 1997. Analysis of Incomplete Multivariate Data. London: Chapman and Hall.

Schafer, Joseph L. 1999. "Multiple Imputation: A Primer." Statistician Methods in Medical Research 8(1):3-15.

Schneider, Mark and Kee Ok Park. 1989. "Metropolitan Counties as Service Delivery Agents: The Still Forgotton Governments." Public Administration Review $49(4): 345-52$.

Schwartz, Thomas. 1987. "Your Vote Counts on Account of the Way It Is Counted: An Institutional Solution to the Paradox of Not Voting." Public Choice 27(Fall):8189.

Smith, Mark A. 2001. "The Contingent Effects of Ballot Initiatives and Candidate Races on Turnout." American Journal of Political Science 45(3):700-06. 
Sniderman, Paul M., Louk Hagendoorn and Markus Prior. 2004. "Predispositional Factors and Situational Triggers: Exclusionary Reactions to Immigrant Minorities." American Political Science Review 98(1):35-50.

Stein, Robert M., Stephanie Post and Allison L. Rinden. 2000. "Reconciling Context and Contact Effects on Racial Attitudes." Political Research Quarterly 53(2):285303.

Taylor, Marylee C. 1998. "How White Attitudes Vary with the Racial Composition of Local Populations: Numbers Count." American Sociological Review 63(4):512-35.

Tolbert, Caroline J. and Rodney E. Hero. 1996. "Race/Ethnicity and Direct Democracy: An Analysis of California's Illegal Immigration Initiative." Journal of Politics 58(3):806-18.

Uhlaner, Carole J. 1989. "Relational Goods and Participation: Incorporating Sociability into a Theory of Rational Action." Public Choice 62(2):253-85.

Uhlaner, Carole J. and F. Chris Garcia. 2005. Learning Which Party Fits. In Diversity in Democracy: Minority Representation in the United States, ed. Gary M. Segura and Shaun Bowler. Charlottesville, VA: University Of Virginia Press. pp. 72-101.

Valentino, Nicholas A., Vincent L. Hutchings and Ismail K. White. 2002. "Cues that Matter: How Political Ads Prime Racial Attitudes During Campaigns." American Political Science Review 96(1):75-90.

Verba, Sidney and Norman H. Nie. 1972. Participation in America: Political Democracy and Social Equality. Chicago: University of Chicago Press.

Verba, Sidney, Kay Lehman Schlozman and Henry E. Brady. 1995. Voice and Equal- 
ity: Civic Voluntarism in American Politics. Cambridge, MA: Harvard University Press.

Voss, D. Stephen. 1996. "Beyond Racial Threat: Failure of an Old Hypothesis in the New South." Journal of Politics 58(4):1156-70.

Wattenberg, Martin P. and Craig Leonard Brians. 1999. "Negative Campaign Advertising: Demobilizer or Mobilizer?" American Political Science Review 93(4):891-99.

Weatherford, M. Stephen. 1982. "Interpersonal Networks and Political Behavior." American Journal of Political Science 26(1):117-43.

Welch, Susan, Lee Sigelman, Timothy Bledsoe and Michael Combs. 2001. Race and Place: Race Relations in an American City. New York: Cambridge University Press.

Wilkinson, Steven I. 2004. Votes and Violence: Electoral Competition and Ethnic Riots in India. New York: Cambridge University Press.

Wolfinger, Raymond E. and Steven J. Rosenstone. 1980. Who Votes? New Haven, CT: Yale University Press.

Zipp, John F. 1985. "Perceived Representativeness and Voting: An Assessment of the Impact of "Choices" vs. "Echoes"." American Political Science Review 79(1):50-61. 


\section{APPENDIX A}

\section{GEOGRAPHICAL IDENTIFICATION}

Respondents' zip codes, provided by the principal investigators of Citizen Participation Study and Jan Leighley at the University of Arizona, were matched to the original data archived at the Inter-University Consortium for Political and Social Research (ICPSR). I identified counties in which respondents' zip codes located using Geographic Correspondence Engine, Version 3.0 (Geocorr) by John Blodgett. This engine is available online at http://plue.sedac.ciesin.org/geocorr/. When zip codes include areas in multiple counties, I chose counties that share the largest size of population of zip code areas. According to Blodgett's estimation, this method correctly identifies counties about $98.2 \%$ of the time. 


\section{APPENDIX B}

\section{A PROCEDURE TO SIMULATE THE MARGINAL EFFECTS OF RACIAL COMPOSITION}

In Chapters IV and V, I presented the marginal effects of racial composition when the modifying variables (i.e., economic diversity, economic affluence, and political heterogeneity) change using a simulation technique. The procedure, partly based on (Brambor, Clark and Golder, 2006), has the following sequence:

1. Estimate a logit model with robust standard errors. The standard errors are clustered by counties.

2. Set values of explanatory variables. The racial composition measures are set to their means and then increased by one unit. The modifying variables are set at the values of 5 percentile, 25 percentile, median, 75 percentile, and 95 percentile. Numerical control variables are set to their mean, ordered control variables are set to their median, and dichotomous control variables are set to their mode.

3. Simulate the probabilities of voting by 1000 times.

4. Take the first difference of the probabilities.

5. Produce the boxplots that demonstrate distributions of the simulated first differences.

6. Add the 95 confidence intervals to the boxplots. 


\section{APPENDIX C}

\section{SURVEY QUESTIONS AND CODING RULES}

Voted in the 1998 National Election: "Thinking back to the national election in November 1988, when the presidential candidates were Michael Dukakis, the Democrat, and George Bush, the Republican, did you happen to vote in that election?" Respondents who voted in the election were coded as one; otherwise zero.

Voted in the Local Election in 1988: "Has there been a local election in your community since November 1988? Did you happen to vote in that election?" Respondents who voted in the election were coded as one; otherwise zero.

Opinion on Government Spending: "Some people feel that the government should provide fewer services, even in areas such as health and education in order to reduce spending. (Suppose these people are at one end of the scale at point number 1.) Other people feel it is important for the government to provide many more services even if it means an increase in spending. (Suppose these people are at the other end, at point 7. And, of course, some other people would have opinions somewhere in between at points $2,3,4,5$, and 6.) Where would you place yourself on this scale?" Respondents who chose "Increase Spending" were coded as one. Respondents who chose "Reduce Spending" were coded as seven.

Opinion on Government Responsibility of Providing Jobs: "Some people feel that the government in Washington should see to it that every person has a job and a good standard of living. Suppose these people are at one end of the scale at point number 
1. Others think that the government should just let each person get ahead on his or her own. Suppose these people are at the other end at point 7 . And of course, some other people have opinions somewhere in between at points $2,3,4,5$, or 6 . Where would you place yourself on this scale?" Respondents who chose "Everyone Has a Job" were coded as one. Respondents who chose "One Get Ahead on Own" were coded as seven.

Party Mobilization: "Thinking about the elections we have had since January 1988, during these election campaigns, have you received any request directed to you personally to work for or contribute money to a candidate for public office, a party group, a Political Action Committee, or any other organization that supports candidates?" Respondents who received a request were coded as one; otherwise zero.

Republican: "Do you think of yourself as closer to the Republican or Democratic Party?" Respondents who identify themselves Republicans are coded as one; otherwise zero.

Democrat: "Do you think of yourself as closer to the Republican or Democratic Party?" Respondents who identify themselves Democrats are coded as one; otherwise zero.

Education: Years in school.

Income: Coded 1-Under $\$ 9999,2-\$ 10000$ to $19999,3-\$ 20000$ to $29999,4-\$ 30000$ to $39999,5-\$ 40000$ to $49999,6-\$ 50000$ to $59999,7-\$ 60000$ to $74999,8-\$ 75000$ to 99999 , 9-\$100000 and over. 
Years in Town: The logged number of years in the town where respondents reside.

Age: Respondent's actual age.

Female: Women were coded as one, otherwise zero.

Black: Blacks were coded as one; otherwise zero.

Latino: Latinos were coded as one; otherwise zero. 


\section{APPENDIX D}

\section{SUMMARY STATISTICS}

Table XI. Summary Statistics

\begin{tabular}{|c|c|c|c|c|}
\hline Variables & mean & $\mathrm{sd}$ & $\min$ & $\max$ \\
\hline \multicolumn{5}{|l|}{ Dependent Variables } \\
\hline Voted in the 1988 National Election & 0.768 & 0.422 & 0.000 & 1.000 \\
\hline Voted in the Local Election $(n=704)$ & 0.649 & 0.478 & 0.000 & 1.000 \\
\hline \multicolumn{5}{|l|}{ Contextual-Level Variables } \\
\hline Out-Group Size $\times$ In-Group Size & 0.114 & 0.083 & 0.002 & 0.250 \\
\hline Out-Group Size & 0.295 & 0.307 & 0.008 & 0.998 \\
\hline Income Diversity & 0.889 & 0.050 & 0.728 & 0.980 \\
\hline Log Median Household Income & 10.110 & 0.256 & 9.477 & 10.903 \\
\hline Political Heterogeneity & 0.383 & 0.068 & 0.176 & 0.485 \\
\hline Log Population Size & 11.097 & 1.139 & 8.068 & 12.595 \\
\hline \multicolumn{5}{|l|}{ Individual-Level Variables } \\
\hline Mobilized & 0.136 & 0.343 & 0.000 & 1.000 \\
\hline Republican & 0.281 & 0.450 & 0.000 & 1.000 \\
\hline Democrat & 0.468 & 0.499 & 0.000 & 1.000 \\
\hline Education & 13.181 & 2.757 & 0.000 & 17.000 \\
\hline Income & 3.995 & 2.326 & 1.000 & 9.000 \\
\hline Log Years in Town & 2.932 & 1.204 & 0.000 & 4.564 \\
\hline Age & 45.212 & 16.368 & 12.000 & 91.000 \\
\hline Female & 0.556 & 0.497 & 0.000 & 1.000 \\
\hline Black & 0.174 & 0.380 & 0.000 & 1.000 \\
\hline Latino & 0.058 & 0.233 & 0.000 & 1.000 \\
\hline $\mathrm{N}$ & & $7 \varepsilon$ & & \\
\hline
\end{tabular}




\section{VITA}

Name

Tetsuya Matsubayashi

\section{Address}

Department of Political Science

University of North Texas

125 Wooten Hall

P.O. Box 305340

Denton, TX 76203-5340

\section{Email}

tmatsubayashi@politics.tamu.edu

\section{Education}

Ph.D. Texas A\&M University, 2007 (Political Science)

M.A. Doshisha University, Kyoto in Japan, 2002 (American Studies)

B.A. Doshisha University, Kyoto in Japan, 2000 (Political Science) 